\title{
Teleodontología: Aplicación a la Odontopediatría durante la pandemia COVID-19
}

Asociación Latinoamericana de Odontopediatría. Equipo Interdisciplinario COVID-19

\section{Introducción}

A la presente fecha, los diferentes organismos de salud internacionales y locales han publicado recomendaciones, regulaciones y protocolos para atención odontológica durante de la pandemia COVID-19, ajustados a las diferentes etapas de la pandemia.

La Asociación Latinoamericana de Odontopediatría, en su misión apoyar y llevar la mejor información disponible a todos los colegas latinos, ha publicado guías prácticas y documentos de apoyo fáciles de utilizar y compartir con todo el personal odontológico que trabaje en ambiente hospitalario, clínicas gubernamentales, instituciones educativas y clínicas privadas, que presten atención a niños, adolescentes y pacientes en situación de discapacidad..$^{1-3}$

Durante la etapa de confinamiento pandemia COVID-19, se debe realizar tratamiento odontológico exclusivamente a pacientes que presenten emergencias y urgencias, difiriendo todo tratamiento electivo. ${ }^{1,-7}$
Sin embargo, conforme evolucionan las etapas de la pandemia en los diferentes países, cambian los protocolos de atención siendo posible la programación de atención odontopediátrica prioritaria y retomando progresivamente la atención odontológica. ${ }^{8,9}$

Como primer paso en la atención surge un cambio importante recomendado para la práctica profesional que es la inclusión de la atención a distancia o Telemedicina, en el caso de la Odontopediatría: Teleodontología, ${ }^{10}$ involucrando atención telefónica, por medios digitales o plataformas virtuales, utilizando toda la tecnología disponible para poder realizar el diagnóstico, orientación terapéutica, seguimiento de los casos, y determinar las situaciones que requieren atención presencial.

Las recomendaciones que a continuación se proponen están vinculadas a la situación excepcional de pandemia y pueden diferir de las prácticas clínicas habituales. Estas recomendaciones pretenden dar una guía al clínico para que pueda realizar de forma eficiente el tamizaje de la consulta, que 
permita orientar la realización de consulta virtual con teleodontología, determinar la mejor ruta de atención según la necesidad y factibilidad de atención presencial, y llevar registro apropiado del seguimiento. No es un protocolo clínico exhaustivo de todos los tratamientos posibles.

Esta información constituye una guía de orientación, sin sustituir regulaciones locales, protocolos específicos, ni leyes vigentes en cada país y son susceptibles a evolucionar y cambiar en función de la situación sanitaria. Instamos a los profesionales a realizar seguimiento a las actualizaciones.

\section{Teleodontología}

La atención odontológica a distancia (teleodontología ${ }^{11}$ ), es la primera línea de la atención en casos excepcionales que se pueden presentar en crisis de salud pública y cuando no es posible el contacto presencial entre el paciente y el especialista por distancias geográficas $\mathrm{u}$ otras restricciones. El soporte tecnológico permite el despistaje (triage) y el manejo sintomático de casos susceptibles, e identificación de los casos que requerirán atención presencial, utilizando todos los recursos de comunicación y tecnología disponibles. ${ }^{4,12-16}$

En Odontopediatría, hay reportes de experiencias previas en las cuales el Odontopediatra ha realizado diagnóstico de caries y recomendaciones de tratamiento con el uso de teleodontología, con la utilización de cámaras intraorales ${ }^{17-19}$ o imágenes obtenidas a través de teléfonos inteligentes ${ }^{20}$ y el apoyo de asistentes dentales o personal auxiliar.

Durante la Pandemia COVID-19, el uso de la teleodontología va enfocado hacia lograr el mejor diagnóstico posible para poder brindar orientación a los padres en cuanto al manejo de la patología por la cual consulta, y es recomendado por todos los protocolos de atención. ${ }^{1-3,6,14,21,22}$ Algunos países han emitido a la fecha regulaciones para la telesalud y la teleodontología (Tabla 1).

Actualmente se definen tres tipos de teleconsultas que pueden ser de utilidad en diferentes contextos: consulta asincrónica usualmente se da cuando el paciente o su cuidador contactan al profesional en salud para requerir su punto de vista o evaluación, requiere un tiempo de espera entre el envío de la pregunta o requerimiento, y la respuesta del especialista; consulta sincrónica cuando la consulta virtual es en tiempo real por medio de llamada telefónica o preferiblemente por video conferencia, para interactuar con el especialista sobre las razones que preocupan en su estado de salud y la consulta mixta en el seguimiento de mediano o largo tiempo de un caso, utilizando tanto consultas asincrónicas como sincrónicas. ${ }^{23,24}$

En todos los casos, se requiere que el especialista en salud estructure un archivo virtual donde almacene todas las comunicaciones, y los soportes visuales (fotos, videos, radiografías) y clínicos que se compartan durante el seguimiento y apoyen el mejor diagnóstico, interacción virtual y manejo de caso.

El papel del Odontólogo tratante es de especial relevancia, por ello se recomienda que exista un medio de contacto que pueda ser utilizado fácilmente por los pacientes (telefónico, videoconferencia o por otras redes) y su Odontólogo/Odontopediatra. Es posible que ante la actual situación de confinamiento exista imposibilidad de acceder a la historia odontológica previa, radiografías y demás registros.

En tiempos de crisis en salud pública o de tensión social, es pertinente contextualizar el tipo de pacientes que realizan la consulta: si son referidos por otro especialista que requiere diagnóstico, si es un paciente habitual o si es un 
Tabla 1: Listado de regulaciones regionales referentes a telesalud y teleodontología por país, aplicables a la actual pandemia COVID-19

\begin{tabular}{|c|c|c|c|c|}
\hline \multirow[t]{2}{*}{ País } & \multicolumn{4}{|c|}{$\begin{array}{l}\text { Normatividad por Pais en TeleSalud y TeleOdontologia / Rules by Country in TeleHealth and Tele- } \\
\text { Dentistry }\end{array}$} \\
\hline & Tipo & Año & Norma/Rule & Enlace \\
\hline \multirow[t]{2}{*}{ Argentina } & TeleSalud & 2020 & $\begin{array}{l}\text { Resolución } 282 \text { de 2020, } \\
\text { SuperSalud Argentina }\end{array}$ & $\begin{array}{l}\text { https://www.boletinoficial.gob.ar/deta- } \\
\text { lleAviso/primera/227378/20200402 }\end{array}$ \\
\hline & Teleodontología & - & $\begin{array}{l}\text { No, pero la regla general } \\
\text { no es excluyente a Odon- } \\
\text { tología. }\end{array}$ & \\
\hline \multirow[t]{2}{*}{ Bolivia } & TeleSalud & 2015 & $\begin{array}{l}\text { Resolución } 200 \text { del } 2015 \\
\text { Ministerio de Salud }\end{array}$ & $\begin{array}{l}\text { https://www.minsalud.gob.bo/images/ } \\
\text { Descarga/resolucion2015/RM200a.pdf }\end{array}$ \\
\hline & Teleodontología & - & $\begin{array}{l}\text { No, pero la regla general } \\
\text { no es excluyente a Odon- } \\
\text { tología. }\end{array}$ & \\
\hline \multirow[t]{3}{*}{ Chile } & TeleSalud & 2007 & Plan Nal de TeleSalud & $\begin{array}{l}\text { https://www.minsal.cl/wp-content/ } \\
\text { uploads/2018/03/Programa-Nacio- } \\
\text { nal-de-Telesalud.pdf }\end{array}$ \\
\hline & & & Res 2042020 MinSalud & $\begin{array}{l}\text { https://www.diariooficial. } \\
\text { interior.gob.cl/publicacio- } \\
\text { nes/2020/03/27/42616/01/1745655.pdf }\end{array}$ \\
\hline & Teleodontología & - & No & \\
\hline \multirow[t]{2}{*}{ Colombia } & TeleSalud & 2019 & $\begin{array}{l}\text { Resolución } 2654 \text { de } 2019 \\
\text { Minsalud }\end{array}$ & $\begin{array}{l}\text { https://www.minsalud.gov.co/Norma- } \\
\text { tividad_Nuevo/Resoluci\%C3\%B3n } \% 20 \\
\text { No.\%202654\%20del\%202019.pdf }\end{array}$ \\
\hline & Teleodontología & 2020 & $\begin{array}{l}\text { Lineamientos Salud Oral } \\
\text { en Urgencias en Co- } \\
\text { vid-19 pandemia. Mayo } \\
2020 .\end{array}$ & $\begin{array}{l}\text { https://www.minsalud.gov.co/Ministerio/ } \\
\text { Institucional/Procesos\%20y\%20procedi- } \\
\text { mientos/GIPS26.pdf }\end{array}$ \\
\hline \multirow[t]{2}{*}{ Costa Rica } & TeleSalud & - & No & \\
\hline & Teleodontología & - & No & \\
\hline \multirow[t]{2}{*}{ Cuba } & TeleSalud & - & No & \\
\hline & Teleodontología & - & No & \\
\hline \multirow[t]{2}{*}{ Ecuador } & TeleSalud & 2010 & $\begin{array}{l}\text { Plan Nacional de TeleSa- } \\
\text { lud Marzo } 2010 .\end{array}$ & $\begin{array}{l}\text { http://dspace.cedia.org.ec/bits- } \\
\text { tream/123456789/68/1/Telemedicina_MSP. } \\
\text { pdf }\end{array}$ \\
\hline & Teleodontología & 2020 & $\begin{array}{l}\text { No, pero la regla general } \\
\text { no es excluyente a Odon- } \\
\text { tología. }\end{array}$ & \\
\hline \multirow[t]{2}{*}{ El Salvador } & TeleSalud & - & No & \\
\hline & Teleodontología & - & No & \\
\hline
\end{tabular}


Tabla 1: Listado de regulaciones regionales referentes a telesalud y teleodontología por país, aplicables a la actual pandemia COVID-19. Cont.

\begin{tabular}{|c|c|c|c|c|}
\hline \multirow[t]{2}{*}{ País } & \multicolumn{4}{|c|}{$\begin{array}{l}\text { Normatividad por Pais en TeleSalud y TeleOdontologia / Rules by Country in TeleHealth and Tele- } \\
\text { Dentistry }\end{array}$} \\
\hline & Tipo & Año & Norma/Rule & Enlace \\
\hline \multirow[t]{2}{*}{ Honduras } & TeleSalud & - & No & \\
\hline & Teleodontología & - & No & \\
\hline \multirow[t]{2}{*}{ México } & TeleSalud & - & $\begin{array}{l}\text { No. Proyecto de Ley de } \\
\text { Telesalud del } 2015 .\end{array}$ & $\begin{array}{l}\text { http://dof.gob.mx/nota_detalle.php?codi- } \\
\text { go=5420782\&fecha=21/12/2015 }\end{array}$ \\
\hline & Teleodontología & - & No & \\
\hline \multirow[t]{2}{*}{ Nicaragua } & TeleSalud & - & No & \\
\hline & Teleodontología & - & No & \\
\hline \multirow[t]{2}{*}{ Panamá } & TeleSalud & - & $\begin{array}{l}\text { No. Anteproyecto Ley } \\
\text { Abril, } 2020\end{array}$ & $\begin{array}{l}\text { https://raulfernandezdiputado.com/ante- } \\
\text { proyectos/anteproyecto-de-ley-que-esta- } \\
\text { blecen-los-lineamientos-para-el-desarro- } \\
\text { llo-de-la-telesalud-en-panama/ }\end{array}$ \\
\hline & Teleodontología & - & No. & \\
\hline \multirow[t]{2}{*}{ Paraguay } & TeleSalud & 2015 & Ley 5.482 de 2015 & $\begin{array}{l}\text { http://www.bacn.gov.py/leyes-paragua- } \\
\text { yas/4465/ley-n-5482-crea-el-programa-na- } \\
\text { cional-de-telesalud }\end{array}$ \\
\hline & Teleodontología & - & $\begin{array}{l}\text { No, pero la regla general } \\
\text { no es excluyente a Odon- } \\
\text { tología. }\end{array}$ & \\
\hline \multirow[t]{2}{*}{ Perú } & TeleSalud & 2009 & \begin{tabular}{|l} 
Norma Técnica NTS N \\
067-MINSA/DGSP-V.01 \\
\end{tabular} & $\begin{array}{l}\text { http://bvs.minsa.gob.pe/local/MIN- } \\
\text { SA/1428.pdf }\end{array}$ \\
\hline & Teleodontología & 2020 & $\begin{array}{l}\text { Directiva Sanitaria } 100 \\
\text { MINSA/2020/DGIESP }\end{array}$ & $\begin{array}{l}\text { https://cdn.www.gob.pe/uploads/docu- } \\
\text { ment/file/716209/DIRECTIVA_SANITA- } \\
\text { RIA_N_100-MINSA-2020-DGIESP.pdf }\end{array}$ \\
\hline \multirow{2}{*}{$\begin{array}{l}\text { República } \\
\text { Dominicana }\end{array}$} & TeleSalud & - & No & \\
\hline & Teleodontología & - & No & \\
\hline \multirow[t]{2}{*}{ Uruguay } & TeleSalud & 2020 & Ley 19.869 de 2020 & $\begin{array}{l}\text { https://www.impo.com.uy/bases/le- } \\
\text { yes/19869-2020 }\end{array}$ \\
\hline & Teleodontología & - & $\begin{array}{l}\text { No, pero la regla general } \\
\text { no es excluyente a Odon- } \\
\text { tología. }\end{array}$ & \\
\hline \multirow[t]{2}{*}{ Venezuela } & TeleSalud & - & $\begin{array}{l}\text { No. Anteproyecto Ley de } \\
\text { Telesalud del } 2015 \\
\end{array}$ & $\begin{array}{l}\text { https://pandectasdigital.blogspot. } \\
\text { com/2017/02/ley-de-telesalud.html }\end{array}$ \\
\hline & Teleodontología & - & No & \\
\hline
\end{tabular}


paciente que contacta por primera vez. De ser factible, el profesional debe intentar acceder al historial para optimizar el diagnóstico. ${ }^{16}$

Al realizar la consulta virtual por teleodontología es importante comunicarse eficientemente, manejar un tono de voz amable, suave, calmado y que transmita confianza. El primer paso es relajar al paciente y a su cuidador, tutor o guardián legal, a la vez que se explica de manera breve, sobre los alcances, beneficios, pero también, sobre las limitaciones y responsabilidades de este tipo de consultas. El profesional debe escuchar atentamente la información que le están proporcionando, mostrando empatía y dando seguridad en que la situación va a ser dirigida y solventada. Al tiempo debe ir llenando el registro de la consulta virtual de acuerdo a la información brindada.

Dependiendo del momento de la Pandemia COVID-19 en cada región, y de las regulaciones establecidas por los organizamos estatales y de salud, la consulta odontológica se verá dirigida hacia la atención exclusiva de urgencias, la realización de tratamientos prioritarios, hasta la reapertura de la consulta para procedimientos de rutina. ${ }^{9}$

\section{Paso 1: Atención con Teleodontología Pre-Consulta Virtual}

La pre-consulta incluye la provisión de un cuestionario previo enviado por medios digitales, que puede ser diligenciado y enviado antes de la consulta sincrónica, o para apoyar la consulta asincrónica (Anexo 1). Es recomendable tener una interacción previa con el paciente o sus cuidadores antes de la consulta que se pretende desarrollar, según las necesidades del paciente o las posibilidades de apoyo que el especialista pueda brindar.

Adicionalmente a ese cuestionario previo, se debe incluir una guía de consulta virtual que debe ser firmada bajo el acuerdo que al realizar la consulta se aceptaron las estipulaciones allí contenidas, incluyendo especificaciones sobre el alcance de la consulta virtual, las limitaciones y los pasos básicos durante esa consulta ya sea sincrónica o asincrónica.

\section{Consulta Virtual}

\section{Anamnesis y Motivo de Consulta}

Con la atención a distancia, sin posibilidad de examen físico, puede realizarse un diagnóstico presuntivo y orientaciones terapéuticas. De ser necesaria la consulta presencial, debe determinarse o seguir los pasos apropiados para brindar la atención óptima, guardando todas las medidas de bioseguridad. ${ }^{1-9}$

En Odontología se ha establecido que los motivos más frecuentes de consulta por urgencia son: dolor, inflamación, traumatismo o hemorragia; 1, 3, 5, 13, 14, 25 sobre los cuales es necesario indagar información referente a los síntomas, utilizando criterios de gravedad, para poder brindar orientación al paciente. En todos los casos, se debe mantener el seguimiento de evolución del paciente, utilizando las mismas vías de comunicación.

\section{Registro Físico de la Consulta Virtual Sincrónica}

Al realizar atención por teleodontología es indispensablellevar un registro delos datos con una ficha diseñada que incluya previamente toda la información referente a la historia médica que se tenga del paciente, o datos referidos por otro especialista. Igualmente se deberá registrar todo lo relativo al episodio, que sirva al clínico como guía al momento de realizar un diagnóstico presuntivo y que le permita mantener el seguimiento por escrito de la teleconsulta o consulta virtual. Anexo a este artículo se propone un modelo de registro durante la consulta virtual sincrónica en Odontología.

De esta manera, cuando el especialista sea contactado por el paciente o sus cuidadores para solicitar una consulta virtual, deberá abrir un nuevo registro que apoyará su 
gestión clínica y todos los respaldos legales de su práctica profesional. Este registro deberá contener información básica como fecha de contacto, iniciales razones de consulta, nombre de la persona que inicio el contacto (cuidador o entidad guardiana), nombre del paciente, si es paciente nuevo o parte de la consulta de su clínica, entre otros. Este registro inicial de requerimiento de consulta puede ser llenado virtualmente y almacenado digitalmente, mientras que las condiciones profesionales, permitan incluir este documento dentro de la Historia Clínica del paciente ubicada en la clínica o consultorio (Anexo 1).

Registro Físico de la Consulta Virtual Asincrónica

$\mathrm{Al}$ responder a una consulta recibida por correo electrónico o por otro medio escrito o referido, el especialista deberá responder en un formato estándar a esta consulta, dando sus apreciaciones clínicas basadas en los datos brindados por el paciente o cuidador. Copia de esta respuesta deberán ser almacenadas en la carpeta abierta para este paciente en el archivo de consultas virtuales o de teleodontología.

\section{Post-Consulta Virtual}

De acuerdo a los hallazgos clínicos que se puedan dar en la consulta virtual sincrónica o asincrónica, el odontólogo definirá el siguiente paso en la ruta de atención: si el paciente requiere consulta de urgencias o de emergencias, o si por el contrario, el caso permite hacer un seguimiento virtual con apoyo de las herramientas tecnológicas disponibles. Se plantea un resumen de las rutas de atención en las figuras 1 y 2 .

\section{Tamizaje de Urgencia. Aspectos Iniciales}

Utilizando teleodontología, realizar el interrogatorio referente a la patología que presenta el paciente mediante el tamizaje (anamnesis, despistaje o triage) para determinar si es factible el tratamiento sintomático a distancia o si se trata de una urgencia o emergencia. Generalmente la consulta virtual de urgencia se realiza de forma sincrónica. A continuación se describen dos diferentes contextos que pueden emerger

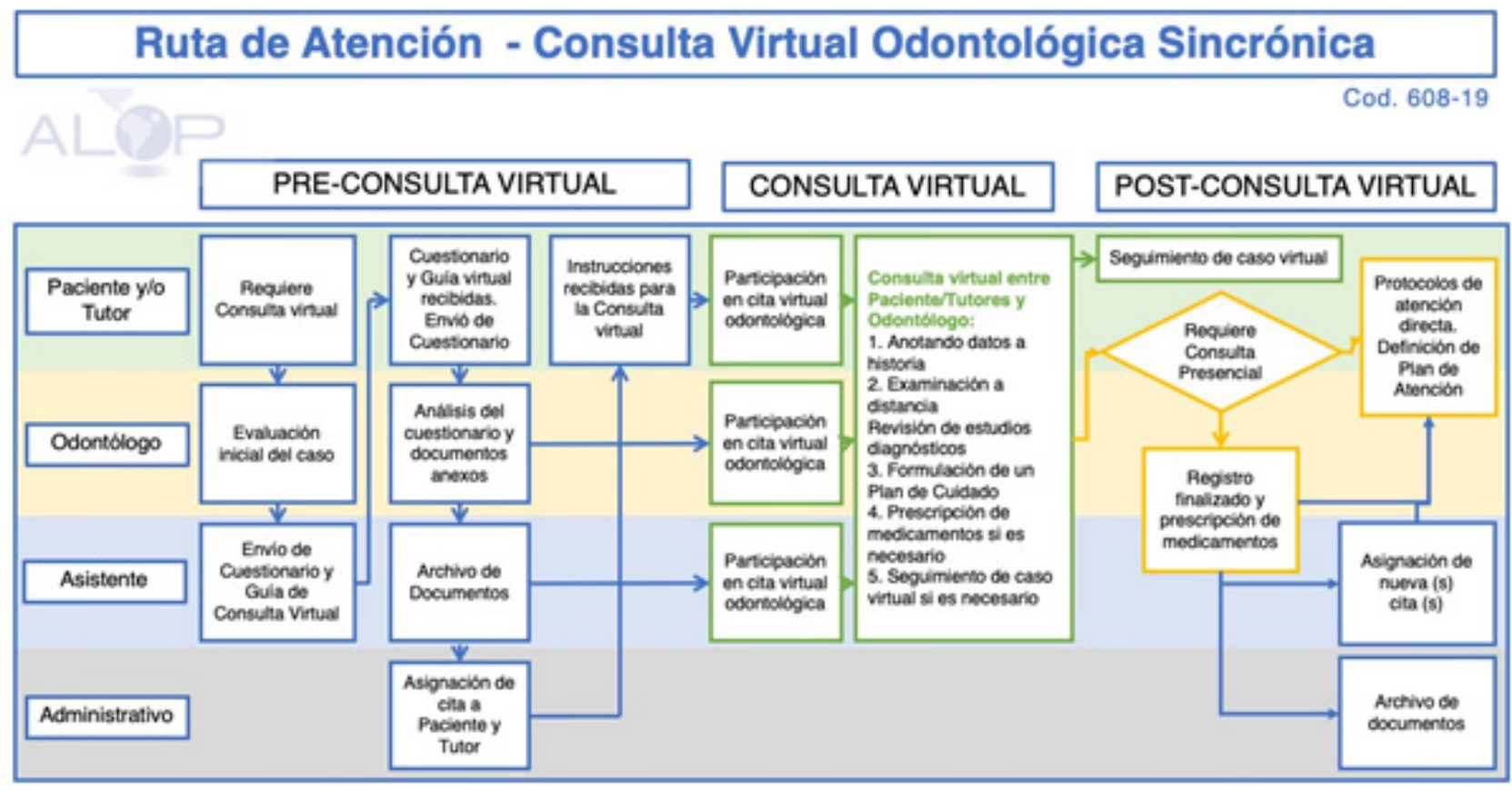

Figura 1. Flujograma de pasos a seguir en la atención Consulta Virtual Odontológica Sincrónica, con el rol de cada participante del equipo odontológico (Adaptado de Mutis et al 48) 


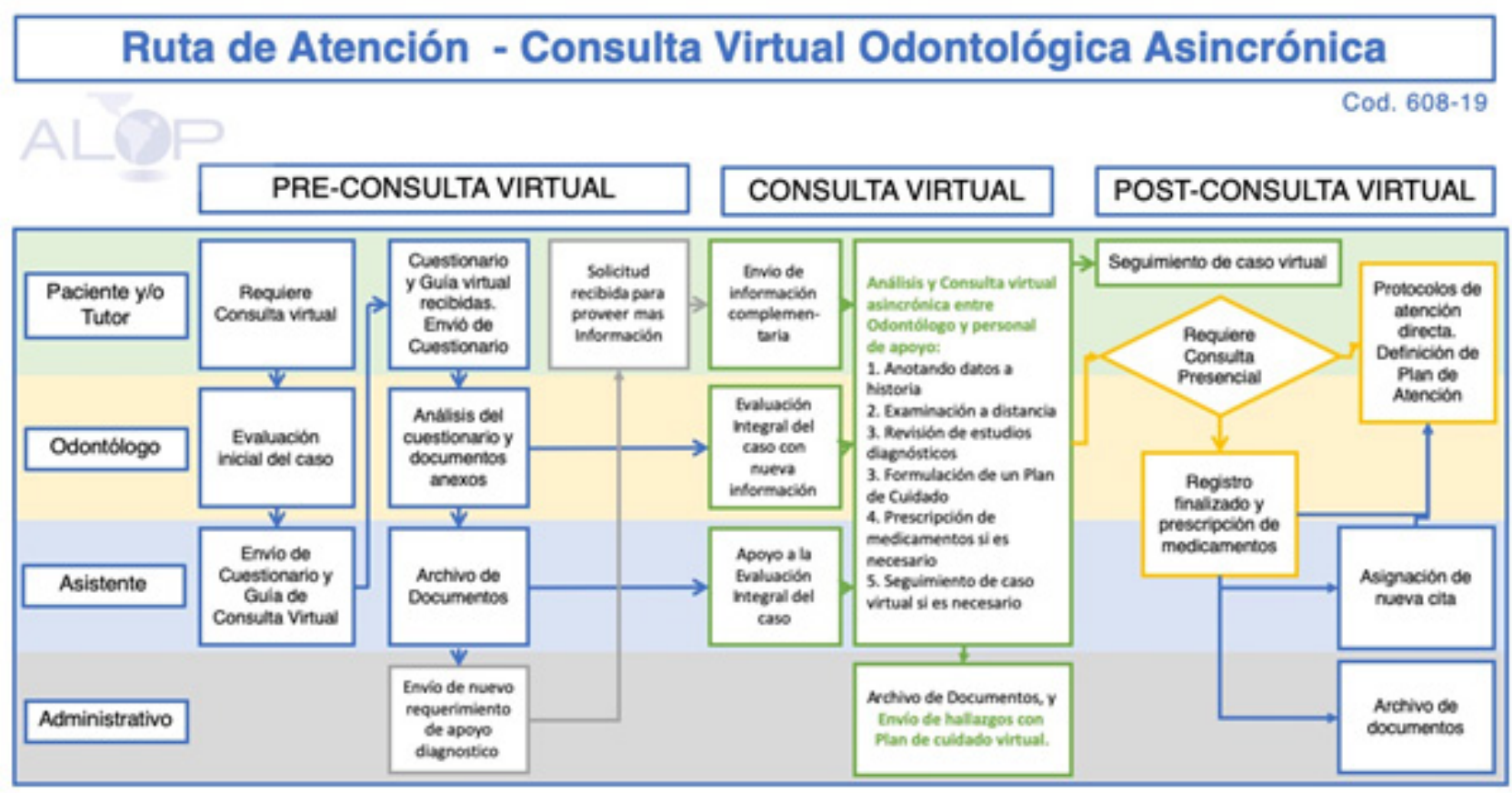

Figura 2. Flujograma de pasos a seguir en la atención Consulta Virtual Odontológica Asincrónica, con el rol de cada participante del equipo odontológico (Adaptado de Mutis et al 48)

de este triage con el paciente o sus guardianes legales durante la consulta virtual sincrónica (Anexo 2):

\section{Urgencia Odontológica: Manejo de} condiciones que requieren tratamiento inmediato para aliviar dolor severo e infección: pulpitis irreversible severa, pericoronaritis, absceso dentoalveolar localizado, fractura dental con dolor, alveolitis, trauma dental con avulsión o luxación, hemorragia, toma de biopsias o preparación odontológica previa a procedimientos médicos. ${ }^{13}$, 25-27 Las urgencias odontológicas pueden ser atendidas en consultorio odontológico bajo las normas de bioseguridad y regulaciones locales que hayan sido definidas por el ente regulatorio en salud.

Emergencia Odontológica: situaciones con potencial de poner en riesgo la vida del paciente que requieren tratamiento inmediato: hemorragia incontrolada, celulitis facial con edema intra y extraoral que compromete la via aérea o planos profundos, trauma dentofacial que pueda comprometer la vía aérea. ${ }^{1,13,25,26}$ Las emergencias odontológicas deben ser atendidas única y exclusivamente en ambiente hospitalario y nunca en el consultorio odontológico (trauma facial con hemorragia activa, edema extraoral con fiebre o celulitis facial).

Varios factores deben tenerse en cuenta durante la consulta virtual en el interrogatorio durante el triage:

Usualmente este paso debe ser desarrollado entre el especialista en salud y el guardián o cuidador del niño, pero es importante la presencia del paciente menor de edad durante la teleconsulta para confirmar síntomas o visualizar algunos signos clínicos que puedan ser vistos por video. El interrogatorio debe incluir datos referentes a la sintomatología:

- Presenta dolor: leve, moderado o severo.

- Presenta edema: determinar si el edema es intraoral o extraoral. Verificar si ha tenido fiebre.

- Presenta trauma dentofacial: cuáles estructuras están afectadas, si presenta 
hemorragia activa, laceración fracturas faciales, fractura dental, avulsión o luxación dental. Verificar si los dientes afectados son primarios o permanentes.

- Presenta hemorragia: verificar si es profusa, si es posible identificar la causa o el origen.

\section{Ayudas Diagnósticas}

Si el paciente no ha recibido atención previa o ha sido referido por otro especialista, dentro de la pre consulta virtual (Anexo 1) se deben haber solicitado imágenes, fotos y otros elementos que permitan realizar el mejor acercamiento diagnóstico y confirmar el inicio de un tratamiento ambulatorio sin necesidad de acudir a la consulta o por el contrario, indicar la necesidad de realizar una evaluación presencial por tratarse de una emergencia o urgencia odontológica.

\section{Diagnosticos Complementarios durante la consulta virtual}

Durante la teleconsulta, el Odontopediatra puede detectar signos y síntomas presentes en la boca y cara de los niños como señal de un maltrato físico, el cual puede darse por acción, omisión o negligencia. ${ }^{28}$ La correlación de los datos obtenidos del interogatorio con las observaciones que puedan realizarse en las fotografías e imágenes de pacientes con diferentes grados de vulerabilidad, ocasionalmente podría sugerir maltrato infantil o violencia intrafamiliar. Por lo tanto, es relevante recordar que el Odontólogo como profesional de la salud tiene el deber de reportar estas situaciones ante el ente encargado en cada país, según los protocolos establecidos.

Una vez logrado el diagnóstico presuntivo con la información suministrada determine si es factible realizar una consulta presencial de urgencias para confirmar el diagnostico presuntivo y realizar un manejo especifico sintomático.
Si logra el manejo de la urgencia y la confirmación del diagnóstico presuntivo dado durante la consulta virtual con esta información y tratamiento sintomático (analgésicos, antibióticos), es aconsejable actualizar todos los registros para terminar la consulta y coordinar el seguimiento por medio de consulta virtual mixta (sincrónico y asincrónico, de acuerdo al contexto del caso clínico), hasta que se puedan tomar otras medidas terapéuticas.

A continuación, se plantean las preguntas que permiten guiar al clínico en la elaboración del diagnóstico. ${ }^{14,}$ 16, 27 Las preguntas planteadas sirven de sistematización hacia la elaboración del diagnóstico. El clínico deberá realizar todas las indagaciones que estime necesarias y utilizar su mejor criterio clínico para determinar la conducta a seguir. Utilizando criterio de severidad, se orienta si la atención debe ser por telemedicina, atención de urgencia presencial o si el paciente debe ser remitido inmediatamente a la sala de urgencias hospitalaria.

Para todos los casos: Solicitar fotos intraorales o extraorales, y todos los recursos que permitan visualizar de forma lo más nítida posible y en diferentes perspectivas el motivo de la consulta.

\section{Prescripción de Medicamentos con Telemedicina}

La prescripción de medicamentos a distancia debe realizarse con sumo cuidado. En el caso de pacientes pediátricos verificando el peso para la correcta dosificación. Al tener en cuenta que la responsabilidad de la prescripción la asume el profesional, se debe advertir a los padres o tutores, que es imperativo el seguimiento estricto de las recomendaciones suministradas, con el fin de evitar posibles eventos adversos. Se deberá enviar de forma escrita una guía que especifique los pasos que los padres o tutores deben seguir en el suministro de estos medicamentos, y recibir 
de parte de ellos un correo electrónico o comunicación por redes sociales privadas, entendiendo y aceptando las recomendaciones brindadas por el especialista.

Previa a la consulta presencial es indispensable el correcto diligenciamiento del consentimiento informado. ${ }^{1,3,14}$

\section{Tamizaje de la Urgencia: Diagnóstico y recomendaciones}

\section{Traumatismo dentofacial}

La atención por teleodontología inmediata debe, en primera instancia, calmar al niño y a los padres o tutores. Las preguntas de despistaje son aquellas que permitan delimitar cuál es la magnitud de la consecuencia del trauma. Puede solicitarse información acerca del ambiente o lugar donde ocurrió el trauma. A continuación, se propone una secuencia de preguntas para orientar al clínico en su diagnóstico, las cuales puede complementar con todas aquellas preguntas que estime necesarias en cada caso particular.

Solicitar fotos intraorales o extraorales, y todos los recursos que permitan llegar al diagnóstico y orientación terapéutica.

Ante cualquier respuesta indicativa de necesidad de atención en Urgencias Hospitalarias, detenga el interrogatorio $y$ remita inmediatamente.

Los pacientes con trauma craneal sospecha de fractura maxilar, hemorragia contínua que requiere sutura deben ser remitidos inmediatamente a la sala de urgencias hospitalaria.

Si presenta abrasión en tejido blando se recomienda usar gluconato de clorhexidina al 0,1\% sin alcohol por vía tópica en el área afectada con hisopos de algodón dos veces al día durante 1 semana. En caso de lesiones labiales uso de bálsamo labial durante el período de cicatrización.

La atención de urgencia de traumatismos dentofaciales presenta varios protocolos dependiendo si el diente afectado es primario o permanente. En todo caso, la atención de urgencia a realizar en el momento de confinamiento debe estar orientada hacia mantener los dientes permanentes funcionales y sanos en boca y realizar procedimientos que minimicen la generación de aerosoles. 3, 12, 26, 29 Siendo así, después de un examen exhaustivo y diagnóstico apropiado, se recomienda la protección pulpar en casos de fracturas dentales. Seguir los lineamientos y protocolos internacionales basados en evidencia científica. $^{30,31}$

En el caso de avulsión de dientes primarios sin otra complicación asociada, trauma dental que se limita a fractura coronal simple de esmalte o de esmalte y dentina sin compromiso pulpar, o luxaciones leves sin interferencia oclusal ni movilidad, pueden ser tratados con telemedicina. La restauración coronal o recolocación de fragmentos puede realizarse posteriormente. Realizar prescripción de analgésicos según el caso, modificaciones de dieta e higiene.

En el caso de luxaciones de dientes permanentes: verificar magnitud del desplazamiento y si hay interferencia oclusal. Indicar intentar realizar la reposición con presión digital (con excepción de luxaciones intrusivas). Seguir los lineamientos y protocolos internacionales basados en evidencia científica. ${ }^{30}$

En caso de avulsión: orientar a los padres a realizar el reimplante del diente (tomar por la corona, evitando tocar la raíz. Si está sucio lavarlo 10 segundos con agua potable, poner el diente en posición y morder un pañuelo para mantenerlo en su lugar). De no ser posible, verificar que el medio de conservación previo a la atención presencial de la urgencia sea apropiado, (recipiente con leche, solución fisiológica o saliva. En pacientes colaboradores es posible transportar al diente dentro de la boca al lado de la mejilla) no en medios secos ni en agua. Los primeros 30 minutos transcurridos desde el traumatismo son 
escenciales para un mejor pronóstico. Seguir los lineamientos y protocolos internacionales basados en evidencia científica. ${ }^{30,32}$

En todos los casos, hacer seguimiento de la evolución.

\section{Inflamación y Edema Extraoral e Intraoral.}

La atención por telemedicina inmediata debe, en primera instancia, calmar al niño y a los padres o tutores. A continuación, se propone una secuencia de preguntas para orientar al clínico en su diagnóstico, las cuales puede complementar con todas aquellas preguntas que estime necesarias en cada caso particular.

Solicitar fotos intraorales o extraorales, y todos los recursos que permitan llegar al diagnóstico y orientación terapéutica.

Ante cualquier respuesta indicativa de necesidad de atención en Urgencias Hospitalarias, detenga el interrogatorio $y$ remita inmediatamente.

Si el paciente presenta trismus, edema submandibular o sublingual con dolor a la deglución, edema palpebral, dificultad para abrir el ojo, eritema o edema que se extiende hacia el cuello, crepitación a la palpación o fiebre debe ser remitido a la sala de urgencias hospitalaria.

La pericoronaritis puede ser tratada de forma sintomática con higiene apropiada de la zona, enjuagatorios antisépticos (clorhexidina 012\% o peróxido de hidrógeno 1\%) modificaciones de dieta y analgésicos. Evaluar evolución. En casos de no mejoría, realizar atención de urgencia.

Si existe inflamación gingival puede sugerir colutorios de clorhexidina al $0.12 \%, 2$ veces al día sin diluir, por quince días. En niños pequeños se puede aplicar con gasa embebida en la solución.

Abscesos dentoalveolares localizados pueden ser tratados por telemedicina con prescripción de antibiótico (Amoxicilina, Amoxicilina +
Ac. Clavulánico, Azitromicina, Clindamicina o el tratamiento farmacológico que decida el profesional de acuerdo al paciente, sus antecedentes médicos y sus requerimientos) según el peso y características del paciente y las directrices nacionales de salud de su país. La cita de urgencia puede planificarse 48 horas después del inicio de la toma de antibióticos de ser necesario.

En casos de dudas, realizar consulta presencial para corroborar diagnóstico.

En todos los casos, hacer seguimiento de la evolución.

\section{Hemorragia}

La atención por telemedicina inmediata debe, en primera instancia, calmar al niño y a los padres o tutores. Las preguntas de despistaje son aquellas que permitan delimitar cuál es la magnitud del sangrado. A continuación, se propone una secuencia de preguntas para orientar al clínico en su diagnóstico, las cuales puede complementar con todas aquellas preguntas que estime necesarias en cada caso particular.

Solicitar fotos intraorales o extraorales, y todos los recursos que permitan llegar al diagnóstico y orientación terapéutica.

Indicaciones: No escupir, no realizar enjuagatorios, aplicar compresas frías en la zona de la hemorragia, realizar compresión continua por 15 minutos.

Pacientes sanos, con causa identificada de la hemorragia la cual se detiene después de realizadas medidas hemostáticas de compresión, puedes ser seguidos con telemedicina.

Si determina que el paciente requiere sutura, debe ser atendido de urgencia.

Si la hemorragia persiste, o si el paciente tiene antecedente médicos relevantes debe ser remitido a urgencias hospitalarias.

En todos los casos, hacer seguimiento de la evolución. 


\section{Dolor Dental}

La atención por telemedicina inmediata debe, en primera instancia, brindar confianza al niño y a los padres o tutores. Las preguntas de despistaje son aquellas que permitan delimitar cuál es la magnitud del dolor. A continuación, se propone una secuencia de preguntas para orientar al clínico en su diagnóstico, las cuales puede complementar con todas aquellas preguntas que estime necesarias en cada caso particular.

Solicitar fotos intraorales o extraorales, y todos los recursos que permitan llegar al diagnóstico y orientación terapéutica.

El dolor en general es difícil de medir debido a su subjetividad, especialmente en niños, dependiendo a menudo del informe de los padres. Sin embargo, en lo posible se recomienda no sustituir el autoreporte de dolor, por el reporte de los padres o tutores,33 en cambio, se podrían utilizar instrumentos de Escala Visual Análoga (EVA) como Wong Baker Faces (WBF), Faces Pain Scale Revised (FPS-R), entre otros, que aunque no son totalmente objetivos, pueden facilitar la evaluación y un autoinforme de la expresión del dolor en niños. $^{34}$

Ante la presencia de lesiones de caries que puedan ocasionar pulpitis, la conducta terapuética a seguir va orientada hacia lograr la detención de la lesión. Siendo así, las recomendaciones de higiene con pasta dental con concentración de fluoruro 1.100 a 1.500 ppm o superior, uso de seda dental e implementación de correctos hábitos de higiene cobra especial importancia. El manejo de la enfermedad caries en el marco de la Pandemia COVID-19 debe realizarse tomando como criterio la reducción de procedimientos que generen aerosoles. ${ }^{2}$

Ante la presencia de dolor leve o provocado que cesa, puede prescribirse Paracetamol (Acetaminofén) según peso del paciente $\mathrm{y}$ características del paciente y las directrices nacionales de salud de su país. ${ }^{35,36}$
En caso de dolor severo o si el paciente ha tomado analgésicos por 48 horas sin mejoría, debe acudir a cita de urgencias. ${ }^{16}$

Ante aparatos de ortodoncia fracturados o desalojados, intentar su remoción en casa. De ser imposible remover el aparato en casa y está produciendo laceración o ulceración, debe ser atendido con cita de urgencia. Esperar culminar el periodo de confinamiento para recementado de aditamentos. ${ }^{22,37}$

En todos los casos, hacer seguimiento de la evolución.

Paso 2: Si determina que es necesario realizar la atención de urgencia odontológica presencial, refuerce el interrogatorio:

Previo a agendar la cita de tratamiento de urgencia debe realizar despistaje de COVID-19. Debido al periodo de incubación asintomático. Recuerde que los niños tienden a presentar menos sintomatología que los adultos. Todos Los pacientes pediátricos deben considerarse portadores potenciales a menos que se haya probado lo contrario. ${ }^{12,27,38}$

\section{SÍNTOMAS COVID-19}

- El paciente ha presentado fiebre en los últimos 14 días

- Ha presentado síntomas respiratorios (tos, odinofagia, rinorrea), síntomas gastrointestinales (diarrea, vómitos, dolor abdominal) o malestar general, en los últimos 14 días

- Ha notado pérdida en el sentido del gusto o del olfato en los últimos 14 días.

\section{EXPOSICIÓN A COVID-19 (sospecha)}

- El paciente o su representante han viajado a países de riesgo en los últimos 14 días.

- Ha estado en contacto estrecho con personas que presentan fiebre o cuadro respiratorio agudo en los últimos 14 días.

- Antecedente de contacto con alguien diagnosticado como sospechoso o confirmado COVID19. 
Si existe al menos una respuesta afirmativa para estas preguntas, indíquele al paciente:

1. Contactar telefónicamente al médico o a la emergencia de su localidad, para activar el protocolo COVID-19 (de responder la presencia de síntomas), iniciar aislamiento o cuarentena según sea el caso.

2. Una vez aprobado por el equipo médico se podrá continuar la atención odontológica.

Debe contar con el EPP apropiado para todo el personal y asegurar el cumplimiento estricto de las normas de bioseguridad. ${ }^{1-5,13-15,27,38-47}$ De lo contrario, debe referir al paciente.

Ver "Ruta de atención para procedimientos de Odontología Pediátrica durante la etapa de confinamiento o cuarentena de la pandemia COVID-19. ${ }^{1}$

\section{Consideraciones}

Estas recomendaciones han sido realizadas de forma independiente y voluntaria por los investigadores de la Asociación Latinoamericana de Odontopediatría, en conjunto con especialistas en las diversas áreas médicas en Latinoamérica, con arbitraje de pares, libres de conflicto de interés.

Las presentes recomendaciones están basadas en la mayor evidencia disponible hasta la fecha siendo el COVID-19 una enfermedad emergente. Se realizarán las actualizaciones necesarias conforme al estado de la ciencia al respecto y a la evolución de la enfermedad.

El grupo de expertos responsables de la curaduría se mantiene activo y en constante monitoreo de la información publicada referente a COVID-19 para realizar las actualizaciones y anexos necesarios.

\section{Autores}

Desarrollo de este artículo liderado por Martha Mutis (Estados Unidos de América), Elías M. Morón (Estados Unidos de América), A. Carolina Medina Díaz (Venezuela), como parte del Equipo Interdisciplinario COVID-19 de la Asociación Latinoamericana de Odontopediatría.

Equipo Interdisciplinario COVID-19 de la Asociación Latinoamericana de Odontopediatría:

Jenny Abanto (Brasil), Mariana Armada (Argentina), Paola Beltri (España), Marisol Carrillo Tabakman (Paraguay), Haydée Casaretto (Argentina), Jorge Luis Castillo (Perú), Mónica Gladys Cesetti (Argentina), Bertha Angélica Chávez González (Perú), Ana Claudia Rodrigues Chibinski (Brasil), Salomon Alberto Cohen (Argentina), Olga Cortés Lillo (España), Luzia Ana Da Silva de Carballo (Venezuela), Gonzalo De la Fuente Alvarez (Chile), Renée Di Nallo (Argentina), María Débora Elizabeth Dricas (Argentina), Sandra Echevarria (Brasil), Piedad Cecilia Echeverry Marin (Colombia), Laura Fedelli (Argentina), Carlos Flores-MIr (Canadá), Andrea Virgina González Carfora (Chile), Lina María Hernández Salas (Colombia), Francisco José Hernández Restrepo (Colombia), Maria Teresa Ibañez Rodriguez (Bolivia), José Carlos Pettorossi Imparato (Brasil), Alejandra Lipari Valdés (Chile), Daniela Madrigal López (Costa Rica), Daniela Catalina Martínez Camus (Chile), María Gabriela Martínez Vásquez (Venezuela), A. Carolina Medina Díaz (Venezuela), Kelly Maria Silva Moreira (Brasil), Elías M. Morón (Estados Unidos de América), Martha Mutis (Estados Unidos de América), Camila Palma (Perú), Gladys Mabel Peña (Argentina), Adriana Pistochini (Argentina), Paloma Planells (España), Gabriel Politano (Brasil), Matias RiosErazo (Chile), Adriana Maria Rubiano Pinzon (Colombia), Karla Mayra Rezende (Brasil), Rosa Gabriela Rondón (Venezuela), Gabriela Scagnet (Argentina), Rosemary Sogbe de Agell (España), Marina Tavares Costa Nóbrega (Canadá), Jorgelina Valente (Argentina), Ernesto Venegas De Herrera (República Dominicana), Rosa Helena Wanderley Lacerda (Brasil), Ana Clara Zabala (Argentina), Gabriel Zambrano (Venezuela).

Información completa del Equipo Interdisciplinario COVID-19 de la Asociación Latinoamericana de Odontopediatría 


\section{Referencias bibliográficas}

1. Asociación Latinoamericana de Odontopediatría. Grupo COVID-19. Ruta de atención para procedimientos de Odontología Pediátrica durante la etapa de confinamiento o cuarentena de la pandemia COVID-19. Revista de Odontopediatría Latinoamericana. 2020;10(2):https://www. revistaodontopediatria.org/ediciones/2020/2/art-1/.

2. Asociación Latinoamericana de Odontopediatria. Tratamiento de la enfermedad de caries en época de COVID-19: protocolos clínicos para el control de aerosoles. Revista de Odontopediatría Latinoamericana. abril 2020;10(2):https://www.revistaodontopediatria.org/ediciones/2020/2/art-2/\#.

3. Asociación Latinoamericana de Odontopediatría ALOP. Modelos de Consentimiento Informado para la Atención de Urgencias en tiempos de COVID-19. abril 4, 2020. Available at: https:// www.alopodontopediatria.org/noticias/consentimiento-informado-indicados-especialmenteatenci\%C3\%B3n-emergencias-odontologicas/.

4. Centers for Disease Control and Prevention CDC. Interim Infection Prevention and Control Recommendations for Patients With Suspected or Confirmed Coronavirus Disease 2019 (Covid-19) in Healthcare Settings. abril 2020. Available at: https://www.cdc.gov/coronavirus/2019-ncov/ hcp/infection-control-recommendations.html?CDC_AA_refVal=https\%3A\%2F\%2Fwww.cdc. gov\%2Fcoronavirus\%2F2019-ncov\%2Finfection-control\%2Fcontrol-recommendations.html.

5. Centers for Disease Control and Prevention CDC. Recommendation: Postpone Non-Urgent Dental Procedures, Surgeries, and Visits. Marzo 27, 2020. Available at: https://www.cdc.gov/oralhealth/ infectioncontrol/statement-COVID.html.

6. American Academy of Pediatric Dentistry. COVID-19 Update/Coronavirus Update. 2020 Abril. Available at: https://www.aapd.org/about/about-aapd/news-room/covid-19/.

7. Dave M, Seoudi N, Coulthard P. Urgent dental care for patients during the COVID-19 pandemic. The Lancet. Abril 2020:DOI:https://doi.org/10.1016/S0140-6736(20)30806-0.

8. COVID-19 Dental Services Evidence Review (CoDER) Working Group. Recommendations for the reopening of dental services: a rapid review of international sources. https://oralhealth.cochrane.org/ sites/oralhealth.cochrane.org/files/public/uploads/covid19_dent. Available at: https:/oralhealth. cochrane.org/sites/oralhealth.cochrane.org/files/public/uploads/covid19_dent.

9. Consejo General de Dentistas de España. Plan estratégico de acción para el periodo de desescalada COVID-19. mayo 1, 2020. Available at: https://www.consejodentistas.es/comunicacion/actualidadconsejo/notas-de-prensa-consejo/item/1783-plan-estrategico-de-accion-para-clinicas-dentalesdurante-el-periodo-de-desescalada.html.

10. Vidal-Alaball J, Acosta-Roja R, Pastor N, et al. Telemedicine in the face of the COVID-19 pandemic. Atención Primaria. 2020:https://doi.org/10.1016/j.aprim.2020.04.003.

11. Jampani ND, Nutalapati R, Dontula BS, Boyapati R. Applications of teledentistry: A literature review and update. J Int Soc Prev Community Dent. 2011;1(2):37-44. doi:10.4103/2231-0762.97695.

12. Mallineni SK, Innes NP, Raggio DP, Araujo MP, Robertson MD, Jayaraman J. Coronavirus Disease (COVID-19): Characteristics in children and considerations for dentists providing their care. Int J Paed Dent. abril 2020:doi: 10.1111/ipd.12653.

13. American Dental Association ADA. Emergency Care. abril 2020. Available at: https://www.aapd. org/about/about-aapd/news-room/emergency-care/.

14. American Dental Association (ADA). Interim Guidance for Minimizing Risk of COVID-19 Transmission. abrl 7, 2020. Available at: https:/www.ada.org/ /media/CPS/Files/COVID/ ADA_COVID_Int_Guidance_Treat_Pts.pdf?utm_source=adaorg\&utm_medium=covidresources-lp\&utm_content $=\mathrm{cv}-\mathrm{pm}$-ebd-interim-response\&utm_campaign=covid-19?utm source=adaorg\&utm_medium=adanews\&utm_content=cv-pm-ebd-interi. Accessed abril 8, 2020.

15. Peng X, Xu X, Li Y, Cheng L, Zhou X, Ren B. Transmission routes of 2019-nCoV and controls in dental practice. Intl J Oral Sci. 2020;12:https://doi.org/10.1038/s41368-020-0075-9.

16. Orde National des Chirugiens-Dentistes. Guide pour la prise en charge téléphonique d'une demande de soins dentaires urgents dans le cadre du stade 3 de l'épidémie de COVID-19. Marzo 30, 2020. Available at: https://societechirorale.com/documents/Recommandations/Guide-praticienDefinitif-V1-30-mars-2020.pdf. 
17. Kopycka-Kedzierawski DT, Billings RJ. Teledentistry in inner-city child-care centres. J Telemed Telecare. 2006;12:176-181.

18. Kopycka-Kedzierawski DT, Billings RJ. Prevalence of dental caries and dental care utilization in preschool urban children enrolled in a comparative effectiveness study. Eur Arch Paediatr Dent. 2011;12:133-138.

19. McLaren SW, Kopycka-Kedzierawski DT, Nordfelt J. Accuracy of teledentistry examinations at predicting actual treatment modality in a pediatric dentistry clinic. J Telemed Telecare. 2016:doi:10 $.1177 / 1357633 X 16661428$.

20. AlShaya MS, Assery MK, Pani SC. Reliability of mobile phone teledentistry in dental diagnosis and treatment planning in mixed dentition. J Telemed Telecare. 2018:Doi: 10.1177/1357633X18793767.

21. Pereira LJ, Pereira CV, Murata RM, Pardi V, Pereira-Dourado SM. Biological and social aspects of Coronavirus Disease 2019 (COVID-19) related to oral health. Braz Oral Res. 2020:34:e041.

22. Suri S, Vandersluis YR, Kichhar AS, Bhasin R, Abdallah MN. Clinical orthodontic management during the COVID-19 pandemic. Angle Orthod. 2020:doi: 10.2319/033120-236.1.

23. Ruiz Ibañez C, Zuluaga de Cadena A, Trujillo Zea A. Telemedicina: Introducción, aplicación y principios de desarrollo. Revista CES MEDICINA. 2007;21:77-93.

24. Allely EB. Synchronous and asynchronous telemedicine. J Med Syst. 1995;19:207-212.

25. American Dental Association ADA. What Constitutes a Dental Emergency?. Marzo 31, 2020. Available at: https://success.ada.org/ /media/CPS/Files/Open\%20Files/ADA_COVID19_Dental_Emergency_ DDS.pdf?utm_source=adaorg\&utm_medium=covid-resources-lp\&utm_content=cv-pm-emergdef\&utm_campaign=covid-19\&_ga=2.2729136.124928618.1586021397-1939509346.1586021396.

26. Meyer B, Casamassimo P, William F Vann, FV. An Algorithm for Managing Emergent Dental Conditions for Children. J Clin Ped Dent. 2019;43(3):doi 10.17796/1053-4625-43.3.10 201.

27. Consejo GeneraldeDentistas deEspaña. Organización ColegialdeDentistas de España. Planestratégico de acción para el periodo posterior a la crisis creada por el COVID-19. abril 13, 2020. Available at: https://gacetadental.com/wp-content/uploads/2020/04/PlanestrategicoposteriorCoronavirus.pdf.

28. Gamboa M, Guerra ME. Manifestaciones bucales del maltrato físico. Reporte de caso.. Revista de Odontopediatría Latinoamericana. 2013;3(2):https://www.revistaodontopediatria.org/ ediciones/2013/2/art-11/.

29. Meng L, Hua F, Bian Z. Coronavirus Disease 2019 (COVID-19): Emerging and Future Challenges for Dental and Oral Medicine Treatment of Emergency Cas. J Dent Res. 2020:DOI: 10.1177/0022034520914246.

30. Bastos JV, Cortex MS, Percinoto C, Tovo MF. Capítulo 19. Lesiones traumáticas en dientes primarios y permanentes jóvenes. Manual de Referencia para Procedimientos en Odontopediatría Segunda Edición: ALOP; 2017.

31. International Association of Dental Traumatology (IADT). IADT Treatment Guidelines. Dental Trauna Guide. Available at: https://dentaltraumaguide.org/iadt-treatment-guidelines/. Accessed marzo 21, 2020.

32. Andersson L, Andreasen JO, Day P, et al. International Association of Dental Traumatology guidelines for the management of traumatic dental injuries: 2. Avulsion of permanent teeth. Dental Traumatology. 2012;28:88-96.

33. Lawson SL, Hogg MM, Moore GC, et al. Pediatric Pain Assessment in the Emergency Department: Patient and Caregiver Agreement Using the Wong-Baker FACES and the Faces Pain Scale-Revised. Pediatric Emergency Care. 2019:doi: 10.1097/PEC.0000000000001837.

34. Tomlinson D, von Baeyer CL, Stinson JN, Sung L. A systematic review of faces scales for the selfreport of pain intensity in children. Pediatrics. 2010;126(5):e1168-98.

35. American Association of Pediatric dentistry. The Reference Manual of Pediatric Dentistry. Policy on Acute Pediatric Dental Pain Management. 2019/2020. Available at: https://www.aapd.org/research/ oral-health-policies--recommendations/acute-pediatric-dental-pain-management/.

36. Sucasas da Costa LR, Vaz Castro AD, Lopes GM, Sucasas da Costa PS. Capítulo 25. Terapéutica medicamentosa en Odontopediatría. Manual de Referencia para Procedimientos en Odontopediatría. 2nd ed. Sao Paulo: ALOP; 2017. 
37. Caprioglio A, Pizzetti GB, Zecca PA, Fastuca R, Maino G, Nanda R. Management of orthodontic emergencies during 2019-NCOV. Progress in Orthodontics. 2020;21(10):https://doi.org/10.1186/ s40510-020-00310-y.

38. Consejo General de Dentistas de España. Informe Técnico II del Consejo General de Dentistas de España: Desafíos emergentes del nuevo Coronavirus COVID-19 en la clínica dental 2020.

39. Centers for Disease Control CDC. Personal Protective Equipment FAQs. marzo 2020. Available at: https://www.cdc.gov/coronavirus/2019-ncov/hcp/respirator-use-faq.html.

40. Cochrane Collaboration. Equipo de protección personal para la prevención de las enfermedades altamente infecciosas por exposición a líquidos orgánicos contaminados en el personal de asistencia sanitaria. Revisión sistemática Cochrane -. Julio 2019. Available at: https://www.cochranelibrary. com/es/cdsr/doi/10.1002/14651858.CD011621.pub3/full/es.

41. Organización Mundial de la Salud OMS. Advice on the use of masks in the community, during home care, and in health care settings in the context of COVID-19. WHO Interim Guidance. Marzo 2020.

42. Organización Mundial de la Salud OMS. Rational use of personal protective equipment (PPE) for coronavirus disease (COVID-19) Interim guidance. Marzo 19, 2020. Available at: https://apps.who. int/iris/bitstream/handle/10665/331498/WHO-2019-nCoV-IPCPPE_use-2020.2-eng.pdf.

43. Organización Mundial de la Salud OMS. Vías de transmisión del virus de la COVID-19: repercusiones para las recomendaciones relativas a las precauciones en materia de prevención y control de las infecciones. marzo 29, 2020. Available at: https://www.who.int/es/news-room/ commentaries/detail/modes-of-transmission-of-virus-causing-covid-19-implications-for-ipcprecaution-recommendations.

44. Sabino-Silva R, Gomes Jardim AC, Siqueira WL. Coronavirus COVID-19 impacts to dentistry and potential salivary diagnosis. Clin Oral Invest. 2002;24:1619-1621.

45. The National Institute for Occupational Safety and Health (NIOSH). Recommended Guidance for Extended Use and Limited Reuse of N95 Filtering Facepiece Respiratorsin HealthcareSettings. abril15, 2020. Available at: https://www.cdc.gov/niosh/topics/hcwcontrols/recommendedguidanceextuse. html.

46. van Doremalen N, Bushmaker T T, Morris DH DH, Holbrook, et al. Aerosol and Surface Stability of SARS-CoV-2 as Compared with SARS-CoV-1. N Engl J Med. abril 2020;https://www.nejm.org/doi/ pdf/10.1056/NEJMc2004973?articleTools=true.

47. $\mathrm{Xu} \mathrm{H}$, Zhong L, Deng J, Peng J, et al. High expression of ACE2 receptor of 2019-nCoV on the epithelial cells of oral mucosa. Intl J Oral Sci. 2020;12(8):https://doi.org/10.1038/s41368-020-0074-x.

48. Mutis MJ, Suarez O, Gold J, Balzer J. How to establish a Teledentistry program in Community based Services: The experience in NYU Langone Family Centers. NYU School of Medicine - NYU Langone Health Dental Division. 2018.

Recibido/Received: 20/04/2020

Primera versión aceptada/First accepted version: 21/04/2020

Modificaciones aceptadas/Final version: 15/05/2020

Correspondencia: e-mail: editor@revistaodontopediatria.org 


\section{Anexo 1}

\section{ALQP ASOCIACIÓN LATINOAMERICANA DE ODONTOPEDIATRÍA}

\section{TELEODONTOLOGÍA: CUESTIONARIO PRE-CONSULTA ODONTOPEDIÁTRICA DURANTE LA PANDEMIA COVID-19}

Odontólogo Tratante:

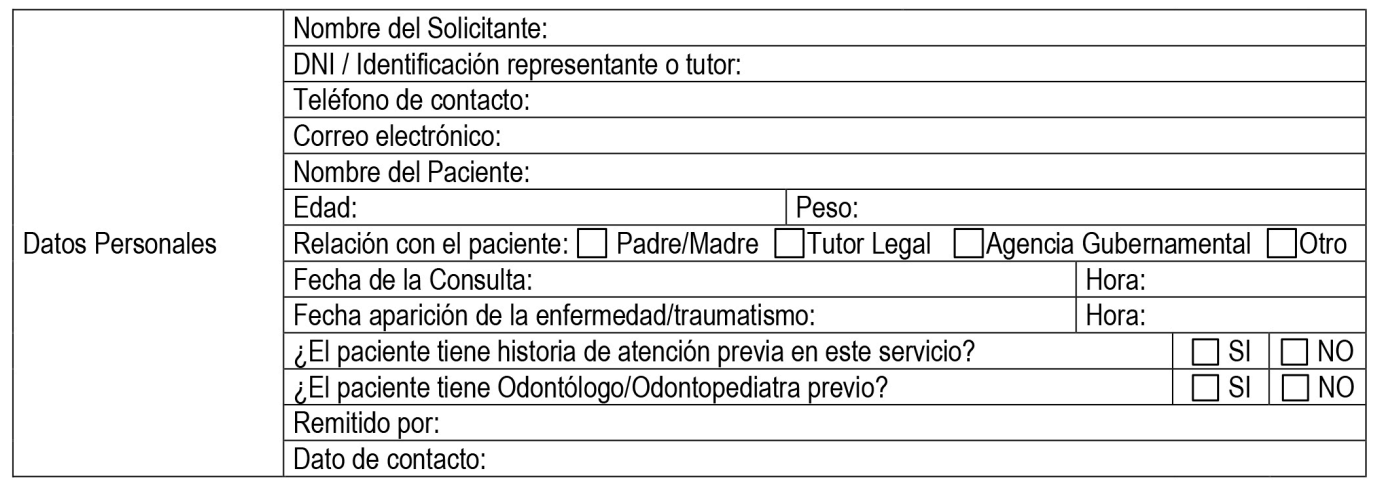

Describa de manera general las razones por las cuales solicita consulta virtual:

\begin{tabular}{|l|l|l|}
\hline $\begin{array}{l}\text { ¿Le ha dado algún tipo de medicamento al paciente para disminuir el dolor o la inflamación durante este } \\
\text { tiempo? }\end{array}$ & $\square$ SI \\
\hline Describa:
\end{tabular}

\begin{tabular}{l|l|l|}
\hline ¿Ha realizado otro tipo de acciones para ayudar a su hijo ante esta situación de salud? & $\square \mathrm{SI}$ \\
\hline Describa & $\square \mathrm{NO}$ \\
\hline
\end{tabular}

\begin{tabular}{|c|c|c|c|}
\hline \multicolumn{2}{|c|}{$\begin{array}{l}\text { ¿Considera que el paciente necesita ser visto por un odontólogo en las próximas } 24-48 \text { horas por cita de } \\
\text { urgencias o emergencias? }\end{array}$} & $\square \mathrm{SI}$ & $\square$ NO \\
\hline \multicolumn{2}{|c|}{ ¿El paciente ha presentado fiebre en los últimos 14 días mayor a $37,5^{\circ} \mathrm{C}$ ? } & $\square \mathrm{SI}$ & $\square \mathrm{NO}$ \\
\hline \multicolumn{2}{|c|}{$\begin{array}{l}\text { ¿El paciente ha presentado síntomas respiratorios (tos, odinofagia, rinorrea), síntomas gastrointestinales } \\
\text { (diarrea, vómitos, dolor abdominal) o malestar general, en los últimos } 14 \text { dias? }\end{array}$} & $\square \mathrm{SI}$ & $\square \mathrm{NO}$ \\
\hline \multicolumn{2}{|c|}{ ¿Ha notado pérdida en el sentido del gusto o del olfato en los últimos 14 días? } & $\square \mathrm{SI}$ & $\square \mathrm{NO}$ \\
\hline \multicolumn{2}{|c|}{ ¿El paciente o su representante han viajado a países de riesgo en los últimos 14 días? } & $\square \mathrm{SI}$ & $\square \mathrm{NO}$ \\
\hline \multicolumn{2}{|c|}{$\begin{array}{l}\text { ¿El paciente o su representante han estado en contacto estrecho con personas que presentan fiebre o cuadro } \\
\text { respiratorio agudo en los últimos } 14 \text { dias? }\end{array}$} & $\square \mathrm{SI}$ & $\square \mathrm{NO}$ \\
\hline \multicolumn{2}{|c|}{$\begin{array}{l}\text { ¿Han estado en contacto con alguien diagnosticado como sospechoso o confirmado COVID19 en los últimos } \\
14 \text { días? }\end{array}$} & $\square \mathrm{SI}$ & $\square \mathrm{NO}$ \\
\hline \multicolumn{2}{|c|}{ ¿El paciente ha pasado la enfermedad del Covid-19 y sigue en cuarentena o aislamiento? } & $\square \mathrm{SI}$ & \\
\hline \multirow{3}{*}{$\begin{array}{l}\text { Recursos diagnósticos } \\
\text { complementarios }\end{array}$} & Envía fo & $\mathrm{SI}$ & \\
\hline & Enví & SI & NO \\
\hline & Envía audioisuales & & \\
\hline
\end{tabular}

CUESTIONARIO PRE-CONSULTA ODONTOPEDIÁTRICA DURANTE LA PANDEMIA COVID-19 1 
Anexo 1. (cont)

\section{ALつP ASOCIACIÓN LATINOAMERICANA DE ODONTOPEDIATRÍA}

Estimado Padre-Tutor:

Las consultas virtuales en salud han sido diseñadas para abordar situaciones inesperadas que puedan vivir los pacientes en momentos donde la atención clínica directa no es posible.

Por favor tenga en cuenta las siguientes recomendaciones para lograr la mejor atención del caso que usted nos está compartiendo en estos momentos:

- Las regulaciones actuales del país, limitan el tipo de atención que se puede realizar a menores de edad a emergencias, urgencias o tratamiento prioritario. Si usted considera que el caso de su hijo puede ser manejado virtualmente, por favor envíenos toda la información pertinente para lograr colaborarle de la mejor manera y disminuir los síntomas que puedan estar experimentando.

- Este tipo de consultas virtuales tienen limitaciones, ya que algunos diagnósticos en Odontología requieren palpación y observación directa de tejidos, como la evaluación directa de signos en el paciente y toma de radiografías.

- Lo apoyaremos de la mejor manera, y según los hallazgos y evaluación de signos y síntomas, definiremos la mejor ruta de atención para el paciente, ya sea el seguimiento virtual del caso, o la remisión a una consulta de urgencias o de emergencias.

- Su colaboración y cumplimiento en los protocolos y pasos definidos para estas citas virtuales, harán la diferencia en la mejor resolución del caso, por favor apórtenos la mejor información que usted tenga, y ayúdenos con una descripción detallada de fechas, evolución de síntomas, y que tipo de paliativos usted le ha brindado al paciente mientras logra una atención especializada.

- Revisaremos toda la información que usted nos brinde, incluyendo fotos y otros documentos de interés, que nos permitan definir la mejor atención clínica para el paciente.

- De igual manera, agradecemos si usted puede comentarnos si alguien en su familia o el paciente, han sentido síntomas de resfriado en los últimos 20 días. Esto podría ayudarnos a entender mejor el cuadro clínico del paciente.

He leído y comprendido la información planteada: $\square$ Si $\square$ No

$\begin{array}{lll}\text { Nombre Padre o tutor: } & \text { Firma: } & \text { DNI o CC: } \\ \text { Nombre Odontólogo Tratante: } & \text { Firma: } & \text { DNI o CC: } \\ & \text { Lugar: } & \text { Fecha: }\end{array}$

PARA SER LLENADO POR EL ODONTOLOGO TRATANTE

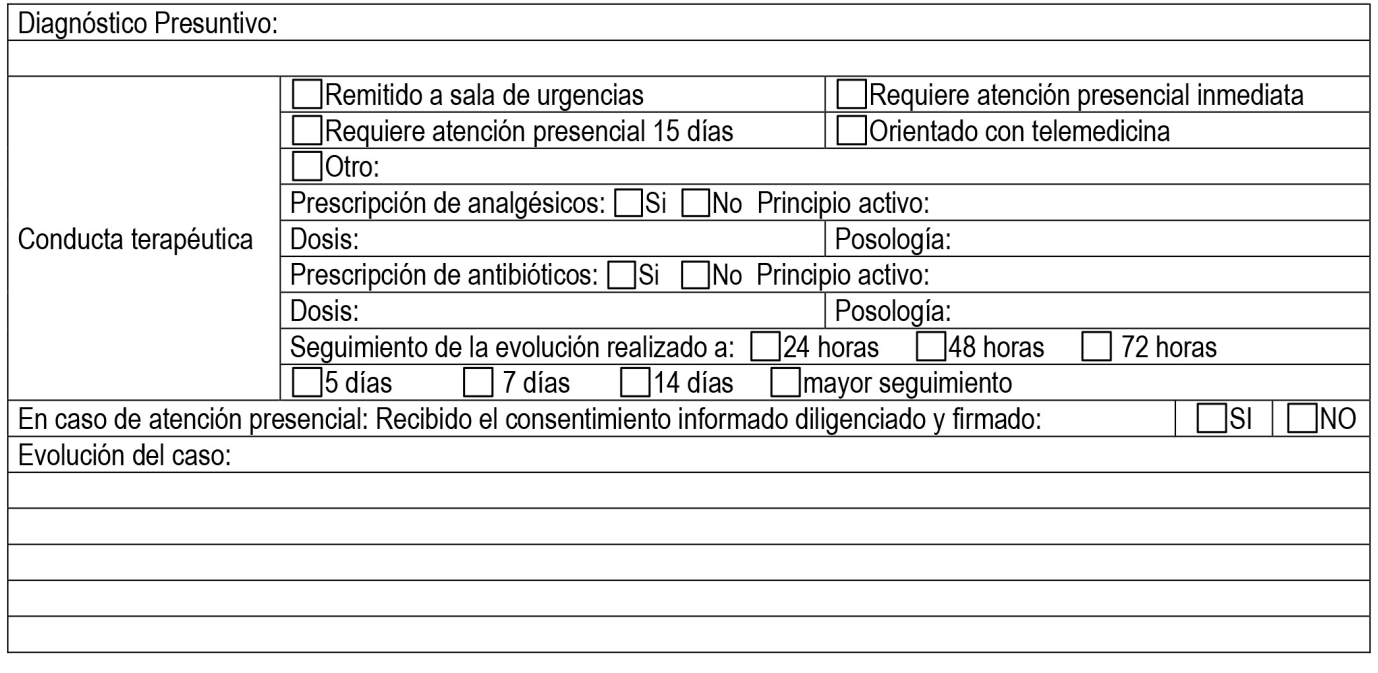

CUESTIONARIO PRE-CONSULTA ODONTOPEDIÁTRICA DURANTE LA PANDEMIA COVID-19 2 


\section{Anexo 2}

\section{ALつ ASOCIACIÓN LATINOAMERICANA DE ODONTOPEDIATRÍA}

\section{TELEODONTOLOGÍA: FICHA DE SEGUIMIENTO DE URGENCIA}

ODONTOPEDIÁTRICA DURANTE LA PANDEMIA COVID-19

\section{Odontólogo Tratante:}

\begin{tabular}{|c|c|c|c|c|c|}
\hline \multirow{10}{*}{ Datos Personales } & \multicolumn{5}{|l|}{ Nombre del Paciente: } \\
\hline & Edad: & \multicolumn{4}{|l|}{ Peso: } \\
\hline & \multicolumn{2}{|l|}{ Fecha de la Consulta: } & \multicolumn{3}{|c|}{ Hora: } \\
\hline & \multicolumn{2}{|c|}{ Fecha aparición de la enfermedad/traumatismo: } & \multicolumn{3}{|c|}{ Hora: } \\
\hline & \multicolumn{5}{|l|}{ Nombre del representante o tutor: } \\
\hline & \multicolumn{3}{|l|}{ DNI / Identificación representante o tutor: } & & \\
\hline & \multicolumn{5}{|l|}{ Teléfono de contacto: } \\
\hline & \multicolumn{5}{|l|}{ Correo electrónico: } \\
\hline & \multicolumn{3}{|c|}{ ¿El paciente tiene historia de atención previa en este servicio? } & $\square \mathrm{SI}$ & $\square \mathrm{NO}$ \\
\hline & \multicolumn{3}{|c|}{ ¿El paciente tiene Odontólogo/Odontopediatra previo? } & $\square \mathrm{SI}$ & $\square \mathrm{NO}$ \\
\hline
\end{tabular}

Antecedentes Médicos

\begin{tabular}{|l|c|c|}
\hline ¿Presenta alergias conocidas? & $\square \mathrm{SI}$ & $\square \mathrm{NO}$ \\
\hline ¿Está actualmente bajo tratamiento médico? & $\square \mathrm{SI}$ & $\square \mathrm{NO}$ \\
\hline ¿Presenta condición sistémica de base? & $\square \mathrm{SI}$ & $\square \mathrm{NO}$ \\
\hline ¿Ha tomado medicamentos auto prescritos? & $\square \mathrm{SI}$ & $\square \mathrm{NO}$ \\
\hline
\end{tabular}

Recursos Diagnósticos

Recepción de fotos intraorales

Complementarios

Recepción de fotos extraorales

Otros recursos audiovisuales o imágenes diagnósticas:

\begin{tabular}{|l|l|}
$\square \mathrm{SI}$ & $\square \mathrm{NO}$ \\
\hline$\square \mathrm{SI}$ & $\square \mathrm{NO}$ \\
\hline$\square \mathrm{SI}$ & $\square \mathrm{NO}$ \\
\hline
\end{tabular}

\begin{tabular}{|c|c|c|c|c|}
\hline \multicolumn{2}{|c|}{$\begin{array}{l}\text { Ruta de atención: } \\
\text { Telemedicina } \\
\text { Urgencia Presencial } \\
\text { Urgencia Hospitalaria }\end{array}$} & \multirow[t]{2}{*}{ 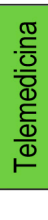 } & 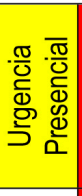 & 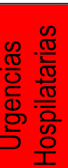 \\
\hline \multirow{18}{*}{$\begin{array}{l}\text { Traumatismo } \\
\text { Dentofacial }\end{array}$} & ¿El traumatismo involucra el cráneo? & & & \\
\hline & ¿Ha tenido pérdida de conocimiento? & & & \\
\hline & ¿Presenta desorientación en tiempo, espacio y lugar? & & & \\
\hline & ¿Ha presentado vómitos? & & & \\
\hline & ¿Ha tenido pérdida del equilibrio? & & & \\
\hline & ¿Tiene trastornos en la visión? & & & \\
\hline & ¿Presenta lateralización visual? & & & \\
\hline & ¿Ha sangrado por las orejas? & & & \\
\hline & ¿Tiene limitación para cerrar la boca? & & & \\
\hline & ¿Presenta asimetría en la cara? & & & \\
\hline & ¿Ha sangrado por la nariz? & & & 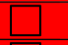 \\
\hline & ¿Presenta hematoma en piso de boca? & & & \\
\hline & ¿Presenta sangramiento que no para solo? & & & \\
\hline & ¿Presenta avulsión dental? & & & \\
\hline & ¿Reimplantó el diente avulsionado? & & & \\
\hline & ¿Conservó el diente avulsionado? $\square$ SI $\square$ No ¿En cuál medio? & & & \\
\hline & ¿El diente se encuentra desplazado? & & & \\
\hline & ¿El diente desplazado impide cerrar la boca? & & & \\
\hline
\end{tabular}

FICHA DE SEGUIMIENTO DE URGENCIA ODONTOPEDIÁTRICA DURANTE LA PANDEMIA COVID-19 1 


\section{Anexo 2. (Cont.)}

\section{ALQP ASOCIACIÓN LATINOAMERICANA DE ODONTOPEDIATRÍA}

¿Presenta fractura de la mitad del diente?

¿Presenta fractura dental pequeña de menos de la mitad?

¿Ve un color diferente en el diente dentro de la fractura?

¿Conservó el fragmento fracturado? $\square \mathrm{SI} \square$ No ¿En cuál medio?

¿El diente presenta movilidad?

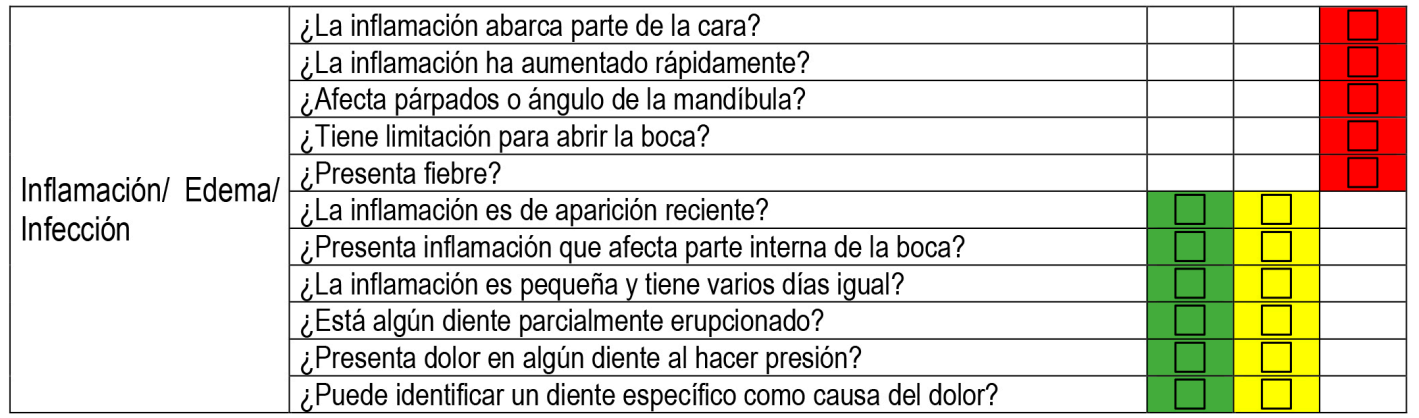

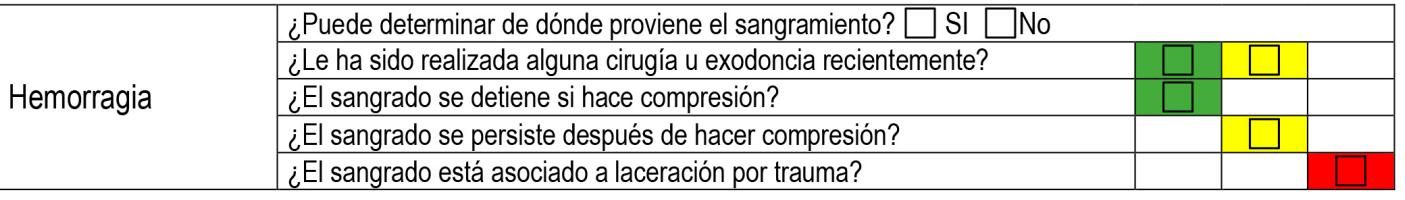

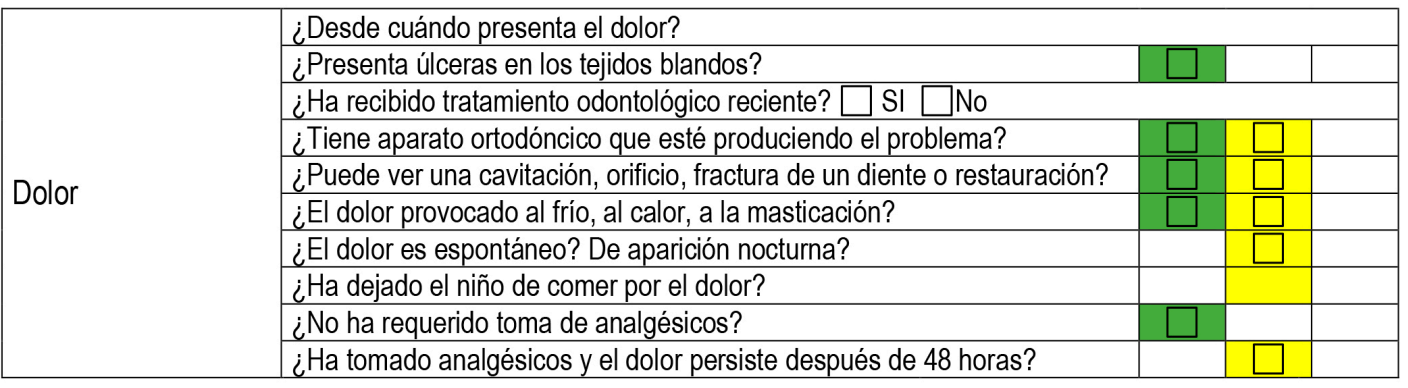

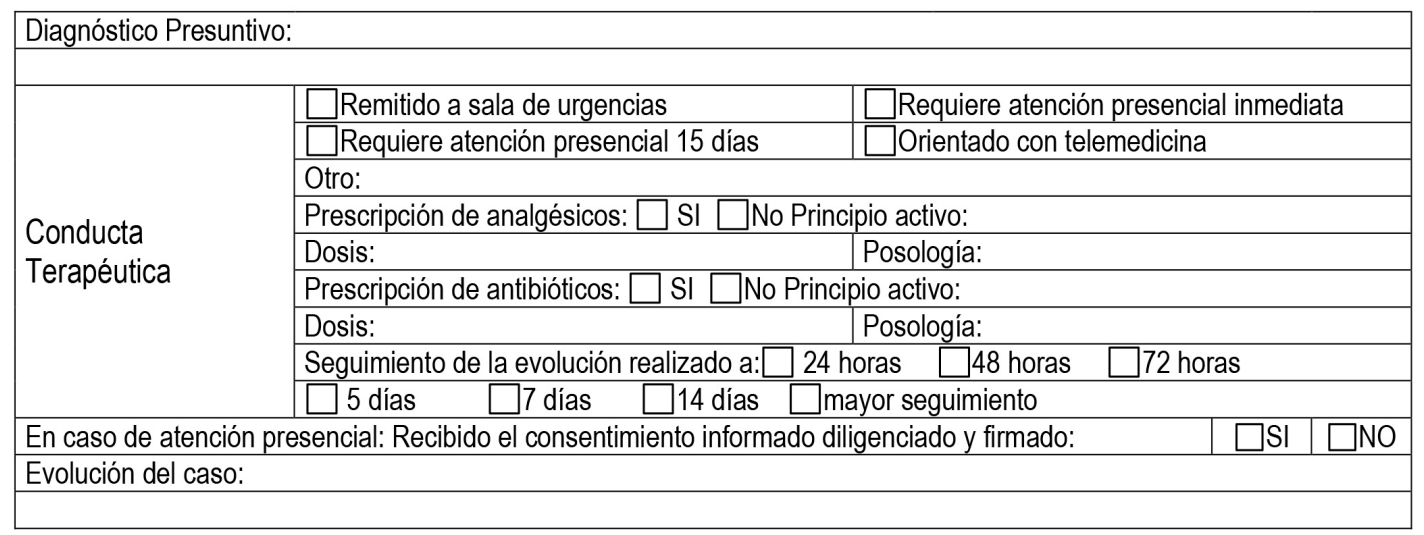




\section{Teleodontologia: Aplicação em Odontopediatria durante a pandemia COVID-19}

\section{Introdução}

Até o momento, as diferentes agências de saúde locais e internacionais publicaram recomendações, regulamentos e protocolos para atendimento odontológico durante a pandemia do COVID-19, ajustada aos diferentes estágios da pandemia.

A Associação Latino-Americana de Odontopediatria, em sua missão de apoiar e trazer as melhores informações disponíveis a todos os colegas latinos, publicamos um documento e os guias de práticas de fácil utilização e de forma a compartilhar com o pessoal odontológico que trabalha em um ambiente hospitalar, clínicas governamentais, instituições de ensino e clínicas particulares, que prestam atenção e atendimentos as crianças, adolescentes e pacientes com deficiência. ${ }^{1-3}$

Durante a pandemia por COVID-19 e as medidas de distanciamento social, se deve realizar tratamento odontológico apenas em pacientes que apresentam urgência e emergência, adiando todo o tratamento eletivo. ${ }^{1,4-7}$

No entanto, à medida que os estágios da pandemia evoluem em diferentes países, os protocolos de atendimento mudam, possibilitando agendar atendimento odontológico prioritário e retomar progressivamente o atendimento odontológico. ${ }^{8,9}$

Comoprimeiro passonoatendimento, surge uma importante mudança recomendada para a prática profissional, que é a inclusão do atendimento à distância ou telemedicina, no caso da odontopediatria, ${ }^{10}$ envolvendo atendimento telefônico, mídia digital ou plataformas virtuais, utilizando todos os a tecnologia disponível para realizar o diagnóstico, orientação terapêutica, acompanhamento dos casos e determinar as situações que requerem atendimento presencial.

As recomendações que, em seguida, se propõe estão ligados à situação excepcional de uma pandemia e podem variar de prática clínica de rotina. Essas recomendações destinam-se a fornecer um guia para o clínico, para que ele possa acompanhar a consulta com eficiência, o que ajudará a orientar a realização de uma consulta virtual com telessaúde, determinar a melhor rota de atendimento de acordo com a necessidade e viabilidade do atendimento presencial e trazer registro de rastreamento adequado. Não é um protocolo clínico abrangente de todos os tratamentos possíveis.

Essas informações constituem um guia de orientação, sem a substituição de regulamentos, protocolos ou leis locais em vigor em cada países são suscetíveis de evoluir e mudar dependendo da situação de saúde. Instamos os profissionais a acompanhar as atualizações.

\section{Teleodontologia}

$\mathrm{O}$ atendimento odontológico a distância (teleodontologia ${ }^{11}$ ) é a primeira linha de atendimento em casos excepcionais que 
podem surgir em crises de saúde pública e quando o contato presencial entre o paciente e o especialista não é possível devido a distâncias geográficas ou outras restrições. O suporte tecnológico permite a triagem e o tratamento de casos sintomático, e a identificação de casos que exigem atenção presencial, utilizando todos os recursos de comunicação e tecnologia disponível. 4, 12-16

Na Odontopediatria, há relatos de experiências anteriores nas quais $\mathrm{o}$ odontopediatra realiza o diagnóstico de lesões de cárie e recomenda o tratamento com uso de teleodontologia com o uso de câmeras intraorais ${ }^{17-19}$ ou imagens obtidas por meio de smartphones ${ }^{20}$ e suporte com ajuda dos seus auxiliares ou assistentes dentários.

Durante o Pandemia do COVID-19, o uso de teleodontologia está focado em alcançar o melhor diagnóstico possível para fornecer orientações aos pais em relação ao manejo da patologia, e é recomendado para todos s protocolos atenção. ${ }^{1-3,6,14,21,22}$

Atualmente, são definidos três tipos de teleconsultas que podem ser úteis em diferentes contextos: a consulta assíncrona geralmente ocorre quando o paciente ou seu responsável entra em contato com o profissional de saúde para solicitar seu ponto de vista ou avaliação, requer um tempo de espera entre o envio da pergunta ou requisito e a resposta do especialista; Consulta síncrona quando a consulta virtual é em tempo real, por meio de uma ligação telefônica ou, preferencialmente, por videoconferência, para interagir com o especialista sobre os motivos que dizem respeito ao seu estado de saúde e a consulta mista no seguimento a médio ou longo prazo de uma consulta. caso, usando consultas assíncronas e síncronas. ${ }^{23,24}$
Em todos os casos, é necessário que o especialista em saúde tenha uma estrutura para criação de um arquivo virtual para armazenar todas as comunicações $\mathrm{e}$ mídia visual (fotos, vídeos, radiográfias) e os clínicos que compartilhem o acompanhamento do paciente, devem apoia e ajudar no melhor diagnóstico, interação virtual e tratamento de cada caso.

O papel do cirurgião-dentista é sem dúvida nenhuma importante, portanto, recomenda-se que se tenha um meio de contato que possa ser utilizado de forma fácil entre ele e os pacientes (telefone, videoconferência ou por outras redes). É possível que, na atual situação de distanciamento social, seja impossível acessar a história odontológica anterior, radiografias e outros registros.

Em tempos de crise na saúde pública ou tensão social, é pertinente para contextualizar o tipo de pacientes que executa $\mathrm{n}$ consulta: Se referidos por outro especialista que exige diagnóstico, se um paciente regular ou se um paciente contatos primeiro. Se possível, o profissional deve tentar acessar o histórico para otimizar o diagnóstico. ${ }^{16}$

Ao realizar a consulta virtual por teleodontologia, é importante se comunicar com eficiência, gerenciar um tom de voz gentil, suave, calmo e que transmita confiança. O primeiro passo é para acalmar o paciente e/ou responsável, ao explicar brevemente, sobre o escopo, benefícios, mas também sobre as limitações e responsabilidades deste tipo de consulta. O profissional deve ouvir com atenção para as informações que eles estão passando, mostrando empatia e dá dando confiança sobre a situação abordada. Ao mesmo tempo, você deve preencher o registro 
de consulta virtual de acordo com as informações fornecidas.

Dependendo do momento da pandemia do COVID-19 em cada região e dos regulamentos estabelecidos pelos Estados e pelas organizações de saúde, a consulta odontológica será direcionada para a atenção exclusiva de emergências, a realização de tratamentos prioritários, até a reabertura do consulta para procedimentos de rotina. ${ }^{9}$

\section{Etapa 1: Cuidado com a Teleodontologia Pré-Consulta Virtual}

A pré-consulta inclui um questionário enviado previamente, por meios digitais, que pode ser preenchido juntamente com o questionário prévio e enviado antes da consulta síncrona, ou para apoiar a consulta assíncrona (Anexo 1). Recomendase uma interação prévia com o paciente e seus responsáveis antes da consulta a ser realizada, de acordo com as necessidades do paciente ou as possibilidades de apoio que o especialista possa oferecer.

Além deste questionário anterior, deve ser incluído um guia de consulta virtual que deve ser assinado com o entendimento de que, ao fazer a consulta, aceitar as cláusulas contidas nele, incluindo as especificações sobre o alcance da consulta virtual, limitações e etapas básicas durante essa consulta, síncrona ou assíncrona.

\section{Consulta Virtual}

\section{Anamnese e motivo da consulta}

Com os cuidados à distância, sem a possibilidade de um exame físico, podese realizar uma hipótese de diagnóstico e orientações terapêuticas. Se, for necessário o atendimento presencial, deve seguir as etapas apropriadas que devem ser determinadas ou seguidas para fornecer o melhor atendimento, mantendo todas as medidas de biossegurança. ${ }^{1-9}$

$\mathrm{Na}$ odontologia foi estabelecido que os motivos mais frequentes de consulta por urgências são: dor, inflamação, trauma ou hemorragia;1, 3, 5, 13, 14, 25 sobre as quais é necessário obter informações sobre sintomas, utilizando critérios de gravidade, a fim de orientar o paciente. Em todos os casos, ele deve acompanhar as alterações no paciente, usando as mesmas vias de comunicações.

Registro Físico da Consulta Virtual Sincrónica Ao realizar o atendimento por teleodontologia é indispensável criar um registro de dados com uma ficha desenhada especifica para esse fim que inclua toda a informação referente a história médica que se tenha do paciente ou outras informações mencionadas por outro especialista.

Do mesmo modo, tudo relacionado ao episódio deve ser gravado, o que serve como um guia para o clínico ao fazer um diagnóstico presuntivo e permite que ele acompanhe por escrito a teleconsulta ou a consulta virtual. No anexo deste artigo, é proposto um modelo de registro durante a consulta virtual síncrona em Odontologia.

Dessa forma, quando o especialista é contatado pelo paciente ou seus cuidadores para solicitar uma consulta virtual, ele deve abrir um novo registro que apoiará seu gerenciamento clínico e todo o suporte jurídico para sua prática profissional. Esse registro deve conter informações básicas como data do contato, motivos iniciais da consulta, nome da pessoa que iniciou o contato (entidade cuidadora ou responsável), nome do 
paciente, se ele é um novo paciente ou parte de sua consulta clínica, entre outros. Esse registro inicial da solicitação de consulta pode ser virtualmente preenchido e armazenado digitalmente, enquanto as condições profissionais permitem que esse documento seja incluído no histórico clínico do paciente localizado na clínica ou no consultório (Anexo 1).

Registro Físico de la Consulta Virtual Asincrónica

Ao responder a uma consulta recebida por e-mail, fax ou por outros meios escritos ou referidos, o especialista deve responder em um formato padrão a essa consulta, dando suas opiniões clínicas com base nos dados fornecidos pelo paciente ou cuidador. Uma cópia dessa resposta deve ser armazenada em uma pasta aberta para o paciente no processo de consulta virtual ou de teleodontolgia.

\section{Pós-Consulta Virtual}

De acordo com os achados clínicos observados nas consultas virtuais sincrônicas ou assincrônicas, o cirurgião dentista irá definir os próximos passos na rota de atenção: se é o paciente que necessita de um atendimento de urgência ou emergência, ou pelo contrário, esse paciente permite fazer o acompanhamento virtual com apoio das ferramentas tecnológicas disponíveis. No final do artigo, as figuras 1 e 2 indica o resumo das rotas de atenção.

\section{Triagem de urgência. Aspectos iniciais}

Usando teleodontologia, realizar as perguntas referentes a patologia no qual o paciente apresenta por meio da triagem (anamnese) para determinar se o tratamento sintomático à distância é viável

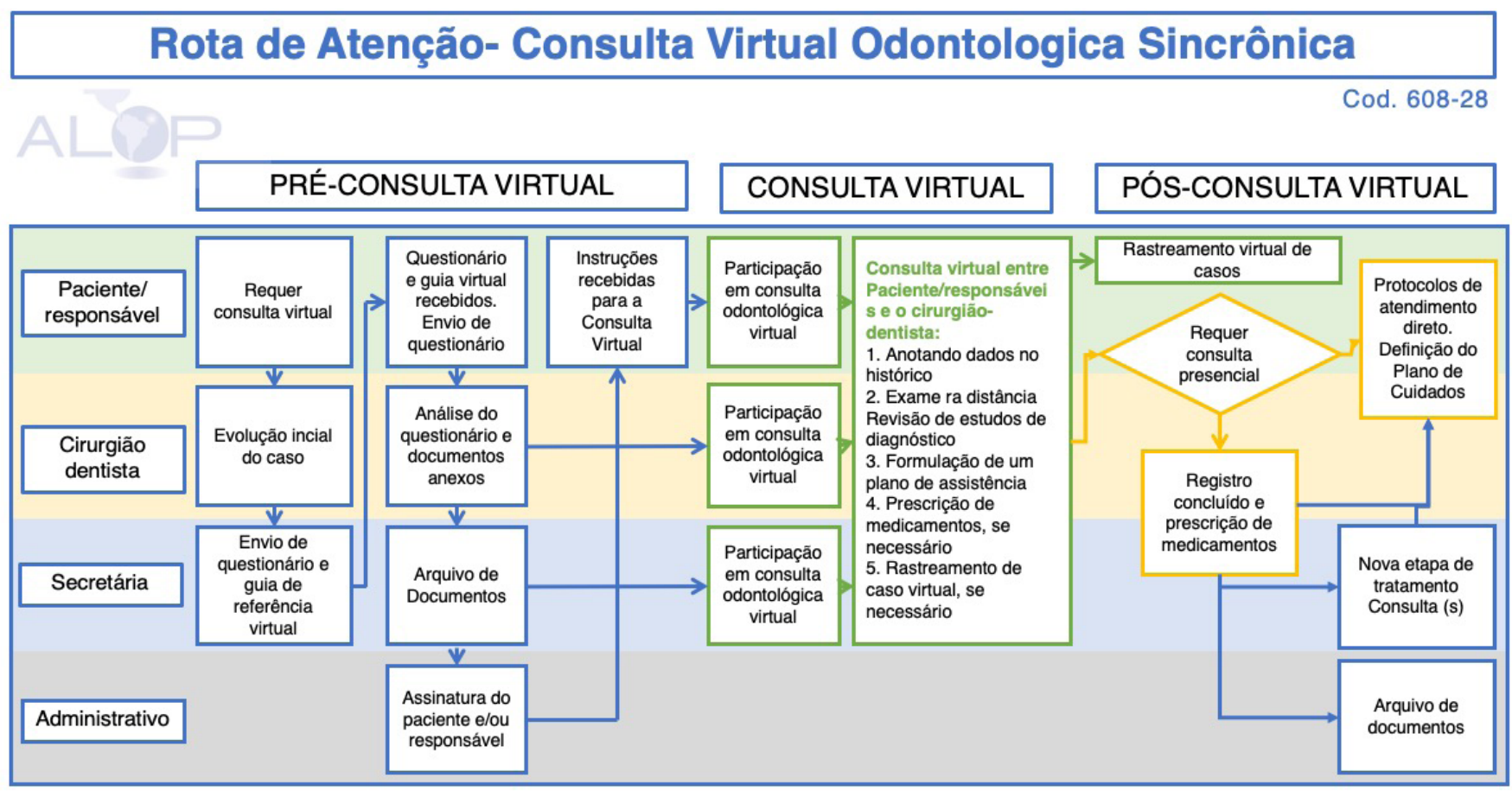

Figura 1. Fluxograma das etapas a seguir na Consulta Odontológica Síncrona Virtual, com o papel de cada participante da equipe odontológica (Adaptado de Mutis et al 48). 


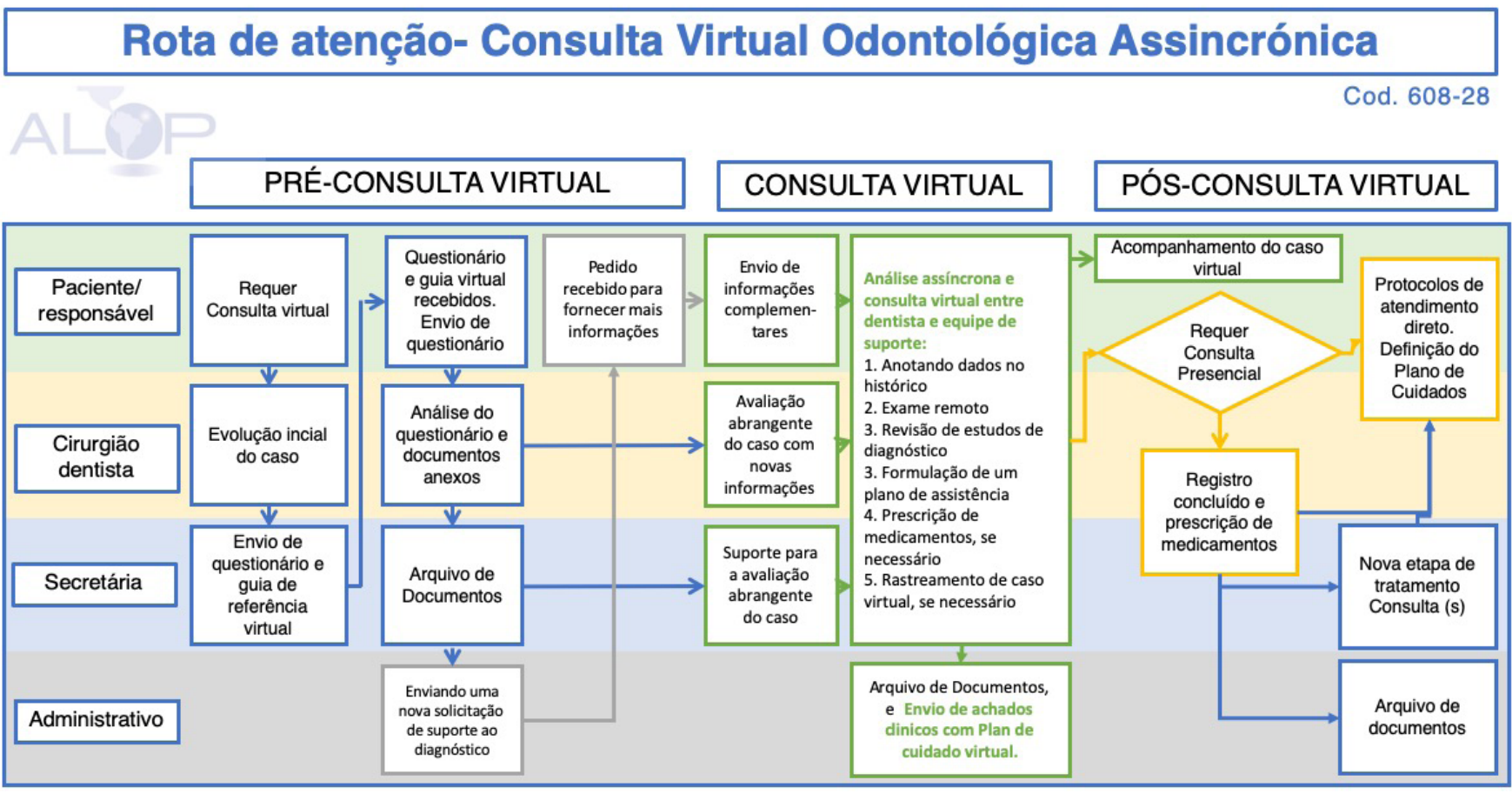

Figura 2. Fluxograma das etapas a serem seguidas no atendimento Consulta Odontológica Virtual Assíncrona, com o papel de cada participante da equipe odontológica (Adaptado de Mutis et al 48)

ou se se trata de uma emergência presencial. Geralmente, a consulta virtual de urgência é realizada de forma síncrona. A seguir descrevemos dois diferentes contextos que podem acontecer a partir desta triagem do paciente ou responsável durante a consulta virtual sincrônica (Anexo 2):

Urgencia Odontológica: Manejo de condições que requerem tratamento imediato para aliviar dores e infecções graves: pulpite irreversível grave, pericoronarite, abscesso dentoalveolar localizado, fratura dentária dolorosa, alveolite, traumatismo dentário com avulsão ou luxação, hemorragia, biópsia ou preparação dentária antes de procedimentos médicos. ${ }^{1,13,25-27}$ As urgências odontológicas podem ser atendidas em consultório com todas as normas de biossegurança e regulamentos locais que foram definidos pelo órgão regulador da saúde de cada cidade.
Emergência Odontológica: situações que tem o potencial de colocar em risco a vida do paciente e necessita de um tratamento imediato: sangramento descontrolado, celulite facial com edema intra e extra-oral que comprometem as vias aéreas, trauma dentofacial.,13,25,26 As emergências odontológicas devem ser atendidas única e exclusivamente em ambiente hospitalar e nunca em consultório odontológico (trauma facial com hemorragia, edema extraoral com febre ou celulite facial).

Alguns fatores devem ser levados em considerações durante a consulta de triagem e anamnese virtual:

Geralmente, essa etapa deve ser desenvolvida entre o especialista em saúde e o responsável da criança, porém a presença da criança durante a teleconsulta é importante para confirmar os sintomas ou visualizar alguns sinais clínicos que podem 
ser vistos no vídeo. As perguntas devem incluir informações sobre os sintomas:

- Você tem dor: leve, moderada ou grave.

- Tem edema: determine se o edema é intraoral ou extraoral. Verifique se você teve febre.

- Você tem trauma dentofacial: quais estruturas são afetadas, se você tiver sangramento ativo, laceração, fraturas faciais, fratura dentária, avulsão ou luxação dentária. Verifique se os dentes afetados são primários ou permanentes.

- Ele apresenta sangramento: verifique se é abundante, se é possível identificar a causa ou a origem.

\section{Auxilio para o diagnóstico}

Se o paciente não recebeu atendimento prévio ou foi encaminhado por outro especialista, nas imagens virtuais de préconsulta (Anexo 1), fotos e outros elementos devem ter sido solicitados para permitir a melhor abordagem diagnóstica e confirmar o início de um tratamento ambulatorial, sem a necessidade de ir à consulta ou, pelo contrário, indicar a necessidade de realizar uma avaliação presencial, por se tratar de uma emergência ou urgência odontológica.

\section{Diagnósticos Complementares durante o atendimento virtual}

Da mesma forma, durante a teleconsulta, o odontopediatra pode detectar sinais e sintomas presentes na boca e na face das crianças como um sinal de abuso físico, que pode ocorrer por ação, omissão ou negligência..$^{28}$ A correlação dos dados obtidos nas perguntas como as observações que podem ser feitas nas fotografias e imagens de pacientes com diferentes graus de vulnerabilidade podem ocasionalmente sugerir abuso infantil ou violência doméstica. Portanto, é relevante lembrar que o dentista como profissional de saúde tem o dever de relatar essas situações à entidade responsável em cada país, de acordo com os protocolos estabelecidos.

Depois que a hipótese de diagnóstica for alcançada, com as informações fornecidas, avaliar se é viável realizar uma consulta de emergência presencial para confirmar ese diagnóstico inical e realizar um tratamento sintomático específico.

Se você realiza o manejo de urgência e confirma a hipótese de diagnóstico baseado durante a consulta virtual com essas informações e tratamento sintomático (analgésicos, antibióticos), é aconselhável atualizar todos os registros para encerrar a consulta e coordenar o acompanhamento por meio de uma consulta virtual mista. (síncrona $e$ assíncrona, de acordo com o contexto do caso clínico), até que outras medidas terapêuticas possam ser tomadas.

Em seguida, são feitas as perguntas que orientam o clínico na preparação do diagnóstico. ${ }^{14,} 16,27$ As perguntas servem como uma sistematização para a preparação do diagnóstico. O clínico deve realizar todas as investigações que julgar necessárias para ter um critério clínico e assim determinar qual a melhor conduta neste momento. Utilizando critérios de gravidade, é orientado se a atenção deve ser por telemedicina, atendimento de emergência frente a frente ou se o paciente deve ser encaminhado imediatamente à sala de emergência do hospital.

Para todos os casos: Solicitar fotos intra e extraorais, todos os recursos que permitem ter uma visualização de imagens mais nítidas possiveis e em diferentes 
perspectivas/ángulos para o motivo da consulta.

\section{Prescrição de Medicamentos por meio da Telemedicina}

A prescrição de medicamentos à distância deve ser realizada com muito cuidado. No caso de pacientes pediátricos, verificar o peso para a dosagem correta. Tendo em vista que a responsabilidade pela prescrição é assumida pelo profissional, pais ou responsáveis devem ser alertados que é imprescindível o cumprimento estrito das recomendações fornecidas, a fim de evitar possíveis eventos adversos. Um guia deve ser enviado por escrito, especificando as etapas que os pais ou responsáveis devem seguir no fornecimento desses medicamentos e receber deles um e-mail ou comunicação através de redes sociais privadas, entendendo e aceitando as recomendações fornecidas pelo especialista.

Antes daconsultapresencialéindispensável a entrega e preenchimento correto do consentimento libre informado. ${ }^{1,3,14}$

\section{Triagem de Urgência: Diagnóstico e recomendações}

\section{Traumatismo dentofacial}

A continuación, se propone una secuencia de preguntas para orientar al clínico en su diagnóstico, las cuales puede complementar con todas aquellas preguntas que estime necesarias en cada caso particular.

Os cuidados imediatos de teledontologia devem, em primeiro lugar, acalmar a criança e os pais e ou responsáveis. As perguntas de triagem são aquelas que permitem determinar qual é a magnitude da consequencia do trauma. Informações sobre o local, tempo e como ocorreu o trauma devem ser solicitadas. Em seguida, é realizada uma sequências que o cirurgião dentista julga necessário para que ele possa ter uma orientação do caso em questão.

Solicitar fotos intraorais o extraorais, $e$ todos os recursos que permitan chegar a um diagnóstico e orientação terapéutica.

Antes de qualquer resposta indicativa da necessidade de atenção em Urgências hospitalares, interrompa as questões $e$ encaminhe imediatamente o paciente ao hospital.

Pacientes com traumatismo craniano com suspeita de fratura maxilar, sangramento contínuo que necessite de sutura devem ser encaminhados imediatamente para a sala de emergência do hospital.

Se houver abrasão nos tecidos moles, recomenda-se o uso tópico de gluconato de clorexidina sem álcool a $0,1 \%$ na área afetada com cotonetes duas vezes ao dia por 1 semana. No caso de lesões labiais, use protetor labial durante o período de cicatrização.

$\mathrm{O}$ atendimento emergencial de trauma dentofacial apresenta vários protocolos, dependendo se o dente afetado é decíduo ou permanente. De qualquer forma, os cuidados de emergência a serem realizados no momento do confinamento devem ser orientados a manter os dentes permanentes funcionais e saudáveis na boca e a executar procedimentos que minimizem a geração de aerossóis. 3, 12, 26, 29 Sendo assim, após um exame minucioso e um diagnóstico adequado, a proteção pulpar é recomendada em casos de fraturas dentárias. Siga diretrizes e protocolos internacionais baseados em evidências científicas. $^{30,31}$

No caso de avulsão de dentes decíduos, sem qualquer outra complicação associada, traumas dentários limitados a fraturas coronais simples de esmalte ou esmalte e dentina sem comprometimento pulpar 
ou luxações leves sem interferência ou mobilidade oclusal podem ser tratados com telemedicina.

A restauração na coroa dentária ou reposicionamento de fragmentos pode ser realizada posteriormente. Realize a prescrição de analgésicos de acordo com o caso, e faça orientação sobre dieta e higiene dentária.

No caso de luxações permanentes dos dentes: verifique a magnitude do deslocamento e se há interferência oclusal. Indique a tentativa de realizar a reposição com pressão digital (com exceção de deslocamentos intrusivos). Siga diretrizes e protocolos internacionais baseados em evidências científicas. ${ }^{30}$

Em caso de avulsão: oriente os pais a reimplantar o dente (segure pela coroa, evitando tocar na raiz. Se estiver sujo, lave-o por 10 segundos com água potável, coloque o dente em posição e morda um lenço para mantê-lo no lugar). Se isso não for possível, verifique se os meios de conservação antes de ir ao pronto-socorro são adequados (recipiente com leite, solução fisiológica ou saliva. Nos pacientes colaborantes, é possível transportar o dente na boca ao lado da bochecha) não em meio seco ou em água. Os primeiros 30 minutos após o trauma são essenciais para um melhor prognóstico. Siga diretrizes e protocolos internacionais baseados em evidências científicas. ${ }^{30,32}$

E m todos os casos, monitore a evolução.

\section{Inflamação e Edema Extraoral e Intraoral}

Os cuidados imediatos com telemedicina devem, em primeiro lugar, acalmar a criança e os pais ou responsáveis. Em seguida, é proposta uma sequência de perguntas para orientar o clínico em seu diagnóstico, que ele pode complementar com todas as perguntas que julgar necessárias em cada caso específico.

Solicite fotos intra-orais ou extra-orais $e$ todos os recursos que permitam identificar o diagnóstico e a orientação terapêutica.

No caso de atendimento em emergência hospitalar, pare qualquer questionamento e encaminhe imdeiatamente o paciente ao hospital.

Se o paciente apresentar trismo, edema submandibular ou sublingual com presença de dor na deglutição, edema palpebral, dificuldade em abrir os olhos, eritema ou edema que se estende até o pescoço, crepitação à palpação ou febre, ele deve ser encaminhado ao prontosocorro do hospital.

A pericoronarite pode ser tratada de forma sintomática, com higiene adequada da área, enxaguamentos anti-sépticos (clorexidina $012 \%$ ou peróxido de hidrogênio 1\%), modificações na dieta e analgésicos. Avalie a evolução. Nos casos em que não há melhora, realize cuidados urgentes.

Se houver inflamação gengival, você pode sugerir enxaguatórios bucais com clorexidina a $0,12 \%, 2$ vezes ao dia sem diluir, por quinze dias. Em crianças pequenas, pode ser aplicado com gaze embebida na solução.

Os abscessos dentoalveolares localizados podem ser tratados por telemedicina com prescrição de antibióticos (Amoxicilina, Amoxicilina + Ac. Clavulânica, Azitromicina, Clindamicina ou o tratamento farmacológico decidido pelo profissional de acordo com o paciente, seu histórico médico e seus requisitos) de acordo com o peso e as características do 
paciente. A consulta de emergência pode ser agendada 48 horas após o início da antibioticoterapia, se necessário.

Em caso de dúvida, faça uma consulta no local para corroborar o diagnóstico.

Em todos os casos, monitore a evolução.

\section{Hemorragia}

Os cuidados imediatos com telemedicina devem, em primeiro lugar, acalmar a criança e os pais ou responsáveis. As perguntas de triagem são aquelas que nos permitem definir a magnitude do sangramento. Em seguida, é proposta uma sequência de perguntas para orientar o clínico em seu diagnóstico, que ele pode complementar com as perguntas que julgar necessárias em cada caso específico.

Solicite fotos intraorais ou extraorais $e$ todos os recursos que permitam alcançar o diagnóstico e a orientação terapêutica.

Indicações: Não cuspir, não fazer bochechos com exaguatórios, aplicar compressas frias na área do sangramento e compressão local contínua por 15 minutos.

Pacientes saudáveis, com uma causa identificada de hemorragia realizar as medidas de compressão hemostática, podem ser acompanhados com telemedicina.

Se ele determinar que o paciente necessita de sutura, ele deve ser tratado com urgência.

Se o sangramento persistir ou se o paciente tiver um histórico médico relevante, ele deverá ser encaminhado para emergências hospitalares.

Em todos os casos, monitore a evolução.

\section{Dor de dente}

Os cuidados imediatos com telemedicina devem, em primeiro lugar, proporcionar confiança à criança e aos pais ou responsáveis. As perguntas de triagem são aquelas que nos permitem definir qual delas é a magnitude da dor. Em seguida, é proposta uma sequência de perguntas para orientar o clínico em seu diagnóstico, que ele pode complementar com as perguntas que julgar necessárias em cada caso específico.

Solicite fotos intraorais ou extraorais e todos os recursos que permitam alcançar o diagnóstico e a orientação terapêutica.

A dor, em geral, é difícil de medir devido à sua subjetividade, principalmente em crianças, que geralmente depende do relato dos pais. No entanto, se possível, recomenda-se não substituir o autorrelato da dor pelo relato dos pais ou responsáveis, ${ }^{33}$ em vez disso, poderiam ser utilizados instrumentos da Escala Visual Analógica (EVA), como Wong Baker Faces (WBF), Faces Pain Scale Revised (FPS-R), entre outros, os quais, embora não totalmente objetivos, possam facilitar a avaliação e um auto-relato de a expressão da dor em crianças. $^{34}$

$\mathrm{Na}$ presença de lesões de cárie que podem causar pulpite, o comportamento terapêutico a ser seguido é orientado para alcançar a parada da lesão. Assim, as recomendações de higiene com creme dental com concentração de fluoreto de 1.100 a 1.500 ppm ou superior, o uso de fio dental e a implementação de hábitos de higiene corretos assumem especial importância. O manejo da doença de cárie no âmbito da pandemia de COVID-19 deve ser realizado tendo como critério a redução de procedimentos que geram aerossóis. ${ }^{2}$

$\mathrm{Na}$ presença de dor leve ou provocada que cessa, o paracetamol (acetaminofeno) pode ser prescrito de acordo com o peso do paciente e as características do paciente e as diretrizes nacionais de saúde de seu país. ${ }^{35,36}$ 
Em caso de dor intensa ou se o paciente tomar analgésicos por 48 horas sem melhora, eles devem ir à consulta de emergência. ${ }^{16}$

No caso de aparelhos ortodônticos fraturados ou desalojados, tente removêlos em casa. Se for impossível remover o dispositivo em casa e estiver produzindo laceração ou ulceração, ele deve ser atendido com uma consulta de emergência. Espere concluir o período de confinamento para a recementação de anexos..$^{22,37}$

Em todos os casos, monitore a evolução.

Etapa 2: Se você determinar que é necessário realizar atendimento odontológico de emergência presencial, reforce a anamnese:

Antes de agendar a consulta de tratamento de emergência, você deve realizar a triagem do COVID-19.

Devido ao período de incubação assintomática. Lembre-se de que as crianças tendem a apresentar menos sintomas que os adultos. Todos os pacientes pediátricos devem ser considerados portadores em potencial, a menos que se prove o contrário. $^{12,27,38}$

\section{SINTOMAS COVID-19}

- O paciente apresentou febre nos últimos 14 dias

- Você teve sintomas respiratórios (tosse, odinofagia, rinorréia), sintomas gastrointestinais (diarréia, vômito, dor abdominal) ou desconforto geral nos últimos 14 dias

- Você notou perda de paladar ou olfato nos últimos 14 dias.

EXPOSIÇÃO AO COVID-19 (suspeita)

- O paciente ou seu resposnável viajou para países de risco nos últimos 14 dias.

- Você esteve em contato próximo com pessoas que têm febre ou sintomas respiratórios agudos nos últimos 14 dias.

- Histórico de contato com alguém diagnosticado como COVID suspeito ou que está fazendo o isolamento. ${ }^{19}$

Se houver pelo menos uma resposta afirmativa para essas perguntas, informe ao paciente:

1. Entre em contato com o médico ou a emergência em sua localidade por telefone para ativar o protocolo COVID-19 (para responder à presença de sintomas), iniciar isolamento ou quarentena conforme apropriado.

2. Depois de aprovado pela equipe médica, o atendimento odontológico pode ser continuado.

Ele deve ter o EPI apropriado para todo o pessoal e garantir a estrita conformidade com os regulamentos de biossegurança. ${ }^{1-5}$, 13-15, 27, 38-47 Caso contrário, você deve encaminhar o paciente.

Consulte "Rota de atendimento para procedimentos de Odontopediatria durante o estágio de confinamento ou quarentena da pandemia de COVID-19. ${ }^{1}$

\section{Considerações}

Essas recomendações foram feitas de forma independente e voluntária por pesquisadores da Associação LatinoAmericana de Odontopediatria, juntamente com especialistas nas diversas áreas médicas da América Latina, com arbitragem por pares, livre de conflitos de interesse.

Essas recomendações são baseadas nas 
maiores evidências disponíveis até o momento, sendo o COVID-19 uma doença emergente. As atualizações necessárias serão feitas de acordo com o estado da ciência a esse respeito e a evolução da doença.

O grupo de especialistas responsáveis pela curadoria permanece ativo e monitora constantemente as informações publicadas sobre o COVID-19 para realizar as atualizações e anexos necessários.

\section{Autores}

Esse artigo foi desenvolvido pelo grupo liderado: Martha Mutis (Estados Unidos de América), Elías M. Morón (Estados Unidos de América), A. Carolina Medina Díaz (Venezuela), como parte da Equipe Interdisciplinar COVID-19 da Associação Latinoamericana de Odontopediatria.

Equipe Interdisciplinar COVID-19 da Associação Latinoamericana de Odontopediatria:

Jenny Abanto (Brasil), Mariana Armada (Argentina), Paola Beltri (España), Marisol Carrillo Tabakman (Paraguay), Haydée Casaretto (Argentina), Jorge Luis Castillo (Perú), Mónica Gladys Cesetti (Argentina), Bertha Angélica Chávez González (Perú), Ana Claudia Rodrigues Chibinski (Brasil), Salomon Alberto Cohen (Argentina), Olga Cortés
Lillo (España), Luzia Ana Da Silva de Carballo (Venezuela), Gonzalo De la Fuente Alvarez (Chile), Renée Di Nallo (Argentina), María Débora Elizabeth Dricas (Argentina), Sandra Echevarria (Brasil), Piedad Cecilia Echeverry Marin (Colombia), Laura Fedelli (Argentina), Carlos Flores-MIr (Canadá), Andrea Virgina González Carfora (Chile), Lina María Hernández Salas (Colombia), Francisco José Hernández Restrepo (Colombia), Maria Teresa Ibañez Rodriguez (Bolivia), José Carlos Pettorossi Imparato (Brasil), Alejandra Lipari Valdés (Chile), Daniela Madrigal López (Costa Rica), Daniela Catalina Martínez Camus (Chile), María Gabriela Martínez Vásquez (Venezuela), A. Carolina Medina Díaz (Venezuela), Kelly Maria Silva Moreira (Brasil), Elías M. Morón (Estados Unidos de América), Martha Mutis (Estados Unidos de América), Camila Palma (Perú), Gladys Mabel Peña (Argentina), Adriana Pistochini (Argentina), Paloma Planells (España), Gabriel Politano (Brasil), Matias RiosErazo (Chile), Adriana Maria Rubiano Pinzon (Colombia), Karla Mayra Rezende (Brasil), Rosa Gabriela Rondón (Venezuela), Gabriela Scagnet (Argentina), Rosemary Sogbe de Agell (España), Marina Tavares Costa Nóbrega (Canadá), Jorgelina Valente (Argentina), Ernesto Venegas De Herrera (República Dominicana), Rosa Helena Wanderley Lacerda (Brasil), Ana Clara Zabala (Argentina), Gabriel Zambrano (Venezuela).

Información completa del Grupo Interdisciplinario COVID-19 de la Asociación Latinoamericana de Odontopediatría

\section{Referências}

1. Asociación Latinoamericana de Odontopediatría. Grupo COVID-19. Ruta de atención para procedimientos de Odontología Pediátrica durante la etapa de confinamiento o cuarentena de la pandemia COVID-19. Revista de Odontopediatría Latinoamericana. 2020;10(2):https://www. revistaodontopediatria.org/ediciones/2020/2/art-1/.

2. Asociación Latinoamericana de Odontopediatria. Tratamiento de la enfermedad de caries en época de COVID-19: protocolos clínicos para el control de aerosoles. Revista de Odontopediatría Latinoamericana. abril 2020;10(2):https://www.revistaodontopediatria.org/ediciones/2020/2/art-2/\#.

3. Asociación Latinoamericana de Odontopediatría ALOP. Modelos de Consentimiento Informado para la Atención de Urgencias en tiempos de COVID-19. abril 4, 2020. Available at: https:// Www.alopodontopediatria.org/noticias/consentimiento-informado-indicados-especialmenteatenci\%C3\%B3n-emergencias-odontologicas/.

4. Centers for Disease Control and Prevention CDC. Interim Infection Prevention and Control Recommendations for Patients With Suspected or Confirmed Coronavirus Disease 2019 (Covid-19) in Healthcare Settings. abril 2020. Available at: https://www.cdc.gov/coronavirus/2019-ncov/ hcp/infection-control-recommendations.html?CDC_AA_refVal=https\%3A\%2F\%2Fwww.cdc. gov\%2Fcoronavirus\%2F2019-ncov\%2Finfection-control\%2Fcontrol-recommendations.html. 
5. Centers for Disease Control and Prevention CDC. Recommendation: Postpone Non-Urgent Dental Procedures, Surgeries, and Visits. Marzo 27, 2020. Available at: https://www.cdc.gov/oralhealth/ infectioncontrol/statement-COVID.html.

6. American Academy of Pediatric Dentistry. COVID-19 Update/Coronavirus Update. 2020 Abril. Available at: https://www.aapd.org/about/about-aapd/news-room/covid-19/.

7. Dave M, Seoudi N, Coulthard P. Urgent dental care for patients during the COVID-19 pandemic. The Lancet. Abril 2020:DOI:https://doi.org/10.1016/S0140-6736(20)30806-0.

8. COVID-19 Dental Services Evidence Review (CoDER) Working Group. Recommendations for the reopening of dental services: a rapid review of international sources. https://oralhealth.cochrane.org/ sites/oralhealth.cochrane.org/files/public/uploads/covid19_dent. Available at: https://oralhealth. cochrane.org/sites/oralhealth.cochrane.org/files/public/uploads/covid19_dent.

9. Consejo General de Dentistas de España. Plan estratégico de acción para el periodo de desescalada COVID-19. mayo 1, 2020. Available at: https://www.consejodentistas.es/comunicacion/actualidadconsejo/notas-de-prensa-consejo/item/1783-plan-estrategico-de-accion-para-clinicas-dentalesdurante-el-periodo-de-desescalada.html.

10. Vidal-Alaball J, Acosta-Roja R, Pastor N, et al. Telemedicine in the face of the COVID-19 pandemic. Atención Primaria. 2020:https://doi.org/10.1016/j.aprim.2020.04.003.

11. Jampani ND, Nutalapati R, Dontula BS, Boyapati R. Applications of teledentistry: A literature review and update. J Int Soc Prev Community Dent. 2011;1(2):37-44. doi:10.4103/2231-0762.97695.

12. Mallineni SK, Innes NP, Raggio DP, Araujo MP, Robertson MD, Jayaraman J. Coronavirus Disease (COVID-19): Characteristics in children and considerations for dentists providing their care. Int J Paed Dent. abril 2020:doi: 10.1111/ipd.12653.

13. American Dental Association ADA. Emergency Care. abril 2020. Available at: https://www.aapd. org/about/about-aapd/news-room/emergency-care/.

14. American Dental Association (ADA). Interim Guidance for Minimizing Risk of COVID-19 Transmission. abrl 7, 2020. Available at: https://www.ada.org/ /media/CPS/Files/COVID/ ADA_COVID_Int_Guidance_Treat_Pts.pdf?utm_source=adaorg\&utm_medium=covidresources-lp\&utm_content $=c v-p m-e b d$-interim-response\&utm_campaign=covid-19? utm source=adaorg\&utm_medium=adanews\&utm_content=cv-pm-ebd-interi. Accessed abril 8, 2020.

15. Peng X, Xu X, Li Y, Cheng L, Zhou X, Ren B. Transmission routes of 2019-nCoV and controls in dental practice. Intl J Oral Sci. 2020;12:https://doi.org/10.1038/s41368-020-0075-9.

16. Orde National des Chirugiens-Dentistes. Guide pour la prise en charge téléphonique d'une demande de soins dentaires urgents dans le cadre du stade 3 de l'épidémie de COVID-19. Marzo 30, 2020. Available at: https://societechirorale.com/documents/Recommandations/Guide-praticienDefinitif-V1-30-mars-2020.pdf.

17. Kopycka-Kedzierawski DT, Billings RJ. Teledentistry in inner-city child-care centres. J Telemed Telecare. 2006;12:176-181.

18. Kopycka-Kedzierawski DT, Billings RJ. Prevalence of dental caries and dental care utilization in preschool urban children enrolled in a comparative effectiveness study. Eur Arch Paediatr Dent. 2011;12:133-138.

19. McLaren SW, Kopycka-Kedzierawski DT, Nordfelt J. Accuracy of teledentistry examinations at predicting actual treatment modality in a pediatric dentistry clinic. J Telemed Telecare. 2016:doi:10 $.1177 / 1357633 \times 16661428$.

20. AlShaya MS, Assery MK, Pani SC. Reliability of mobile phone teledentistry in dental diagnosis and treatment planning in mixed dentition. J Telemed Telecare. 2018:Doi: 10.1177/1357633X18793767.

21. Pereira LJ, Pereira CV, Murata RM, Pardi V, Pereira-Dourado SM. Biological and social aspects of Coronavirus Disease 2019 (COVID-19) related to oral health. Braz Oral Res. 2020:34:e041.

22. Suri S, Vandersluis YR, Kichhar AS, Bhasin R, Abdallah MN. Clinical orthodontic management during the COVID-19 pandemic. Angle Orthod. 2020:doi: 10.2319/033120-236.1.

23. Ruiz Ibañez C, Zuluaga de Cadena A, Trujillo Zea A. Telemedicina: Introducción, aplicación y principios de desarrollo. Revista CES MEDICINA. 2007;21:77-93.

24. Allely EB. Synchronous and asynchronous telemedicine. J Med Syst. 1995;19:207-212. 
25. American Dental Association ADA. What Constitutes a Dental Emergency?. Marzo 31, 2020. Available at: https://success.ada.org/ /media/CPS/Files/Open\%20Files/ADA_COVID19_Dental_Emergency_ DDS.pdf?utm_source=adaorg\&utm_medium=covid-resources-lp\&utm_content=cv-pm-emergdef\&utm_campaign=covid-19\&_ga=2.2729136.124928618.1586021397-1939509346.1586021396.

26. Meyer B, Casamassimo P, William F Vann, FV. An Algorithm for Managing Emergent Dental Conditions for Children. J Clin Ped Dent. 2019;43(3):doi 10.17796/1053-4625-43.3.10 201.

27. Consejo GeneraldeDentistas deEspaña. Organización ColegialdeDentistas de España.Planestratégico de acción para el periodo posterior a la crisis creada por el COVID-19. abril 13, 2020. Available at: https://gacetadental.com/wp-content/uploads/2020/04/PlanestrategicoposteriorCoronavirus.pdf.

28. Gamboa M, Guerra ME. Manifestaciones bucales del maltrato físico. Reporte de caso.. Revista de Odontopediatría Latinoamericana. 2013;3(2):https://www.revistaodontopediatria.org/ ediciones/2013/2/art-11/.

29. Meng L, Hua F, Bian Z. Coronavirus Disease 2019 (COVID-19): Emerging and Future Challenges for Dental and Oral Medicine Treatment of Emergency Cas. J Dent Res. 2020:DOI: $10.1177 / 0022034520914246$.

30. Bastos JV, Cortex MS, Percinoto C, Tovo MF. Capítulo 19. Lesiones traumáticas en dientes primarios y permanentes jóvenes. Manual de Referencia para Procedimientos en Odontopediatría Segunda Edición: ALOP; 2017.

31. International Association of Dental Traumatology (IADT). IADT Treatment Guidelines. Dental Trauna Guide. Available at: https://dentaltraumaguide.org/iadt-treatment-guidelines/. Accessed marzo 21, 2020.

32. Andersson L, Andreasen JO, Day $\mathrm{P}$, et al. International Association of Dental Traumatology guidelines for the management of traumatic dental injuries: 2. Avulsion of permanent teeth. Dental Traumatology. 2012;28:88-96.

33. Lawson SL, Hogg MM, Moore GC, et al. Pediatric Pain Assessment in the Emergency Department: Patient and Caregiver Agreement Using the Wong-Baker FACES and the Faces Pain Scale-Revised. Pediatric Emergency Care. 2019:doi: 10.1097/PEC.0000000000001837.

34. Tomlinson D, von Baeyer CL, Stinson JN, Sung L. A systematic review of faces scales for the selfreport of pain intensity in children. Pediatrics. 2010;126(5):e1168-98.

35. American Association of Pediatric dentistry. The Reference Manual of Pediatric Dentistry. Policy on Acute Pediatric Dental Pain Management. 2019/2020. Available at: https://www.aapd.org/research/ oral-health-policies--recommendations/acute-pediatric-dental-pain-management/.

36. Sucasas da Costa LR, Vaz Castro AD, Lopes GM, Sucasas da Costa PS. Capítulo 25. Terapéutica medicamentosa en Odontopediatría. Manual de Referencia para Procedimientos en Odontopediatría. 2nd ed. Sao Paulo: ALOP; 2017.

37. Caprioglio A, Pizzetti GB, Zecca PA, Fastuca R, Maino G, Nanda R. Management of orthodontic emergencies during 2019-NCOV. Progress in Orthodontics. 2020;21(10):https://doi.org/10.1186/ s40510-020-00310-y.

38. Consejo General de Dentistas de España. Informe Técnico II del Consejo General de Dentistas de España: Desafíos emergentes del nuevo Coronavirus COVID-19 en la clínica dental 2020.

39. Centers for Disease Control CDC. Personal Protective Equipment FAQs. marzo 2020. Available at: https://www.cdc.gov/coronavirus/2019-ncov/hcp/respirator-use-faq.html.

40. Cochrane Collaboration. Equipo de protección personal para la prevención de las enfermedades altamente infecciosas por exposición a líquidos orgánicos contaminados en el personal de asistencia sanitaria. Revisión sistemática Cochrane -. Julio 2019. Available at: https://www.cochranelibrary. com/es/cdsr/doi/10.1002/14651858.CD011621.pub3/full/es.

41. Organización Mundial de la Salud OMS. Advice on the use of masks in the community, during home care, and in health care settings in the context of COVID-19. WHO Interim Guidance. Marzo 2020.

42. Organización Mundial de la Salud OMS. Rational use of personal protective equipment (PPE) for coronavirus disease (COVID-19) Interim guidance. Marzo 19, 2020. Available at: https://apps.who. int/iris/bitstream/handle/10665/331498/WHO-2019-nCoV-IPCPPE_use-2020.2-eng.pdf.

43. Organización Mundial de la Salud OMS. Vías de transmisión del virus de la COVID-19: repercusiones para las recomendaciones relativas a las precauciones en materia de prevención 
y control de las infecciones. marzo 29, 2020. Available at: https://www.who.int/es/news-room/ commentaries/detail/modes-of-transmission-of-virus-causing-covid-19-implications-for-ipcprecaution-recommendations.

44. Sabino-Silva R, Gomes Jardim AC, Siqueira WL. Coronavirus COVID-19 impacts to dentistry and potential salivary diagnosis. Clin Oral Invest. 2002;24:1619-1621.

45. The National Institute for Occupational Safety and Health (NIOSH). Recommended Guidance for Extended Use and Limited Reuse of N95 Filtering Facepiece Respirators in Healthcare Settings. abril15, 2020. Available at: https://www.cdc.gov/niosh/topics/hcwcontrols/recommendedguidanceextuse. html.

46. van Doremalen N, Bushmaker T T, Morris DH DH, Holbrook, et al. Aerosol and Surface Stability of SARS-CoV-2 as Compared with SARS-CoV-1. N Engl J Med. abril 2020;https://www.nejm.org/doi/ pdf/10.1056/NEJMc2004973?articleTools=true.

47. Xu H, Zhong L, Deng J, Peng J, et al. High expression of ACE2 receptor of 2019-nCoV on the epithelial cells of oral mucosa. Intl J Oral Sci. 2020;12(8):https://doi.org/10.1038/s41368-020-0074-x.

48. Mutis MJ, Suarez O, Gold J, Balzer J. How to establish a Teledentistry program in Community based Services: The experience in NYU Langone Family Centers. NYU School of Medicine - NYU Langone Health Dental Division. 2018.

Recibido/Received: 20/04/2020

Primera versión aceptada/First accepted version: 21/04/2020

Modificaciones aceptadas/Final version: 15/05/2020

Correspondencia: e-mail: editor@revistaodontopediatria.org 


\section{Anexo 1}

\section{ALQP ASOCIACIÓN LATINOAMERICANA DE ODONTOPEDIATRÍA

\section{TELEODONTOLOGIA: QUESTIONÁRIO PRÉ-CONSULTA ODONTOPEDIATRICA DURANTE A PANDÊMICA COVID-19}

\section{Odontopediatra:}

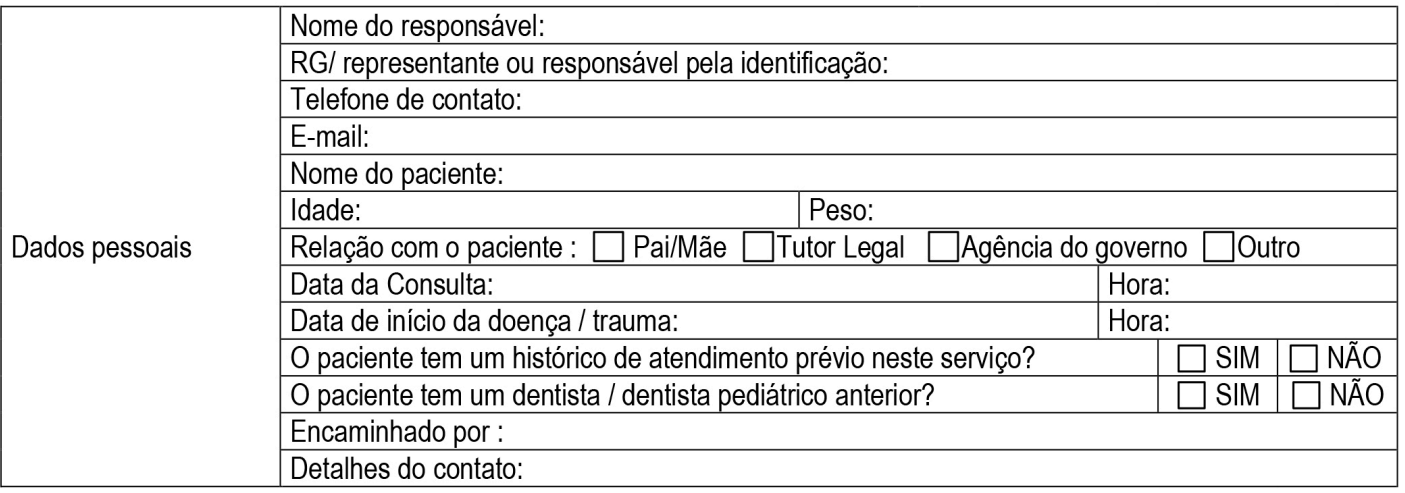

\begin{tabular}{|l|}
\hline Descreva em geral os motivos pelos quais você solicita uma consulta virtual : \\
\hline
\end{tabular}

\begin{tabular}{|l|l|l|}
\hline $\begin{array}{l}\text { Você deu algum medicamento ao paciente para diminuir a dor ou a inflamação durante esse } \\
\text { período? }\end{array}$ & $\square$ SIM \\
\hline Descrever : \\
\hline
\end{tabular}

\begin{tabular}{|l|l|l|}
\hline ¿Ha realizado otro tipo de acciones para ayudar a su hijo ante esta situación de salud? & $\square$ SIM \\
\hline Describa & NÃO \\
\hline
\end{tabular}

\begin{tabular}{|c|c|c|c|}
\hline \multicolumn{2}{|c|}{$\begin{array}{l}\text { Você acha que o paciente precisa ser atendido por um dentista nas próximas } 24 \text { a } 48 \text { horas para uma } \\
\text { consulta de emergência? }\end{array}$} & $\square \mathrm{SIM}$ & $\square$ NÃO \\
\hline \multicolumn{2}{|c|}{ O paciente apresentou febre nos últimos 14 dias mais do que $37,5^{\circ} \mathrm{C} ?$} & SIM & NÃO \\
\hline \multicolumn{2}{|c|}{$\begin{array}{l}\text { O paciente tem apresentado sintomas respiratórios ( tosse, dor de garganta, corrimento nasal), sintomas } \\
\text { gastrointestinais (diarreia, vómitos, dor abdominal) ou mal-estar , nos últimos } 14 \text { dias? }\end{array}$} & $\square$ SIM & $\square$ NÃO \\
\hline \multicolumn{2}{|c|}{ Você notou perda de paladar ou olfato nos últimos 14 dias? } & SIM & NÃO \\
\hline \multicolumn{2}{|c|}{ O paciente ou seu representante viajou para países em risco nos últimos 14 dias? } & SIM & NÃO \\
\hline \multicolumn{2}{|c|}{$\begin{array}{l}\text { O paciente ou seu representante esteve em contato próximo com pessoas que têm febre ou sintomas } \\
\text { respiratórios agudos nos últimos } 14 \text { dias? }\end{array}$} & SIM & NÃO \\
\hline \multicolumn{2}{|c|}{$\begin{array}{l}\text { Eles estiveram em contato com alguém diagnosticado como COVID19 suspeito ou confirmado nos últimos } \\
14 \text { dias? }\end{array}$} & SIM & NÃO \\
\hline \multicolumn{2}{|c|}{ O paciente h uma doença do passado Covid-19 e permanece em quarentena ou isolamento? } & SIM & NÃO \\
\hline \multirow{3}{*}{$\begin{array}{l}\text { Recursos } \\
\text { complementares de } \\
\text { diagnóstico }\end{array}$} & Enviar fotos intraorais & SIM & NÃO \\
\hline & Envie fotos extra-orais & SIM & NÃO \\
\hline & Envie audiovisuais ou imagens de diagnóstico: & SIM & NÃO \\
\hline
\end{tabular}


Anexo 1. (cont)

\section{ALQP ASOCIACIÓN LATINOAMERICANA DE ODONTOPEDIATRÍA}

Prezados pais e/ouresponsável:

As consultas virtuais de saúde foram projetadas para lidar com situações inesperadas que os pacientes podem enfrentar em momentos em que o atendimento clínico direto não é possível.

Leve em consideração as seguintes recomendações para obter o melhor atendimento do caso que você está compartilhando conosco no momento:

- Os regulamentos atuais do país limitam o tipo de atendimento que pode ser prestado aos menores em emergências, emergências ou tratamento prioritário. Se você acredita que o caso de seu filho pode ser tratado virtualmente, envie-nos todas as informações relevantes para nos ajudar a colaborar da melhor maneira e reduzir os sintomas que você pode estar enfrentando.

- Esse tipo de consulta virtual tem limitações, pois alguns diagnósticos odontológicos exigem palpação e observação direta dos tecidos, como avaliação direta dos sinais no paciente e realização de radiografias.

- Nós o apoiaremos da melhor maneira e, com base nos achados e na avaliação de sinais e sintomas, definiremos a melhor rota de atendimento ao paciente, seja o acompanhamento virtual do caso ou o encaminhamento para uma consulta de emergência ou emergência.

- Sua colaboração e conformidade com os protocolos e etapas definidas para esses compromissos virtuais farão a diferença na melhor resolução do caso, forneça as melhores informações que você possui e ajude-nos com uma descrição detalhada das datas, evolução dos sintomas e quais tipo de cuidados paliativos que você prestou ao paciente enquanto obtinha atendimento especializado.

- Analisaremos todas as informações que você nos fornecer, incluindo fotos e outros documentos de interesse, que nos permitam definir o melhor atendimento clínico para o paciente.

- Da mesma forma, agradecemos se você puder nos dizer se alguém da sua família ou do paciente teve sintomas de resfriado nos últimos 20 dias. Isso poderia nos ajudar a entender melhor o quadro clínico do paciente.

Li e compreendi as informações fornecidas: $\square$ SIM $\square$ NÃO

Nome do pai ou responsável :

Cirurgião dentista:

CRO
Assinatura:

Assinatura:

Local de atendimento:
RG:

RG:

Data:

A SER PREENCHIDO PELO CIRUGIÃO DENTISTA

\section{Hipótese de diagnóstico:}

\begin{tabular}{|c|c|c|c|c|}
\hline \multirow{9}{*}{ Conduta terapêutica } & $\square$ Encaminhado para emergência & \multicolumn{3}{|c|}{ Requer atendimento presencial imediato } \\
\hline & Requer cuidados presenciais a cada 15 dias & \multicolumn{3}{|c|}{ Requer atendimento presencial imediato } \\
\hline & \multicolumn{4}{|l|}{ Outra conduta: } \\
\hline & Prescrição de analgésico: $\square$ sim & \multicolumn{3}{|c|}{ não. Principio ativo } \\
\hline & Dose: & \multicolumn{3}{|l|}{ Posologia: } \\
\hline & Prescrição de antibióticos: $\square$ sim & \multicolumn{3}{|c|}{ não. Principio ativo } \\
\hline & Dose: & \multicolumn{3}{|l|}{ Posologia: } \\
\hline & Monitoramento da evolução realizada para: & 48 horas & 72 horas & \\
\hline & $\square 7$ dias & \multicolumn{3}{|c|}{ mais dias } \\
\hline \multicolumn{3}{|c|}{ Em caso de atendimento presencial: Recebeu o consentimento informado preenchido e assinado: } & $\Longrightarrow \mathrm{SIM}$ & $\sqsupseteq \mathrm{NÃO}$ \\
\hline \multicolumn{5}{|l|}{ Evolução do caso: } \\
\hline
\end{tabular}


Anexo 2.

\section{ALQP ASOCIACIÓN LATINOAMERICANA DE ODONTOPEDIATRÍA}

Cod. 608-26

\section{TELEODONTOLOGIA: FORMULÁRIO DE ACOMPANHAMENTO DE ATENDIMENTO \\ ODONTOLOGICO DURANTE O PANDEMIA COVID-19}

Cirurgião dentista:

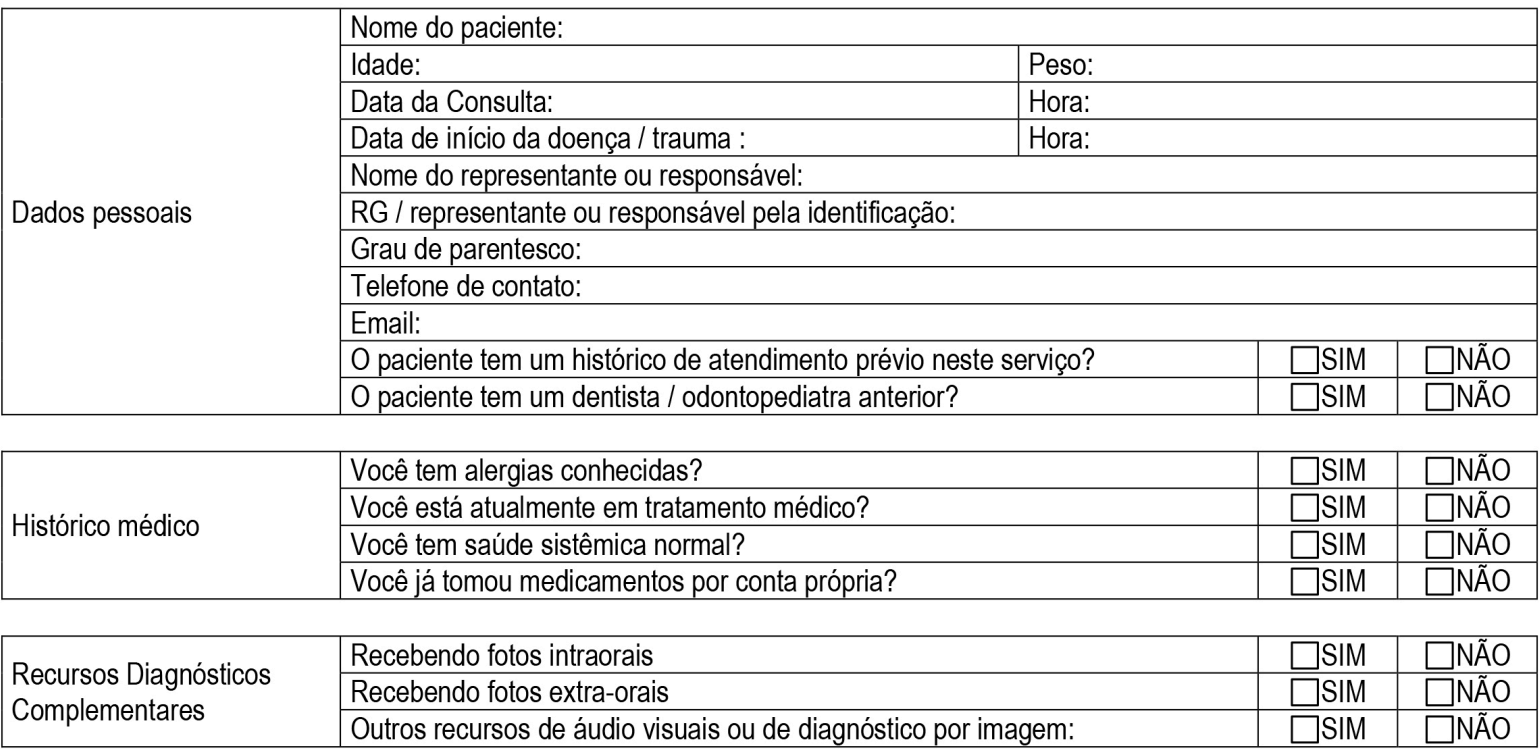

\begin{tabular}{|c|c|c|c|c|}
\hline \multicolumn{2}{|c|}{$\begin{array}{l}\text { Rota da atenção: } \\
\text { Telemedicina } \\
\text { Urgência P resencial } \\
\text { H.Hospital de Emergência }\end{array}$} & 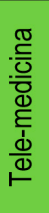 & 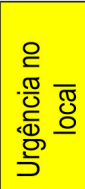 & 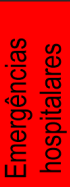 \\
\hline \multirow{19}{*}{ Trauma Dentofacial } & O trauma envolve o crânio? & & & $\square$ \\
\hline & Você já perdeu a consciência? & & & "E \\
\hline & Apresenta desorientação no tempo, espaço e lugar? & & & $\equiv$ \\
\hline & Você já teve vômito? & & & "- \\
\hline & Você teve uma perda de equilibrio? & & & "E \\
\hline & Você tem problemas de visão? & & & "E \\
\hline & Apresenta lateralização visual? & & & "- \\
\hline & Você sangrou de seus ouvidos? & & & "E \\
\hline & Você tem uma limitação para fechar a boca? & & & 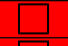 \\
\hline & Você tem assimetria no rosto? & & & 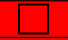 \\
\hline & Você sangrou pelo nariz? & & & 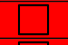 \\
\hline & Você tem hematomas no chão da boca? & & & "E \\
\hline & Você tem sangramento que não para por conta própria? & & & E \\
\hline & Você tem avulsão dentária? & & & \\
\hline & Você reimplantou o dente avulsionado? & & & \\
\hline & Você ficou com o dente avulsionado? SIM Não Em que meio? & & & \\
\hline & O dente está deslocado? & & 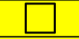 & \\
\hline & O dente deslocado impede o fechamento da boca? & & & \\
\hline & Você tem uma fratura de metade do dente? & & & \\
\hline
\end{tabular}

FORMULÁRIO DE SEGUIMENTO DE ACOMPANHAMENTO DENTAL DURANTE A PANDÊMICA COVID-19 
Anexo 2. (cont)

\section{ALQP ASOCIACIÓN LATINOAMERICANA DE ODONTOPEDIATRÍA}

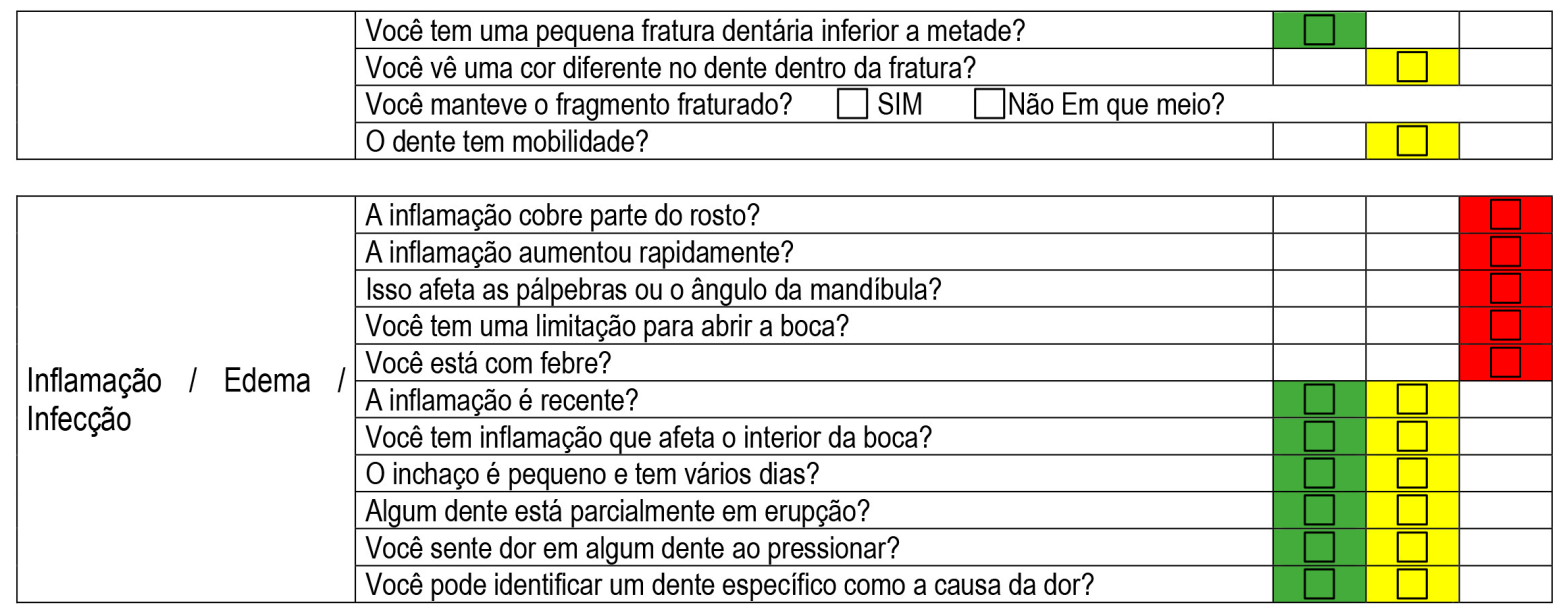

\begin{tabular}{|l|l|c|c|c|}
\hline \multirow{4}{*}{ Hemorragia } & \multicolumn{2}{|l|}{ Você pode determinar de onde vem o sangramento ? $\square$ SIM $\square$ Não } & $\square$ & $\square$ \\
\hline & Você já teve alguma cirurgia recente ou extração dentária? & $\square$ & \\
\hline & O sangramento pára se você comprimir? & & $\square$ \\
\hline & O sangramento persiste após a compressão? & & $\square$ \\
\hline & O sangramento está associado à laceração do trauma? & \\
\hline
\end{tabular}

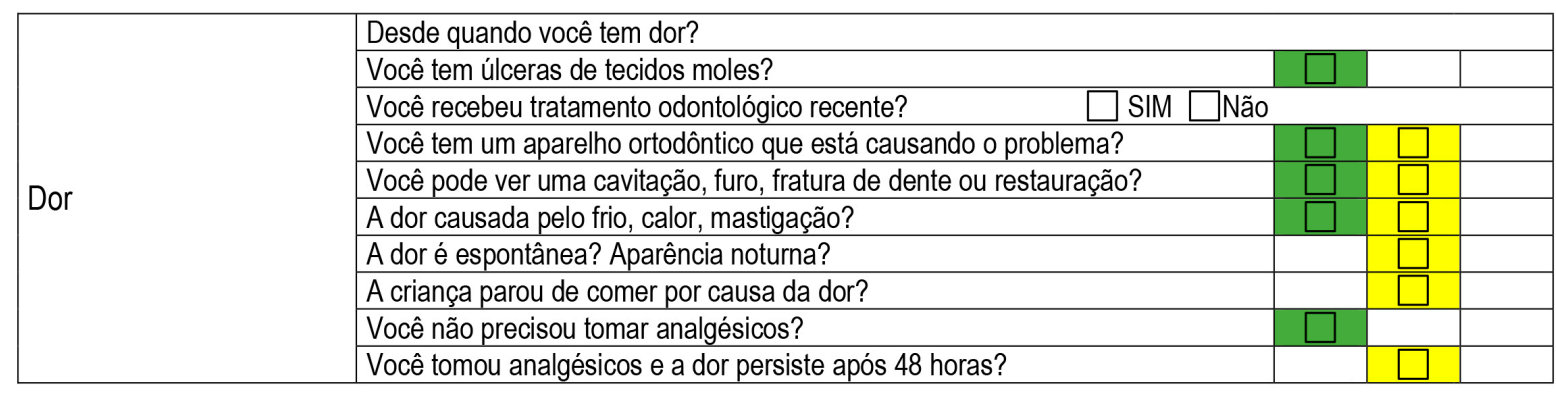

\begin{tabular}{|c|c|c|}
\hline \multicolumn{3}{|c|}{ Hipótese de diagnóstico: } \\
\hline \multirow{9}{*}{ Conduta terapêutica } & Encaminhado para emergência $\square$ & Requer atendimento presencial imediato [ \\
\hline & Requer cuidados presenciais a cada 15 dias $\square$ & Orientado com telemedicina $\square$ \\
\hline & \multicolumn{2}{|l|}{ Outra conduta: } \\
\hline & \multicolumn{2}{|l|}{ Prescrição de analgésico: $\square$ sim $\square$ não. Principio ativo } \\
\hline & \multicolumn{2}{|l|}{ Posologia: } \\
\hline & \multicolumn{2}{|l|}{ Prescrição de antibióticos: $\square$ sim $\square$ não. Principio ativo } \\
\hline & \multicolumn{2}{|l|}{ Dose: $\quad$ Posologia: } \\
\hline & Monitoramento da evolução realizada para: $\square 24$ horas & $\square 48$ horas $\square 72$ horas \\
\hline & \multicolumn{2}{|l|}{$\square$ 5 dias $\square 7$ dias $\square$ 14 dias $\square$ mais dias } \\
\hline \multicolumn{3}{|c|}{ Em caso de atendimento presencial: Recebeu o consentimento informado preenchido e assinado: } \\
\hline
\end{tabular}

FORMULÁRIO DE SEGUIMENTO DE ACOMPANHAMENTO DENTAL DURANTE A PANDÊMICA COVID-19 


\section{Anexo 3.}

Tabla 1: Listado de regulaciones regionales referentes a telesalud y teleodontología por país, aplicables a la actual pandemia COVID-19. Cont.

\begin{tabular}{|c|c|c|c|c|}
\hline \multirow[t]{2}{*}{ País } & \multicolumn{4}{|c|}{$\begin{array}{l}\text { Normatividad por Pais en TeleSalud y TeleOdontologia / Rules by Country in TeleHealth and Tele- } \\
\text { Dentistry }\end{array}$} \\
\hline & Tipo & Año & Norma/Rule & Enlace \\
\hline \multirow[t]{2}{*}{ Argentina } & TeleSalud & 2020 & $\begin{array}{l}\text { Resolución } 282 \text { de 2020, } \\
\text { SuperSalud Argentina }\end{array}$ & $\begin{array}{l}\text { https://www.boletinoficial.gob.ar/deta- } \\
\text { lleAviso/primera/227378/20200402 }\end{array}$ \\
\hline & Teleodontología & - & $\begin{array}{l}\text { No, pero la regla general } \\
\text { no es excluyente a Odon- } \\
\text { tología. }\end{array}$ & \\
\hline \multirow[t]{2}{*}{ Bolivia } & TeleSalud & 2015 & $\begin{array}{l}\text { Resolución } 200 \text { del } 2015 \\
\text { Ministerio de Salud }\end{array}$ & $\begin{array}{l}\text { https://www.minsalud.gob.bo/images/ } \\
\text { Descarga/resolucion2015/RM200a.pdf }\end{array}$ \\
\hline & Teleodontología & - & $\begin{array}{l}\text { No, pero la regla general } \\
\text { no es excluyente a Odon- } \\
\text { tología. }\end{array}$ & \\
\hline \multirow[t]{3}{*}{ Chile } & TeleSalud & 2007 & Plan Nal de TeleSalud & $\begin{array}{l}\text { https://www.minsal.cl/wp-content/ } \\
\text { uploads/2018/03/Programa-Nacio- } \\
\text { nal-de-Telesalud.pdf }\end{array}$ \\
\hline & & & Res 2042020 MinSalud & $\begin{array}{l}\text { https://www.diariooficial. } \\
\text { interior.gob.cl/publicacio- } \\
\text { nes/2020/03/27/42616/01/1745655.pdf }\end{array}$ \\
\hline & Teleodontología & - & $\mathrm{No}$ & \\
\hline \multirow[t]{2}{*}{ Colombia } & TeleSalud & 2019 & $\begin{array}{l}\text { Resolución } 2654 \text { de } 2019 \\
\text { Minsalud }\end{array}$ & $\begin{array}{l}\text { https://www.minsalud.gov.co/Norma- } \\
\text { tividad_Nuevo/Resoluci\%C3\%B3n\%20 } \\
\text { No.\%202654\%20del\%202019.pdf }\end{array}$ \\
\hline & Teleodontología & 2020 & $\begin{array}{l}\text { Lineamientos Salud Oral } \\
\text { en Urgencias en Co- } \\
\text { vid-19 pandemia. Mayo } \\
2020 .\end{array}$ & $\begin{array}{l}\text { https://www.minsalud.gov.co/Ministerio/ } \\
\text { Institucional/Procesos\%20y\%20procedi- } \\
\text { mientos/GIPS26.pdf }\end{array}$ \\
\hline \multirow[t]{2}{*}{ Costa Rica } & TeleSalud & - & No & \\
\hline & Teleodontología & - & No & \\
\hline \multirow[t]{2}{*}{ Cuba } & TeleSalud & - & No & \\
\hline & Teleodontología & - & No & \\
\hline \multirow[t]{2}{*}{ Ecuador } & TeleSalud & 2010 & $\begin{array}{l}\text { Plan Nacional de TeleSa- } \\
\text { lud Marzo } 2010 .\end{array}$ & $\begin{array}{l}\text { http://dspace.cedia.org.ec/bits- } \\
\text { tream/123456789/68/1/Telemedicina_MSP. } \\
\text { pdf }\end{array}$ \\
\hline & Teleodontología & 2020 & $\begin{array}{l}\text { No, pero la regla general } \\
\text { no es excluyente a Odon- } \\
\text { tología. }\end{array}$ & \\
\hline \multirow[t]{2}{*}{ El Salvador } & TeleSalud & - & No & \\
\hline & Teleodontología & - & No & \\
\hline
\end{tabular}




\section{Anexo 3. (cont)}

Tabla 1: Listado de regulaciones regionales referentes a telesalud y teleodontología por país, aplicables a la actual pandemia COVID-19. Cont.

\begin{tabular}{|c|c|c|c|c|}
\hline \multirow[t]{2}{*}{ País } & \multicolumn{4}{|c|}{$\begin{array}{l}\text { Normatividad por Pais en TeleSalud y TeleOdontologia / Rules by Country in TeleHealth and Tele- } \\
\text { Dentistry }\end{array}$} \\
\hline & Tipo & Año & Norma/Rule & Enlace \\
\hline \multirow[t]{2}{*}{ Honduras } & TeleSalud & - & No & \\
\hline & Teleodontología & - & No & \\
\hline \multirow[t]{2}{*}{ México } & TeleSalud & - & $\begin{array}{l}\text { No. Proyecto de Ley de } \\
\text { Telesalud del } 2015 .\end{array}$ & $\begin{array}{l}\text { http://dof.gob.mx/nota_detalle.php?codi- } \\
\text { go=5420782\&fecha=21/12/2015 }\end{array}$ \\
\hline & Teleodontología & - & No & \\
\hline \multirow[t]{2}{*}{ Nicaragua } & TeleSalud & - & No & \\
\hline & Teleodontología & - & No & \\
\hline \multirow[t]{2}{*}{ Panamá } & TeleSalud & - & $\begin{array}{l}\text { No. Anteproyecto Ley } \\
\text { Abril, } 2020\end{array}$ & $\begin{array}{l}\text { https://raulfernandezdiputado.com/ante- } \\
\text { proyectos/anteproyecto-de-ley-que-esta- } \\
\text { blecen-los-lineamientos-para-el-desarro- } \\
\text { llo-de-la-telesalud-en-panama/ }\end{array}$ \\
\hline & Teleodontología & - & No. & \\
\hline \multirow[t]{2}{*}{ Paraguay } & TeleSalud & 2015 & Ley 5.482 de 2015 & $\begin{array}{l}\text { http://www.bacn.gov.py/leyes-paragua- } \\
\text { yas/4465/ley-n-5482-crea-el-programa-na- } \\
\text { cional-de-telesalud }\end{array}$ \\
\hline & Teleodontología & - & $\begin{array}{l}\text { No, pero la regla general } \\
\text { no es excluyente a Odon- } \\
\text { tología. }\end{array}$ & \\
\hline \multirow[t]{2}{*}{ Perú } & TeleSalud & 2009 & $\begin{array}{l}\text { Norma Técnica NTS N } \\
\text { 067-MINSA/DGSP-V.01 }\end{array}$ & $\begin{array}{l}\text { http://bvs.minsa.gob.pe/local/MIN- } \\
\text { SA/1428.pdf }\end{array}$ \\
\hline & Teleodontología & 2020 & $\begin{array}{l}\text { Directiva Sanitaria } 100 \\
\text { MINSA/2020/DGIESP }\end{array}$ & $\begin{array}{l}\text { https://cdn.www.gob.pe/uploads/docu- } \\
\text { ment/file/716209/DIRECTIVA_SANITA- } \\
\text { RIA_N_100-MINSA-2020-DGIESP.pdf }\end{array}$ \\
\hline \multirow{2}{*}{$\begin{array}{l}\text { República } \\
\text { Dominicana }\end{array}$} & TeleSalud & - & No & \\
\hline & Teleodontología & - & No & \\
\hline \multirow[t]{2}{*}{ Uruguay } & TeleSalud & 2020 & Ley 19.869 de 2020 & $\begin{array}{l}\text { https://www.impo.com.uy/bases/le- } \\
\text { yes/19869-2020 }\end{array}$ \\
\hline & Teleodontología & - & $\begin{array}{l}\text { No, pero la regla general } \\
\text { no es excluyente a Odon- } \\
\text { tología. }\end{array}$ & \\
\hline \multirow[t]{2}{*}{ Venezuela } & TeleSalud & - & $\begin{array}{l}\text { No. Anteproyecto Ley de } \\
\text { Telesalud del } 2015\end{array}$ & $\begin{array}{l}\text { https://pandectasdigital.blogspot. } \\
\text { com/2017/02/ley-de-telesalud.html }\end{array}$ \\
\hline & Teleodontología & - & No & \\
\hline
\end{tabular}




\section{Tele dentistry Guidelines in Pediatric Dentistry during the COVID-19 pandemic}

\section{Introduction}

At the present time, the different international and local health agencies have published recommendations, regulations and protocols for dental care practitioners to face the COVID-19 pandemic, adjusting the steps to follow in dental practice according to the different stages of the pandemic.

The Latin American Association of Pediatric Dentistry (ALOP) under its mission has supported to bring the best available information to allLatin American colleagues across its existence, publishing practical guides and supporting understandable documents that can be easily used. Equally, ALOP shares all its publications with all dental personnel working in hospital environments, government clinics, educational institutions and private clinics that provide care for children, adolescents and patients with disabilities. ${ }^{1-3}$

During several of the COVID-19 pandemic confinement phases, dental settings should only can provide treatments for patients requiring dental urgent care or emergencies, delaying all elective dental treatments. ${ }^{1,-7}$ However, the rules involved in each phase of the pandemic are adjusted according to the contexts experienced by each country, and in this way the protocols in health care also change continuously, but always making possible to schedule priority dental care and progressively resume dental care. ${ }^{8,9}$
As an innovative component of this current pandemic, an important change has been recommended to health care practitioners, including Pediatric Dentists, as the need for health care increases at this time: the inclusion of Telehealth or remote care, Telemedicine, and Tele dentistry. ${ }^{10}$ This modality of remote care involves dental care by phone, by digital channels or virtual platforms, using all the available technology to carry out the diagnosis, therapeutic orientation, follow-up of cases, and definition of the clinic cases that require on-site dental care.

The recommendations proposed below by ALOP are related to the current exceptional pandemic situation and may be differ from the routine clinical practice. These recommendations have the main purpose to provide guidance to the clinicians for an appropriate dental screen at the virtual visit. Additionally, these recommendations have as goals, to guide the implementation of virtual visits using basic concepts of tele dentistry, to help choosing the best route of dental care according to the need of the patient and feasibility of on-site care, keeping appropriate dental records and follow-up.

This information constitutes an orientation guide, without the intention to replace local rules, specific protocols, or current regulations each country. In the same manner, this information is susceptible to be updated and it can change according to the health context. We urge the dental 
professionals to keep informed about updates and changes on this public health crisis, to adjust protocols and measures at the dental settings for the benefit of patients, dental staff and communities.

\section{OVERVIEW}

\section{Teledentistry}

Distance dental care (tele dentistry ${ }^{11}$ ), is the first line of care in exceptional cases that may arise in public health crises and when on-site contact between the patient and the specialist is not possible due to geographical distances or other restrictions. ${ }^{11}$ Technological support allows screening and symptomatic management of susceptible cases, and identification of cases that will require on-site care, using all available communication and technology resources. ${ }^{4,12-16}$

In Pediatric Dentistry, there are reports of previous experiences in which the Pediatric Dentist has made a diagnosis of caries and treatment recommendations with the use of tele dentistry, with the use of intraoral cameras or images obtained through smart phones and the support of dental assistants or auxiliary staff. ${ }^{17-20}$

During the COVID-19 Pandemic, the use of tele dentistry is focused on achieving the best possible diagnosis in order to provide guidance to parents in the management of the pathology for which they are consulting, and it is recommended by all care protocols. ${ }^{1-3,6,14,21,22}$

Currently there are three types of teleconsultations defined that can be useful in different contexts: Asynchronous, Synchronous and Mixed approaches. The Asynchronous approach usually occurs when the patient or their caregiver contacts the health professional to request their point of view or evaluation, requiring a waiting time between the question or request is sending, and the response of the specialist is best provided. The Synchronous approach occurs when the virtual visit is in real time by phone call or preferably by video conference, to interact with the specialist about concern on the patient's health. The Mixed approach uses both asynchronous and synchronous approaches, defining a medium or long term follow up according to the clinical case. ${ }^{23,24}$

In all cases, for the health specialist is required to build a virtual archive where all communications will be stored, including digital media (i.e. photos, videos, radiographs) and clinics files. All these digital resources can support the best diagnosis, the record management, and the virtual interaction with the patient and the parents. In the same context, all these digital records need to be part of an active platform, at the specialist's hand to carry out the follow-ups, and to be reviewed and updated according to the progress of the clinical case.

The role of the Dental practitioner has special relevance, whereby is recommended a pertinent channel of communication between the Dentist/Pediatric Dentist and the patients or their legal guardians (telephone, videoconference or other platforms). It is possible that in the current situation of confinement the specialist has no access to previous dental records, $\mathrm{x}$-rays or to other records.

In public health crisis or social tension, it is pertinent to contextualize what type of patients request dental services: if they are referred by another specialist who requires support in the diagnosis, if it is a regular 
patient or if it is a patient who contacts the office for first time. If possible, it is always recommended that the professional should try to access the previous dental records to optimize the diagnosis. ${ }^{16}$

When the virtual visit is conducted by tele dentistry, it is important to have effective communication skills, handling a kind voice that transmits confidence. The first step is to calm the patient and their caregiver, guardian or legal custodian, while briefly explaining the scope, benefits, but also the limitations and responsibilities of this type of approach. The specialist must listen carefully the information provided, showing empathy and giving confidence about the situation and how it will be addressed and resolved. At the same time, the records of each virtual visit must be filled according to the provided information.

According the evolution of the COVID-19 Pandemic in each region, and the regulations established by the states and health organizations, the dental virtual visits will be focused only on the care of emergencies cases and the performance of priority treatments, until the reopening of the dental visits for routine procedures. ${ }^{9}$

ALOP is including a general list of regional regulations about Telehealth and Teledentistry per country, to support the better understanding of the local rules applicable to virtual dental visits in the context of the COVID-19 pandemic (Appendix 3).

\section{Step 1: Teledentistry Care}

\section{Pre Virtual Dental Visit}

The pre virtual dental visit includes the provision of a prior questionnaire sent by digital channels, to be completed by patient and legal guardian, including all possible diagnostic digital aids (as pictures, radiographies, among others). This questionnaire has to be sent before the synchronous approach, or to support the asynchronous approach (Appendix $1)$. It is recommended to have a previous interaction with the patient or his/her caregivers before the dental virtual visit, to better contextualize all the factors around the clinical case, and in this way adjust the approach according to the patient's needs or the real scope of the dental virtual.

In addition to this questionnaire, a guide for virtual dental visits and a patient consent form must be provided for patients and guardians, and these forms must be signed and sent before the virtual appointment. About the guide for virtual dental visits, other possibility is to obtain a confirmation of a full understanding of the guide at the beginning of the virtual visit. Within the stipulations that must be accepted are the specifications on the scope of the virtual visit, limitations and basic steps during that either synchronous or asynchronous approaches.

\section{Virtual Dental Visit}

Anamnesis and reason for the virtual dental visit.

With remote care, without the possibility for a physical examination, a presumptive diagnosis and therapeutic guidance can be made. If on-site dental visit is needed, the appropriate steps must be determined or followed to provide optimal care, keeping all biosecurity measures. ${ }^{1-9}$

In dentistry it has been established that the most frequent reasons for urgent virtual 
dental care are: pain, inflammation, trauma or hemorrhage. In this context, itis necessary to investigate information regarding symptoms, using severity criteria, in order to provide guidance to the patient. In all cases, patient follow-up should continue using the same communication channels. ${ }^{1,}$ $3,5,13,14,25$

Data Collection and Data Management for the Synchronous Virtual Dental Visit

When a specialist is performing care by tele dentistry, it is essential to keep data validation within a trusted methodology to maintain the confidentiality and accessibility of all provided information. The data collection during the virtual dental visit has to be written in a digital form designed in advance, including all the information regarding the relevant medical records of the patient, or the data referred by another specialist. Everything related to the clinical case should be also recorded, which will serve the specialist as a guide when he/she is ready to make a presumptive diagnosis and will allow him/her to keep a written record of the teleconsultation or virtual consultation. Attached to this guideline, are several annexes that will help to design or adjust several teledentistry forms, including a proposed form that could be used during the synchronous virtual dental visit.

In this way, when the specialist is contacted by the patient or their caregivers to request a virtual dental visit, they must open a new file that will support their clinical virtual approach and comply with all legal and administrative regulations involved in the professional practice. This record should contain basic information such as initial date of contact, initial motive to contact, name of the person starting the contact (caregiver or guardian), name of the patient, if it's a new patient or part of your clinic's practice, among others. This initial virtual dental visit request a standard form to be filled out virtually and stored digitally, while the context allow to include this document in the clinical active archive located at the clinic or office (Appendix 1).

Data Collection and Data Management for the Asynchronous Virtual Dental Visit

To answer an initial dental visit by asynchronous approach that could be received by e-mail, fax or other digital channels, the specialist should respond in a standard format. This form has to contain basic information about the patient, his/her guardian, summary of information initially received, and a space giving clinical assessments based on the data initially provided by the patient or caregiver. A copy of this answer should be stored within the digital records opened for this patient in the tele dentistry specialist's files.

\section{Post Virtual Dental Visit}

According to the clinical findings that may be given in the synchronous or asynchronous virtual dental visit, the dentist will define the next step to be followed in the care path: if the patient requires an emergency or urgent visit, or if on the contrary, the case allows a virtual follow-up with the support of the available technological tools. A summary of the care routes is presented in Figures 1 and 2.

\section{Emergency screening Part 1: Essential Framework}

Using tele dentistry, perform the examination regarding the pathology 


\section{Attention Route - Virtual Synchronous Dental Consultation}

Cod. 608-24

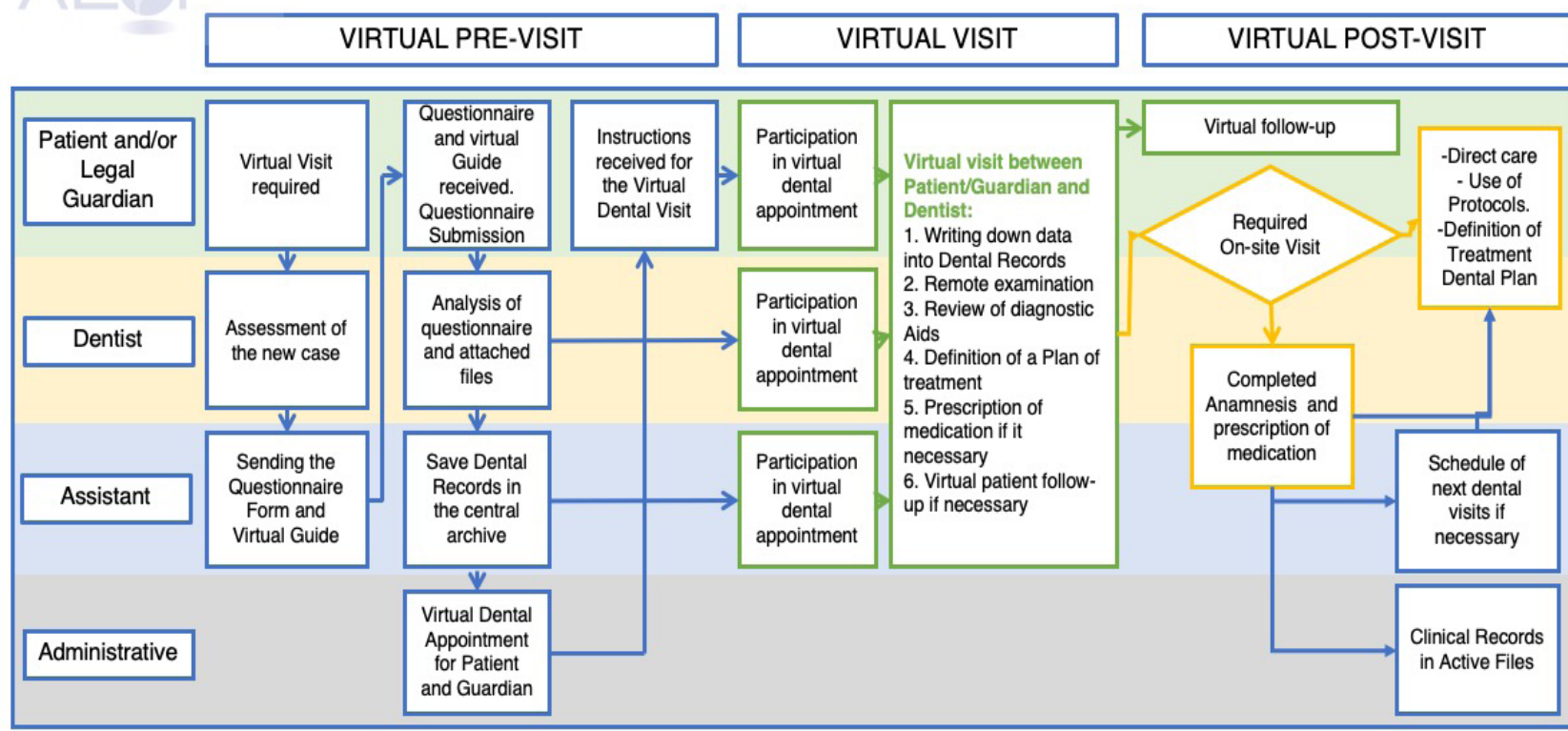

Figure 1. Flowchart of the Synchronous Virtual Dental Approach, with the role of each participant of the dental team (Adaptation from Mutis et al.48)

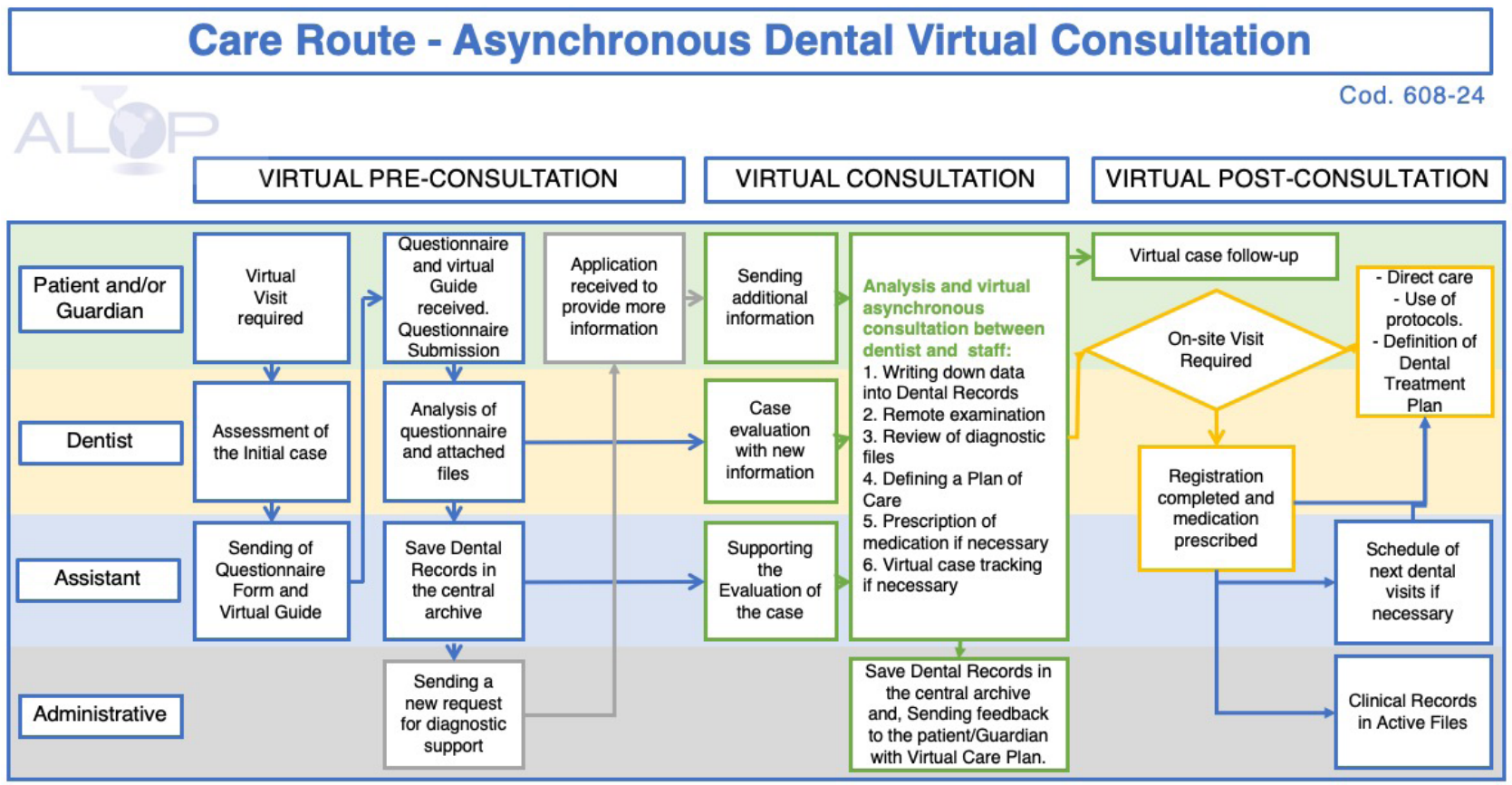

Figure 2. Flowchart of the Asynchronous Virtual Dental Approach, with the role of each participant of the dental team (Adaptation from Mutis et al.48) 
presented by the patient by screening (anamnesis, screening or triage) to determine whether symptomatic treatment is remotely feasible or if it is required an onsite urgency or emergency approach. Usually the virtual emergency dental visit is done synchronously. Two different contexts could emerge from this initial triage with the patient or his/her legal guardians during the synchronous virtual dental visit, and they are described below (Appendix 2):

\section{Basic Concepts}

Dental Urgencies: Management of clinical conditions that require immediate treatment to alleviate severe pain and infection. These conditions include severe irreversible pulpitis, pericoronitis, localized dentoalveolar abscess, painful dental fracture, alveolitis, dental trauma with avulsion or dislocation, hemorrhage, biopsy, or perioperative dental evaluation prior to a required medical procedure. ${ }^{1,13,}$ ${ }^{25-27}$ Dental emergencies can be treated in a dental office under biosecurity rules and local regulations that have been defined by the health regulatory body.

Dental Emergencies: any clinical situation in which the life of the patient may be put in danger and require immediate management. These include uncontrolled bleeding, facial cellulitis with intra and extraoral edema that compromises the airway or affect oral tissues deeply, dentofacial trauma that may compromise the airway. ${ }^{1,13,25,26}$ Dental emergencies should be attended only and exclusively in a hospital setting and never in the dental office (facial trauma with active bleeding, extraoral edema with fever or facial cellulitis).
Several factors must be taken into account during the virtual dental visit in the examination (including interrogation) during the triage:

Usually this step must be developed between the dental specialist and the child's guardian or caregiver, but the presence of the minor patient is important during the telehealth visit to confirm symptoms or visualize some clinical signs that can be seen by video. The interrogation within the virtual examination should include data related to the symptomatology:

Pain level: mild, moderate or severe.

- Edema: determine whether the edema is intraoral or extraoral. Verify whether the patient has had fever.

- Dentofacial Trauma: which structures have been affected, whether there is active hemorrhage, facial laceration or fracture, dental fracture, avulsion or dental luxation, and verify whether the affected teeth are primary or permanent.

- Bleeding: Verify if it is profuse, if it is possible to identify the cause or origin.

\section{Diagnostic Aids}

If the patient has not received prior care with the specialist, or has been referred by another specialist, it is necessary to include diagnostic aids within the virtual Pre-Dental Visit (Appendix 1). The best diagnostic aids can be images, intraoral photos, extraoral photos, digital radiographs and other digital resources that must have been previously collected, to allow the best diagnosis and to confirm the pathway to follow in the dental treatment. If any of the possible diagnostic aids can be provided by the guardian or the referred specialist, the 
specialist has to use the severity criteria to define if an onsite dental visit is required, evaluating the severity of the pathology, because the clinical case can be considered as a dental urgency or emergency.

\section{Complementary diagnosis during the virtual dental visit}

During the virtual dental visit the pediatric dentist also can detect signs and symptoms in the child's mouth, face and neck as a sign of physical abuse, which can occur by action, omission or by negligence.28 In this way, the specialist can make a better correlation of the data obtained from the virtual examination with the analysis of the diagnostic aids, as photographs and images of the patient, that possible may show different degrees of vulnerability, and could suggest child abuse or domestic violence. Therefore, it is relevant to remember that the dentists are part of the health professionals that have the duty to report these situations to the entity in charge in each country, according to the established protocols.

Once the presumptive diagnosis has been made with the provided information, determine if an in-person emergency dental visit is required to confirm the presumptive diagnosis, to perform the specific treatment and follow-up of the national guidelines related to social welfare and protection of children's lives.

If you are able to manage the urgency during the virtual dental visit and confirm the presumptive diagnosis based on the given information and diagnostic aids, you can proceed to define the prescription of analgesics and antibiotics, if it is needed. Followed this, it is desirable to update all records to end the virtual dental visit, and coordinate the follow-up through mixed virtual dental visits (synchronous and asynchronous), according to the context of the clinical case, until other therapeutic measures can be taken.

The initial questions included within the virtual examination are used to guide the clinician to define a presumptive diagnosis.14, 16, 27 Additional questions can raised during the virtual dental visit, and serve as a confirmatory evidence towards the validation of the diagnosis.

The clinician must carry out all the examination necessary and use the best clinical criteria to determine the conduct to be followed. Using severity criteria, it is guided whether the care should be telemedicine, in-person emergency care or whether the patient should be immediately referred to the hospital emergency room

For all cases: it is desirable to require intraoral and/or extraoral photos, and all digital aids that allow the specialist to clearly visualize the different perspectives about the reason and clinical advice of the virtual dental visit.

\section{Remote prescribing using Telehealth}

The medication prescription remotely, or remote prescribing must be handled very carefully, especially in the case of pediatric patients that need the verification of weight for the correct dosage. Taking into account that the responsibility for the prescription is assumed by the specialist, parents or guardians should be warned during the virtual interaction with the specialist, that it is imperative to strictly follow the recommendations provided by the dentist, in order to avoid possible adverse events. 
It is desirable that parents or guardians receive a written digital guide following the virtual dental visit, specifying the steps to be followed in the giving the medications to the child, and sending a feedback as a reply to the Dentist understanding and accepting the recommendations provided by the specialist.

Prior to the in-person dental visit, the complete filling of the informed consent is essential. ${ }^{1,3,14}$

\section{Emergency screening Part 2: Diagnosis}

\section{Dentofacial Trauma}

Tele dentistry care should be focused to calm the child and the parents or guardians. Screening questions are those that allow defining the magnitude and/or the consequences of the trauma. Information about the environment or place where the trauma occurred may be requested. Next, a sequence of questions is proposed to guide the clinician in his/her diagnosis, which it can complemented with all those questions that the specialist considers necessary in each particular case.

Requirement of intraoral or extraoral photos, and other aid resources could allow reaching the adequate diagnosis and therapeutics.

If any response during the examination indicates the need for hospital emergency care, stop the virtual interaction and refer the patient immediately to the closest Hospital Emergency Room.

Patients with head trauma suspected of maxillary fracture, continuous bleeding requiring suturing should be referred immediately to the hospital emergency room.

In presence of abrasion in soft tissue, it is recommended to use $0.1 \%$ alcohol-free chlorhexidine gluconate topically in the affected area with cotton swabs twice a day for 1 Week. In case of lip lesions use lip balm during the healing period.

Emergency care for dentofacial trauma has several protocols depending on whether the affected tooth is primary or permanent. In any case, the emergency care to be performed at the time of confinement should be oriented towards keeping the permanent teeth functional and healthy in the mouth and perform procedures that minimize the generation of aerosols. ${ }^{3,12,26,29}$ Therefore, after a thorough examination and appropriate diagnosis, pulp protection is recommended in cases of dental fractures. Follow international guidelines and protocols based on scientific evidence. ${ }^{30,31}$

In the case of avulsion of primary teeth without other associated complication, dental trauma that is limited to simple crown fracture of enamel or enamel and dentin without pulp compromise, or mild dislocations withoutocclusal interference or mobility, can be treated with teledentistry. Coronal restoration or repositioning of fragments can be performed later, and the prescription of pain relievers according to the case, providing diet and hygiene routines.

For dislocations of permanent teeth: verify magnitude of displacement and whether there is occlusal interference. Indicate attempting to perform the replacement with digital pressure (with the exception of intrusive dislocations). Follow international guidelines and protocols based on scientific evidence. ${ }^{30}$

In case of avulsion: guide parents to reimplant the tooth (take by the crown, avoiding touching the root. If it is dirty, 
wash it for 10 seconds with potable water, place the tooth in position and bite down on a tissue to keep it in place). If this is not possible, verify that the means of preservation prior to on-site emergency care is appropriate (container with milk, physiological solution or saliva). In collaborating patients, it is possible to transport the tooth inside the mouth (next to the cheek) not in a dry environment or in water. The first 30 minutes elapsed of the trauma are essential for a better prognosis. Follow international guidelines and protocols based on scientific evidence. ${ }^{30,32}$

Follow-up all clinical cases, using asynchronous o synchronous approaches.

\section{Extraoral and Intraoral inflammation and Edema.}

Tele dentistry care should be focused to calm the child and the parents or guardians. A sequence of questions previously defined can guide the clinician in his/her diagnosis, and additional questions emerged during the virtual interaction can complete the overview in each particular case.

Requirement of intraoral or extraoral photos, and other aid resources could allow reaching the adequate diagnosis and therapeutics.

If any response during the examination indicates the need for hospital emergency care, stop the virtual interaction and refer the patient immediately to the closest Hospital Emergency Room.

If the patient presents trismus, submandibular or sublingual edema with pain on swallowing, palpebral edema, difficulty opening the eye, erythema or edema extending to the neck, crepitation on palpation or fever, he should be referred to the hospital emergency room.
Pericoronitis may can be treated with proper hygiene of the affected areas, antiseptic rinses (chlorhexidine 012\% or hydrogen peroxide $1 \%$ ) diet modifications and analgesics. Evaluate evolution. In cases of no improvement, perform emergency care.

If there is gingival inflammation you may suggest $0.12 \%$ chlorhexidine mouthwashes, twice a day undiluted, for fifteen days. In young children it can be applied with gauze embedded in the solution.

Localized dentoalveolar abscesses can be treated by teledentistry with antibiotic prescription (amoxicillin, amoxicillin + Clavulanic acid, azithromycin, clindamycin or the pharmacological treatment decided by the professional according to the patient, their medical history and requirements) according to the patient's weight and characteristics and on the authority of the national health agency guidelines. The emergency appointment can be scheduled 48 hours after the patient has started taking antibiotics if necessary.

In cases of doubt, make an on-site dental visit to corroborate the diagnosis.

Follow-up all clinical cases, using asynchronous o synchronous approaches.

\section{Hemorrhage}

Tele dentistry care should be focused to calm the child and the parents or guardians. Screening questions are those that allow the specialist to define the magnitude of the bleeding. A sequence of questions previously defined can guide the clinician in his/her diagnosis, and additional questions emerged during the virtual interaction can complete the overview in each particular case. 
Requirement of intraoral or extraoral photos, and other aid resources could allow reaching the adequate diagnosis and therapeutics.

If any response during the examination indicates the need for hospital emergency care, stop the virtual interaction and refer the patient immediately to the closest Hospital Emergency Room.

Directions for the patient: Do not spit, do not rinse, apply cold compresses to the bleeding area, and perform continuous compression for 15 minutes.

Healthy patients, with an identified cause of bleeding which stops after hemostatic compression measures have been performed, can be followed up with teledentistry.

If it is determined that the patient requires suturing, he or she should be treated urgently at a Hospital Emergency Room.

If the bleeding persists, or if the patient has a relevant medical background, he or she should be referred to a hospital emergency room.

Follow-up all clinical cases, using asynchronous o synchronous approaches.

\section{Dental and Orofacial pain}

Tele dentistry care should be focused to calm the child and the parents or guardians. Screening questions are those that allow us to define the magnitude of the Dental or Orofacial pain. A sequence of questions previously defined can guide the clinician in his/her diagnosis, and additional questions emerged during the virtual interaction can complete the overview in each particular case.

Requirement of intraoral or extraoral photos, and other aid resources could allow reaching the adequate diagnosis and therapeutics.

If any response during the examination indicates the need for hospital emergency care, stop the virtual interaction and refer the patient immediately to the closest Hospital Emergency Room.

Pain in general is difficult to measure because of its subjectivity, especially in children, often depending on the parents' report. However, whenever possible, it is recommended not to replace the self-report of pain with the report of the parents or guardians, ${ }^{33}$ instead, instruments of analog Visual scale (VAS) could be used, like Wong Baker Faces (WBF), Faces Pain Scale Revised (FPS-R), among others, although not entirely objective, they can facilitate the assessment and self-reporting of pain expression in children. ${ }^{34}$

In the presence of caries lesions that can cause pulpitis, the therapeutic behavior to be followed is oriented towards achieving the arrest of the lesion. Therefore, hygiene recommendations with toothpaste with fluoride concentration 1,100 to 1,500 ppm or higher, use of dental floss and implementation of correct hygiene habits are of particular importance. The management of caries in the context of the COVID-19 Pandemic should be carried out taking into account the reduction of procedures that generate aerosols. ${ }^{2}$

In the presence of mild or provoked pain that ceases, Paracetamol (acetaminophen) may be prescribed according to patient weight, medical condition and under the national health agency guidelines of your country. ${ }^{35,36}$

In case of severe pain or if the patient has taken pain relievers for 48 hours without 
any improvement, they should go to the emergency room. ${ }^{16}$

If the patient has broken or dislodged his/ her dental braces, tell the parent to try to remove them at home. If is not possible to remove the appliance at home and it is causing laceration or ulceration, the patient will require an urgent dental visit at the dental office, and after when the confinement ends, a new appointment will be assigned at the dental office for recementation of the dental attachments. ${ }^{22,}$ 37

Follow-up all clinical cases, using asynchronous o synchronous approaches.

\section{Step 2: In-person Emergency or Urgent dental care during the COVID-19 pandemic}

Prior to schedule an emergency dental appointment based on your virtual diagnosis, you must have to perform or request a COVID-19 screening. Due to asymptomatic incubation period, the specialist needs to remember that children tend to have less symptomatology than adults. All pediatric patients should be considered potential carriers of the virus unless proven otherwise. ${ }^{12,27,38}$

\section{COVID-19 SYMPTOMS}

- The patient has had a fever within the last 14 days.

- The patient has had respiratory symptoms (coughing, odynophagia, runny nose) gastrointestinal symptoms (diarrhea, vomiting, and abdominal pain) or general discomfort during the last 14 days.

- You have noticed loss of taste or smell in the last 14 days.

\section{SUSPECTED EXPOSURE TO COVID}

- The patient or his/her relative has traveled to countries at risk and returned during the last 14 days.

- The patient or relatives have been in close contact with people who had fever or acute respiratory issues during the last 14 days.

- History of contact with someone diagnosed as a suspect or confirmed COVID-19.

If the answer for any of these questions is affirmative, tell the parents or legal guardian to follow these steps:

1. Call the family physician or emergency facilities near them to activate the local COVID-19 (if symptoms are present)

2. Initiate isolation or quarantine as appropriate according to the case.

3. Once the local medical team has given its approval, onsite dental care can be provided.

You must ensure that all clinical and administrative staff has the appropriate Personal Protective Equipment (PPE). Equally, you must ensure that your dental staff has enough knowledge about the standard precautions, contact precautions, airborne precautions, eye protections and all biosafety norms to decrease the risk of occupational exposure to SARS-CoV-2. ${ }^{1-5}$ 13-15, 27, 38-47 Otherwise, you must refer the patient to a dental facility that meet all standards in the current context.

See "Pediatric dentistry management guidelines during the confinement or quarantine stage of the COVID-19 pandemic." 1 


\section{Considerations}

These management guidelines have been independently developed and voluntarily by researchers from the Latin American Pediatric Dentistry Association (Asociación Latinoamericana de Odontopediatría), in a joint effort with Latin American medical specialists in diverse areas and have been peer reviewed. Authors claim no conflict of interest.

The management guidelines are based on scientific research available to date, given that COVID-19 is an emerging problem. Updates will be made when needed, in accordance with scientific advances and evolution of the pandemic.

The group of experts responsible for curation of this document remains active and in constant screening of newly published COVID-19 data in order to develop any necessary updates and supplemental resources.

\section{Autors}

Development of this article led by: Martha Mutis (Estados Unidos de América), Elías M. Morón (Estados Unidos de América), A. Carolina Medina Díaz (Venezuela), on behalf of the COVID-19 Interdisciplinary team, Latin-American Pediatric Dentistry Association (Asociación Latinoamericana de Odontopediatría).

COVID-19 Interdisciplinary team, Latin-American Pediatric Dentistry Association (Asociación Latinoamericana de Odontopediatría):
Jenny Abanto (Brasil), Mariana Armada (Argentina), Paola Beltri (España), Marisol Carrillo Tabakman (Paraguay), Haydée Casaretto (Argentina), Jorge Luis Castillo (Perú), Mónica Gladys Cesetti (Argentina), Bertha Angélica Chávez González (Perú), Ana Claudia Rodrigues Chibinski (Brasil), Salomon Alberto Cohen (Argentina), Olga Cortés Lillo (España), Luzia Ana Da Silva de Carballo (Venezuela), Gonzalo De la Fuente Alvarez (Chile), Renée Di Nallo (Argentina), María Débora Elizabeth Dricas (Argentina), Sandra Echevarria (Brasil), Piedad Cecilia Echeverry Marin (Colombia), Laura Fedelli (Argentina), Carlos Flores-MIr (Canadá), Andrea Virgina González Carfora (Chile), Lina María Hernández Salas (Colombia), Francisco José Hernández Restrepo (Colombia), Maria Teresa Ibañez Rodriguez (Bolivia), José Carlos Pettorossi Imparato (Brasil), Alejandra Lipari Valdés (Chile), Daniela Madrigal López (Costa Rica), Daniela Catalina Martínez Camus (Chile), María Gabriela Martínez Vásquez (Venezuela), A. Carolina Medina Díaz (Venezuela), Kelly Maria Silva Moreira (Brasil), Elías M. Morón (Estados Unidos de América), Martha Mutis (Estados Unidos de América), Camila Palma (Perú), Gladys Mabel Peña (Argentina), Adriana Pistochini (Argentina), Paloma Planells (España), Gabriel Politano (Brasil), Matias RiosErazo (Chile), Adriana Maria Rubiano Pinzon (Colombia), Karla Mayra Rezende (Brasil), Rosa Gabriela Rondón (Venezuela), Gabriela Scagnet (Argentina), Rosemary Sogbe de Agell (España), Marina Tavares Costa Nóbrega (Canadá), Jorgelina Valente (Argentina), Ernesto Venegas De Herrera (República Dominicana), Rosa Helena Wanderley Lacerda (Brasil), Ana Clara Zabala (Argentina), Gabriel Zambrano (Venezuela).

Información completa del Grupo Interdisciplinario COVID-19 de la Asociación Latinoamericana de Odontopediatría

\section{References}

1. Asociación Latinoamericana de Odontopediatría. Grupo COVID-19. Ruta de atención para procedimientos de Odontología Pediátrica durante la etapa de confinamiento o cuarentena de la pandemia COVID-19. Revista de Odontopediatría Latinoamericana. 2020;10(2):https://www. revistaodontopediatria.org/ediciones/2020/2/art-1/.

2. Asociación Latinoamericana de Odontopediatria. Tratamiento de la enfermedad de caries en época de COVID-19: protocolos clínicos para el control de aerosoles. Revista de Odontopediatría Latinoamericana. abril 2020;10(2):https://www.revistaodontopediatria.org/ediciones/2020/2/art-2/\#. 
3. Asociación Latinoamericana de Odontopediatría ALOP. Modelos de Consentimiento Informado para la Atención de Urgencias en tiempos de COVID-19. abril 4, 2020. Available at: https:// www.alopodontopediatria.org/noticias/consentimiento-informado-indicados-especialmenteatenci\%C3\%B3n-emergencias-odontologicas/.

4. Centers for Disease Control and Prevention CDC. Interim Infection Prevention and Control Recommendations for Patients With Suspected or Confirmed Coronavirus Disease 2019 (Covid-19) in Healthcare Settings. abril 2020. Available at: https://www.cdc.gov/coronavirus/2019-ncov/ hcp/infection-control-recommendations.html?CDC_AA_refVal=https\%3A\%2F\%2Fwww.cdc. gov\%2Fcoronavirus\%2F2019-ncov\%2Finfection-control\%2Fcontrol-recommendations.html.

5. Centers for Disease Control and Prevention CDC. Recommendation: Postpone Non-Urgent Dental Procedures, Surgeries, and Visits. Marzo 27, 2020. Available at: https://www.cdc.gov/oralhealth/ infectioncontrol/statement-COVID.html.

6. American Academy of Pediatric Dentistry. COVID-19 Update/Coronavirus Update. 2020 Abril. Available at: https://www.aapd.org/about/about-aapd/news-room/covid-19/.

7. Dave M, Seoudi N, Coulthard P. Urgent dental care for patients during the COVID-19 pandemic. The Lancet. Abril 2020:DOI:https://doi.org/10.1016/S0140-6736(20)30806-0.

8. COVID-19 Dental Services Evidence Review (CoDER) Working Group. Recommendations for the reopening of dental services: a rapid review of international sources. https://oralhealth.cochrane.org/ sites/oralhealth.cochrane.org/files/public/uploads/covid19_dent. Available at: https://oralhealth. cochrane.org/sites/oralhealth.cochrane.org/files/public/uploads/covid19_dent.

9. Consejo General de Dentistas de España. Plan estratégico de acción para el periodo de desescalada COVID-19. mayo 1, 2020. Available at: https://www.consejodentistas.es/comunicacion/actualidadconsejo/notas-de-prensa-consejo/item/1783-plan-estrategico-de-accion-para-clinicas-dentalesdurante-el-periodo-de-desescalada.html.

10. Vidal-Alaball J, Acosta-Roja R, Pastor N, et al. Telemedicine in the face of the COVID-19 pandemic. Atención Primaria. 2020:https://doi.org/10.1016/j.aprim.2020.04.003.

11. Jampani ND, Nutalapati R, Dontula BS, Boyapati R. Applications of teledentistry: A literature review and update. J Int Soc Prev Community Dent. 2011;1(2):37-44. doi:10.4103/2231-0762.97695.

12. Mallineni SK, Innes NP, Raggio DP, Araujo MP, Robertson MD, Jayaraman J. Coronavirus Disease (COVID-19): Characteristics in children and considerations for dentists providing their care. Int J Paed Dent. abril 2020:doi: 10.1111/ipd.12653.

13. American Dental Association ADA. Emergency Care. abril 2020. Available at: https://www.aapd. org/about/about-aapd/news-room/emergency-care/.

14. American Dental Association (ADA). Interim Guidance for Minimizing Risk of COVID-19 Transmission. abrl 7, 2020. Available at: https:/www.ada.org/ /media/CPS/Files/COVID/ ADA_COVID_Int_Guidance_Treat_Pts.pdf?utm_source=adaorg\&utm_medium=covidresources-lp\&utm_content=cv-pm-ebd-interim-response\&utm_campaign=covid-19?utm_ source=adaorg\&utm_medium=adanews\&utm_content=cv-pm-ebd-interi. Accessed abril 8, 2020.

15. Peng X, Xu X, Li Y, Cheng L, Zhou X, Ren B. Transmission routes of 2019-nCoV and controls in dental practice. Intl J Oral Sci. 2020;12:https://doi.org/10.1038/s41368-020-0075-9.

16. Orde National des Chirugiens-Dentistes. Guide pour la prise en charge téléphonique d'une demande de soins dentaires urgents dans le cadre du stade 3 de l'épidémie de COVID-19. Marzo 30, 2020. Available at: https://societechirorale.com/documents/Recommandations/Guide-praticienDefinitif-V1-30-mars-2020.pdf.

17. Kopycka-Kedzierawski DT, Billings RJ. Teledentistry in inner-city child-care centres. J Telemed Telecare. 2006;12:176-181.

18. Kopycka-Kedzierawski DT, Billings RJ. Prevalence of dental caries and dental care utilization in preschool urban children enrolled in a comparative effectiveness study. Eur Arch Paediatr Dent. 2011;12:133-138.

19. McLaren SW, Kopycka-Kedzierawski DT, Nordfelt J. Accuracy of teledentistry examinations at predicting actual treatment modality in a pediatric dentistry clinic. J Telemed Telecare. 2016:doi:10 $.1177 / 1357633 \times 16661428$. 
20. AlShaya MS, Assery MK, Pani SC. Reliability of mobile phone teledentistry in dental diagnosis and treatment planning in mixed dentition. J Telemed Telecare. 2018:Doi: 10.1177/1357633X18793767.

21. Pereira LJ, Pereira CV, Murata RM, Pardi V, Pereira-Dourado SM. Biological and social aspects of Coronavirus Disease 2019 (COVID-19) related to oral health. Braz Oral Res. 2020:34:e041.

22. Suri S, Vandersluis YR, Kichhar AS, Bhasin R, Abdallah MN. Clinical orthodontic management during the COVID-19 pandemic. Angle Orthod. 2020:doi: 10.2319/033120-236.1.

23. Ruiz Ibañez C, Zuluaga de Cadena A, Trujillo Zea A. Telemedicina: Introducción, aplicación y principios de desarrollo. Revista CES MEDICINA. 2007;21:77-93.

24. Allely EB. Synchronous and asynchronous telemedicine. J Med Syst. 1995;19:207-212.

25. American Dental Association ADA. What Constitutes a Dental Emergency?. Marzo 31, 2020. Available at: https://success.ada.org/ /media/CPS/Files/Open\%20Files/ADA_COVID19_Dental_Emergency_ DDS.pdf?utm_source=adaorg\&utm_medium $=$ covid-resources-lp\&utm_content $=$ cv-pm-emergdef\&utm_campaign=covid-19\&_ga=2.2729136.124928618.1586021397-1939509346.1586021396.

26. Meyer B, Casamassimo P, William F Vann, FV. An Algorithm for Managing Emergent Dental Conditions for Children. J Clin Ped Dent. 2019;43(3):doi 10.17796/1053-4625-43.3.10 201.

27. Consejo GeneraldeDentistas deEspaña. Organización ColegialdeDentistas de España. Planestratégico de acción para el periodo posterior a la crisis creada por el COVID-19. abril 13, 2020. Available at: https://gacetadental.com/wp-content/uploads/2020/04/PlanestrategicoposteriorCoronavirus.pdf.

28. Gamboa M, Guerra ME. Manifestaciones bucales del maltrato físico. Reporte de caso.. Revista de Odontopediatría Latinoamericana. 2013;3(2):https://www.revistaodontopediatria.org/ ediciones/2013/2/art-11/.

29. Meng L, Hua F, Bian Z. Coronavirus Disease 2019 (COVID-19): Emerging and Future Challenges for Dental and Oral Medicine Treatment of Emergency Cas. J Dent Res. 2020:DOI: 10.1177/0022034520914246.

30. Bastos JV, Cortex MS, Percinoto C, Tovo MF. Capítulo 19. Lesiones traumáticas en dientes primarios y permanentes jóvenes. Manual de Referencia para Procedimientos en Odontopediatría Segunda Edición: ALOP; 2017.

31. International Association of Dental Traumatology (IADT). IADT Treatment Guidelines. Dental Trauna Guide. Available at: https://dentaltraumaguide.org/iadt-treatment-guidelines/. Accessed marzo 21, 2020.

32. Andersson L, Andreasen JO, Day P, et al. International Association of Dental Traumatology guidelines for the management of traumatic dental injuries: 2. Avulsion of permanent teeth. Dental Traumatology. 2012;28:88-96.

33. Lawson SL, Hogg MM, Moore GC, et al. Pediatric Pain Assessment in the Emergency Department: Patient and Caregiver Agreement Using the Wong-Baker FACES and the Faces Pain Scale-Revised. Pediatric Emergency Care. 2019:doi: 10.1097/PEC.0000000000001837.

34. Tomlinson D, von Baeyer CL, Stinson JN, Sung L. A systematic review of faces scales for the selfreport of pain intensity in children. Pediatrics. 2010;126(5):e1168-98.

35. American Association of Pediatric dentistry. The Reference Manual of Pediatric Dentistry. Policy on Acute Pediatric Dental Pain Management. 2019/2020. Available at: https://www.aapd.org/research/ oral-health-policies--recommendations/acute-pediatric-dental-pain-management/.

36. Sucasas da Costa LR, Vaz Castro AD, Lopes GM, Sucasas da Costa PS. Capítulo 25. Terapéutica medicamentosa en Odontopediatría. Manual de Referencia para Procedimientos en Odontopediatría. 2nd ed. Sao Paulo: ALOP; 2017.

37. Caprioglio A, Pizzetti GB, Zecca PA, Fastuca R, Maino G, Nanda R. Management of orthodontic emergencies during 2019-NCOV. Progress in Orthodontics. 2020;21(10):https://doi.org/10.1186/ s40510-020-00310-y.

38. Consejo General de Dentistas de España. Informe Técnico II del Consejo General de Dentistas de España: Desafíos emergentes del nuevo Coronavirus COVID-19 en la clínica dental 2020.

39. Centers for Disease Control CDC. Personal Protective Equipment FAQs. marzo 2020. Available at: https://www.cdc.gov/coronavirus/2019-ncov/hcp/respirator-use-faq.html. 
40. Cochrane Collaboration. Equipo de protección personal para la prevención de las enfermedades altamente infecciosas por exposición a líquidos orgánicos contaminados en el personal de asistencia sanitaria. Revisión sistemática Cochrane -. Julio 2019. Available at: https://www.cochranelibrary. com/es/cdsr/doi/10.1002/14651858.CD011621.pub3/full/es.

41. Organización Mundial de la Salud OMS. Advice on the use of masks in the community, during home care, and in health care settings in the context of COVID-19. WHO Interim Guidance. Marzo 2020.

42. Organización Mundial de la Salud OMS. Rational use of personal protective equipment (PPE) for coronavirus disease (COVID-19) Interim guidance. Marzo 19, 2020. Available at: https://apps.who. int/iris/bitstream/handle/10665/331498/WHO-2019-nCoV-IPCPPE_use-2020.2-eng.pdf.

43. Organización Mundial de la Salud OMS. Vías de transmisión del virus de la COVID-19: repercusiones para las recomendaciones relativas a las precauciones en materia de prevención y control de las infecciones. marzo 29, 2020. Available at: https://www.who.int/es/news-room/ commentaries/detail/modes-of-transmission-of-virus-causing-covid-19-implications-for-ipcprecaution-recommendations.

44. Sabino-Silva R, Gomes Jardim AC, Siqueira WL. Coronavirus COVID-19 impacts to dentistry and potential salivary diagnosis. Clin Oral Invest. 2002;24:1619-1621.

45. The National Institute for Occupational Safety and Health (NIOSH). Recommended Guidance for Extended Use and Limited Reuse of N95 Filtering Facepiece Respirators in HealthcareSettings. abril15, 2020. Available at: https://www.cdc.gov/niosh/topics/hcwcontrols/recommendedguidanceextuse. html.

46. van Doremalen N, Bushmaker T T, Morris DH DH, Holbrook, et al. Aerosol and Surface Stability of SARS-CoV-2 as Compared with SARS-CoV-1. N Engl J Med. abril 2020;https://www.nejm.org/doi/ pdf/10.1056/NEJMc2004973?articleTools=true.

47. Xu H, Zhong L, Deng J, Peng J, et al. High expression of ACE2 receptor of 2019-nCoV on the epithelial cells of oral mucosa. Intl J Oral Sci. 2020;12(8):https://doi.org/10.1038/s41368-020-0074-x.

48. Mutis MJ, Suarez O, Gold J, Balzer J. How to establish a Teledentistry program in Community based Services: The experience in NYU Langone Family Centers. NYU School of Medicine - NYU Langone Health Dental Division. 2018.

Recibido/Received: 20/04/2020

Primera versión aceptada/First accepted version: 21/04/2020

Modificaciones aceptadas/Final version: 15/05/2020

Correspondencia: e-mail: editor@revistaodontopediatria.org 


\section{Appendix 1}

\section{AL@P ASOCIACIÓN LATINOAMERICANA DE ODONTOPEDIATRÍA \\ ALOP - LATIN AMERICAN ASSOCIATION OF PEDIATRIC DENTISTRY

\section{TELE DENTISTRY: FORM FOR PRE DENTAL VISIT APPROACH \\ QUESTIONNAIRE FOR PEDIATRIC DENTISTRY \\ DURING THE PANDEMIC COVID-19}

Dentist:

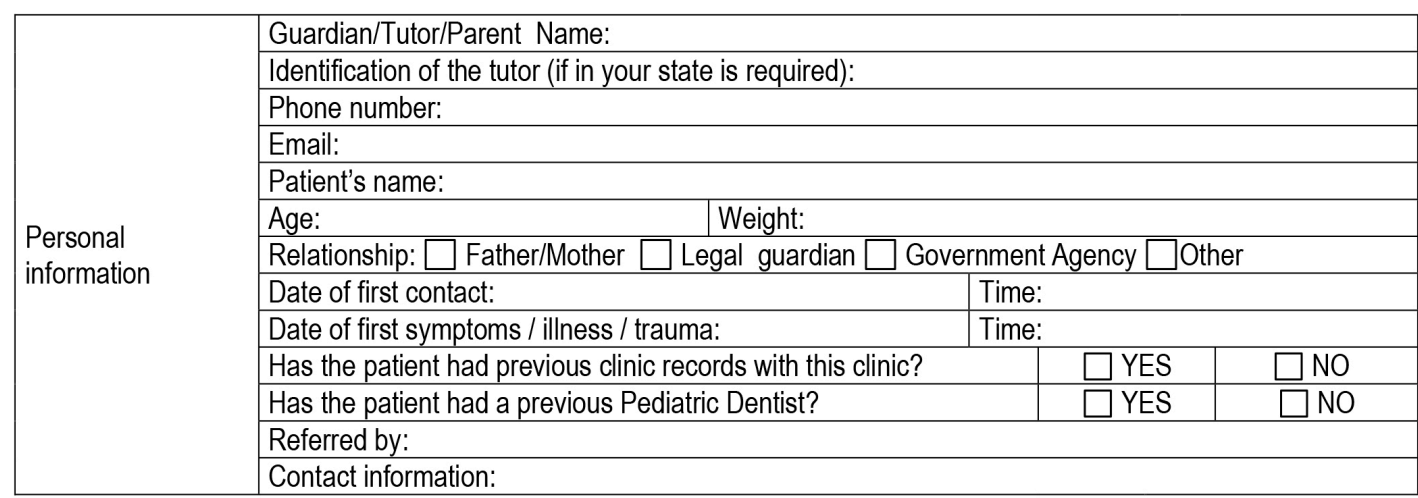

Please, describe the reasons contacting our dental services, and why do you think a virtual dental visit is required?

\begin{tabular}{|l|c|c|}
\hline Have you given medications to the patient to decrease pain or swelling during this time? & $\square$ YES & $\square$ NO \\
\hline
\end{tabular} Describe:

\begin{tabular}{|l|c|c|}
\hline Have you taken any other actions to help your child in this health situation? & $\square$ YES \\
\hline Describe & $\square$ NO \\
\hline
\end{tabular}

\begin{tabular}{|l|c|c|}
\hline $\begin{array}{l}\text { Do you think that the patient needs to be seen by a dentist in the next 24-48 hours for an } \\
\text { emergency appointment? }\end{array}$ & $\square$ YES \\
\hline Has the patient had fever in the last 14 days? & $\square$ YES & $\square$ NO \\
\hline $\begin{array}{l}\text { Has the patient had respiratory symptoms (cough, odynophagia, rhinorrhea), gastrointestinal } \\
\text { symptoms (diarrhea, vomiting, abdominal pain) or general discomfort, in the last 14 days? }\end{array}$ & $\square$ YES \\
\hline Have you noticed loss of taste or smell in the patient during the last 14 days?. & $\square$ NO \\
\hline Has the patient or his / her guardian traveled abroad in the last 14 days? & $\square$ YES & $\square$ NO \\
\hline $\begin{array}{l}\text { Has the patient or his / her guardian been in close contact with people with fever or acute } \\
\text { respiratory disease in the past 14 days? }\end{array}$ & $\square$ YES \\
\hline History of contact with someone diagnosed as a suspect or confirmed COVID-19. & $\square$ NO \\
\hline History of confirmed COVID-19 & $\square$ YES & $\square$ NO \\
\hline & $\square$ YES & $\square$ NO \\
\hline
\end{tabular}

FORM FOR PRE DENTAL VISIT APPROACH IN PEDIATRIC DENTISTRY - COVID-19 PANDEMIC 1 
Appendix 1. (cont)

\section{ALQP ASOCIACIÓN LATINOAMERICANA DE ODONTOPEDIATRÍA ALOP - LATIN AMERICAN ASSOCIATION OF PEDIATRIC DENTISTRY

Complementary diagnostic resources

Dear Parent-Guardian:

Virtual health Dental Visits have been designed to address unexpected situations that patients may experience in events when onsite clinical care is not possible.

Please consider the following recommendations to achieve the best case care that you are sharing with us at this time:

- Current country regulations limit the type of care that can be provided to minors to emergencies, urgent or priority treatment. If you believe that your child's case can be handled virtually, please send us all the relevant information to help you in the best way and decrease the symptoms you may be experiencing.

- This type of virtual dental visit has limitations, since some diagnoses in dentistry require palpation and direct observation on tissues, such as the direct evaluation of patients' signs and taking x-rays.

- We will support you in the best way, and based on the findings and on an exhaustive evaluation of signs and symptoms, we will define the best route of care for the patient, whether virtual follow - up of the case, or a referral to an emergency or urgent dental visit.

- Your collaboration and compliance in the protocols and steps defined for these virtual appointments will make the difference to obtain the best resolution of the case. Please provide us the best information you have, and help us with a detailed description of dates, evolution of symptoms, and type of palliative care that you have provided to the patient while you achieved a dental specialized care.

- We will review all information that you provide us, including photos and other digital media of interest that allow us to define the best clinical care for the patient.

- We also appreciate if you can tell us if anyone in your family, or the patient, has felt symptoms of a cold in the last 20 days. This may help us to better understand the patient's clinical background.

I have read and understood the information provided: $\square$ YES $\square$ No

Name of parent or guardian:

Name of dentist:

$\begin{array}{ll}\text { Signature: } & \text { ID : } \\ \text { Signature: } & \text { ID : } \\ \text { Place: } & \text { Date: }\end{array}$

TO BE FILLED BY THE DENTAL PRACTICIONER

\begin{tabular}{|c|c|c|c|c|c|c|}
\hline \multicolumn{7}{|l|}{ Presumptive diagnosis: } \\
\hline \multirow{9}{*}{ Therapeutic behavior } & \multicolumn{3}{|c|}{$\square$ Patient referred to emergency room } & \multicolumn{3}{|c|}{ Patient requires urgency dental visit } \\
\hline & \multicolumn{3}{|c|}{$\square$ Patient requires on-site care 15 days } & \multicolumn{3}{|c|}{ Patient can be followed by Telehealth } \\
\hline & \multicolumn{6}{|l|}{ Other: } \\
\hline & \multicolumn{6}{|c|}{ Analgesics: $\square$ YES $\square$ No Active Principle: } \\
\hline & \multicolumn{3}{|l|}{ Dose: } & \multicolumn{3}{|c|}{ Indications: } \\
\hline & \multicolumn{6}{|c|}{ Antibiotics: $\square$ YES $\square$ No Active Principle: } \\
\hline & \multicolumn{3}{|l|}{ Dose: } & \multirow{2}{*}{\multicolumn{3}{|c|}{$\begin{array}{l}\text { Indications: } \\
72 \text { hours }\end{array}$}} \\
\hline & Follow up in: & 24 hours & 48 hours & & & \\
\hline & & 5 days & 7 days & 14 days & greater follow-up & \\
\hline \multicolumn{7}{|c|}{ In case of urgency dental visit: Filled and Signed Informed consent } \\
\hline \multicolumn{7}{|c|}{ Evolution of the Case: } \\
\hline
\end{tabular}


Appendix 2.

\section{AL@P ASOCIACIÓN LATINOAMERICANA DE ODONTOPEDIATRÍA}

\section{TELEDENTISTRY: FORM FOR DENTAL URGENCIES IN PEDIATRIC DENTISTRY DURING THE COVID-19 PANDEMIC}

Dentist:

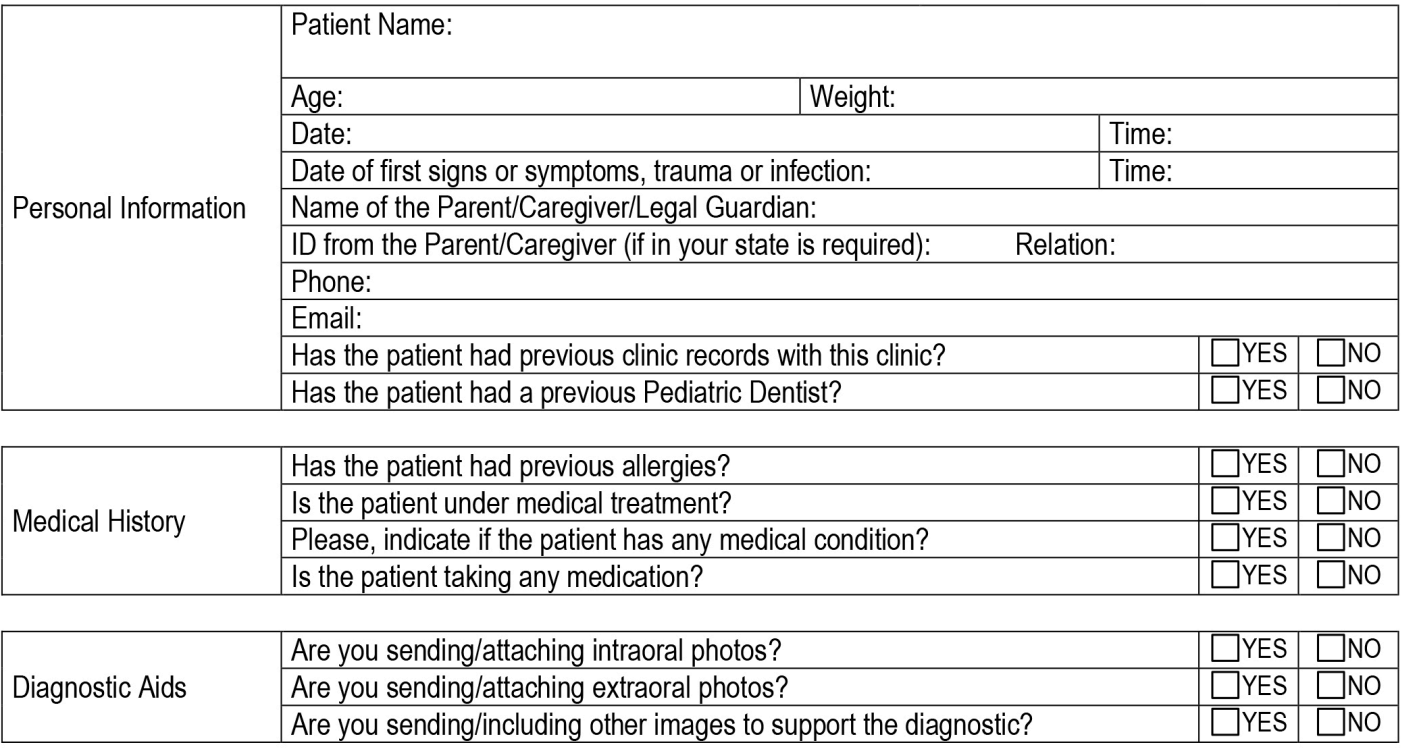

\begin{tabular}{|c|c|c|c|c|}
\hline \multicolumn{2}{|c|}{$\begin{array}{l}\text { Area of Service: } \\
\text { Tele-Health / Tele-Dentistry } \\
\text { Office visit - Dental Emergency } \\
\text { Hospital visit - Dental Emergency }\end{array}$} & 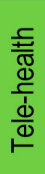 & 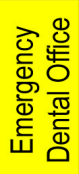 & 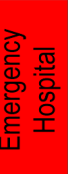 \\
\hline \multirow{18}{*}{ Dentofacial Trauma } & Does the patient's trauma involves the skull (head bones)? & & & \\
\hline & Has the patient a loss of consciousness? & & & \\
\hline & Does the patient has disorientation in time, space, and place? & & & \\
\hline & Has the patient vomited? & & & \\
\hline & Has the patient had loss of balance? & & & \\
\hline & Does the patient has vision disorders? & & & \\
\hline & Does the patient has visual lateralization? & & & \\
\hline & Has the patient bled from the ears? & & & \\
\hline & Does the patient has a limitation to close the mouth? & & & \\
\hline & Does the patient has asymmetry on the face? & & & \\
\hline & Has the patient bleeding from his/her nose? & & & \\
\hline & Has the patient a bruising (hematoma) on the floor of the mouth? & & & \\
\hline & Does the patient has a bleeding that does not stop on its own? & & & \\
\hline & Does the patient has a dental avulsion (expulsion of the tooth from its normal place)? & & & \\
\hline & Did you re-implant the avulsed tooth? & & & \\
\hline & Did you keep the avulsed tooth? $\square$ YES $\square$ NO ¿How? & & & \\
\hline & Is the tooth displaced? & & & \\
\hline & Is the displaced tooth preventing closing the mouth? & & & \\
\hline
\end{tabular}

DENTAL EMERGENCY FORM FOR PEDIATRIC DENTAL OFFICES - DURING COVID-19 PANDEMIC 1 


\section{Appendix 2 (cont)}

\section{ALQP ASOCIACIÓN LATINOAMERICANA DE ODONTOPEDIATRÍA LATIN AMERICAN ASSOCIATION OF PEDIATRIC DENTISTRY Cod. 608-15} \begin{tabular}{|l|l|l|l|l|} 
Is there a fracture in the middle of the tooth? & $\square$ & $\square$ & \\
\hline Does the tooth has a small dental fracture of less than half? & $\square$ & & \\
\hline Do you see a different color on the tooth within the fracture? & & $\square$ & \\
\hline Did you keep the fractured piece? $\square$ YES $\square$ NO ¿How? & & $\square$ & \\
\hline Does the tooth has movement?
\end{tabular}

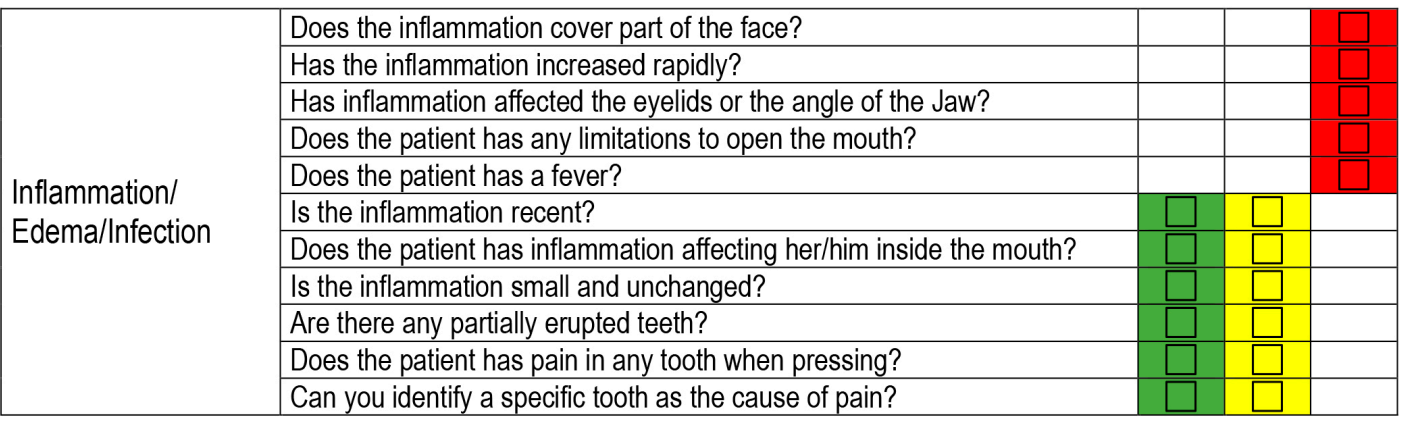

\begin{tabular}{|l|l|l|l|l|}
\hline \multirow{4}{*}{$\begin{array}{l}\text { Hemorrhage/ } \\
\text { Bleeding }\end{array}$} & Can you determine where the bleeding is coming from? $\square$ YES $\square$ NO & $\square$ & $\square$ & \\
\cline { 2 - 4 } & Has the patient a recent record of surgery or tooth extraction? & $\square$ & & \\
\hline & Does the bleeding stop if you compress? & & $\square$ & \\
\hline & Does the bleeding persist after compression? & & $\square$ \\
\hline & Is the bleeding associated with trauma laceration? & & $\square$ \\
\hline
\end{tabular}

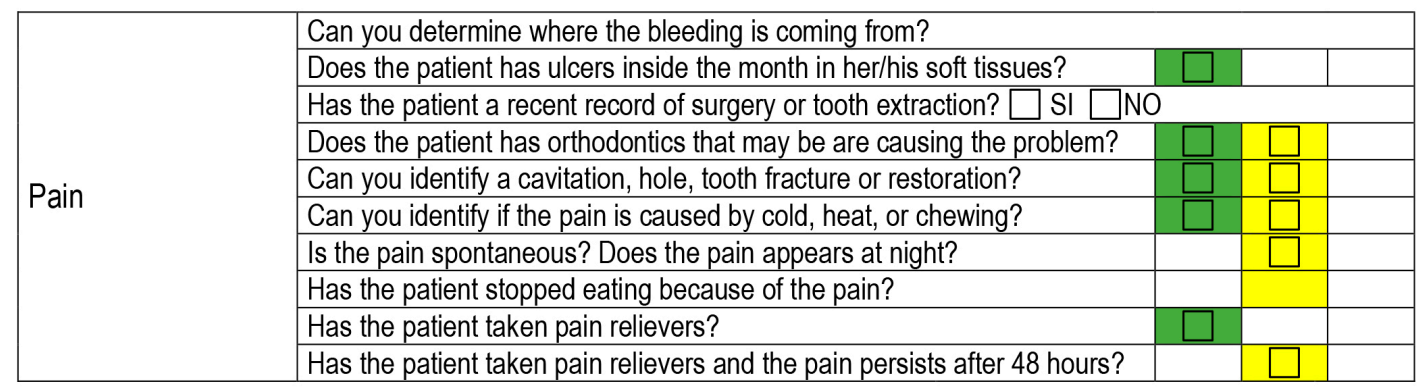

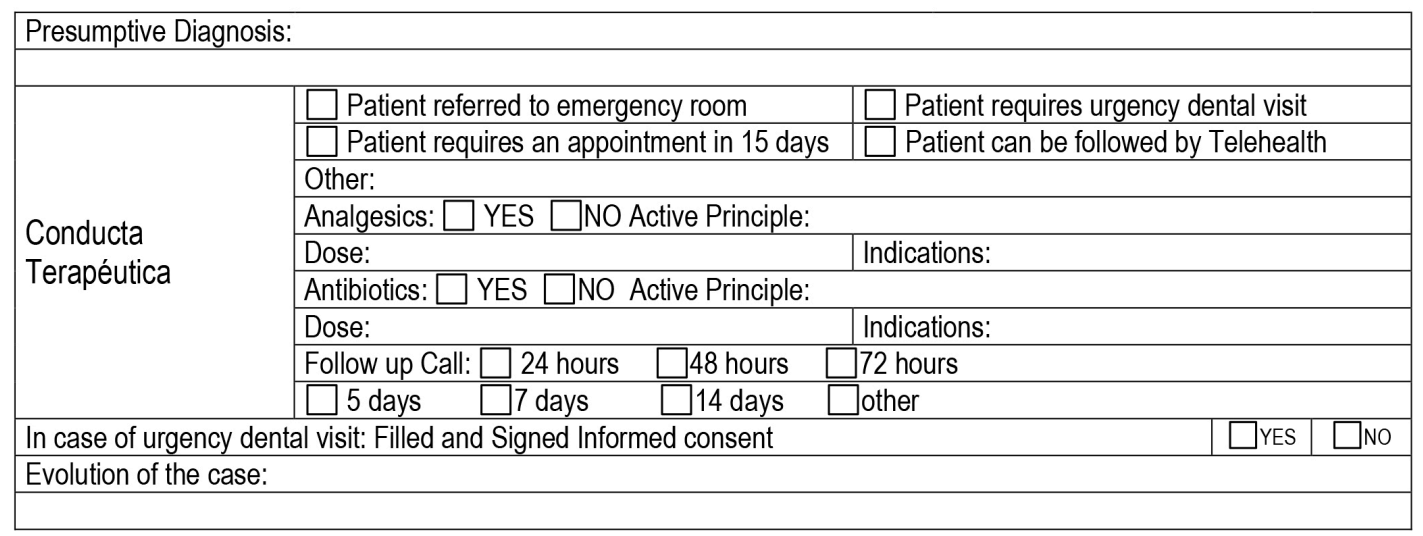

DENTAL EMERGENCY FORM FOR PEDIATRIC DENTAL OFFICES - DURING COVID-19 PANDEMIC 2 


\section{Appendix 3.}

List of Regional regulations in Telehealth and Teledentistry per Country applicable to the current COVID-19 pandemic

\begin{tabular}{|c|c|c|c|c|}
\hline \multirow[t]{2}{*}{ Country } & \multicolumn{4}{|c|}{ Rules by Country in TeleHealth and TeleDentistry } \\
\hline & Type & Year & Rule & Link \\
\hline \multirow[t]{2}{*}{ Argentina } & TeleHealth & 2020 & $\begin{array}{l}\text { Resolution } 282 \text { de 2020, } \\
\text { SuperSalud Argentina }\end{array}$ & $\begin{array}{l}\text { https://www.boletinoficial.gob.ar/deta- } \\
\text { lleAviso/primera/227378/20200402 }\end{array}$ \\
\hline & TeleDentistry & - & $\begin{array}{l}\text { No, but the general rule } \\
\text { is not limiting activities } \\
\text { in Dentistry. }\end{array}$ & \\
\hline \multirow[t]{2}{*}{ Bolivia } & TeleHealth & 2015 & $\begin{array}{l}\text { Resolution } 200 \text { del } 2015 \\
\text { Ministerio de Salud }\end{array}$ & $\begin{array}{l}\text { https://www.minsalud.gob.bo/images/ } \\
\text { Descarga/resolucion2015/RM200a.pdf }\end{array}$ \\
\hline & TeleDentistry & - & $\begin{array}{l}\text { No, but the general rule } \\
\text { is not limiting activities } \\
\text { in Dentistry. }\end{array}$ & \\
\hline \multirow[t]{3}{*}{ Chile } & TeleHealth & 2007 & National TeleHealth Plan & $\begin{array}{l}\text { https://www.minsal.cl/wp-content/ } \\
\text { uploads/2018/03/Programa-Nacio- } \\
\text { nal-de-Telesalud.pdf }\end{array}$ \\
\hline & & & Res 2042020 MinSalud & $\begin{array}{l}\text { https://www.diariooficial. } \\
\text { interior.gob.cl/publicacio- } \\
\text { nes/2020/03/27/42616/01/1745655.pdf }\end{array}$ \\
\hline & TeleDentistry & - & No & \\
\hline \multirow[t]{2}{*}{ Colombia } & TeleHealth & 2019 & $\begin{array}{l}\text { Resolution } 2654,2019 \\
\text { Minsalud }\end{array}$ & $\begin{array}{l}\text { https://www.minsalud.gov.co/Norma- } \\
\text { tividad_Nuevo/Resoluci\%C3\%B3n\%20 } \\
\text { No.\%202654\%20del\%202019.pdf }\end{array}$ \\
\hline & TeleDentistry & 2020 & $\begin{array}{l}\text { Oral Health guidance for } \\
\text { urgencies in COVID-19, } \\
\text { May, } 2020 .\end{array}$ & $\begin{array}{l}\text { https://www.minsalud.gov.co/Ministerio/ } \\
\text { Institucional/Procesos\%20y\%20procedi- } \\
\text { mientos/GIPS26.pdf }\end{array}$ \\
\hline \multirow[t]{2}{*}{ Costa Rica } & TeleHealth & - & No & \\
\hline & TeleDentistry & - & No & \\
\hline \multirow[t]{2}{*}{ Cuba } & TeleHealth & - & No & \\
\hline & TeleDentistry & - & No & \\
\hline \multirow[t]{2}{*}{ Ecuador } & TeleHealth & 2010 & $\begin{array}{l}\text { National Health Plan } \\
\text { March } 2010 .\end{array}$ & $\begin{array}{l}\text { http://dspace.cedia.org.ec/bits- } \\
\text { tream/123456789/68/1/Telemedicina_MSP. } \\
\text { pdf }\end{array}$ \\
\hline & TeleDentistry & 2020 & $\begin{array}{l}\text { No, but the general rule } \\
\text { is not limiting activities } \\
\text { in Dentistry. }\end{array}$ & \\
\hline \multirow[t]{2}{*}{ El Salvador } & TeleHealth & - & No & \\
\hline & TeleDentistry & - & No & \\
\hline
\end{tabular}




\section{Appendix 3. (cont)}

List of Regional regulations in Telehealth and Teledentistry per Country applicable to the current COVID-19 pandemic. Cont.

\begin{tabular}{|c|c|c|c|c|}
\hline \multirow[t]{2}{*}{$\overline{\text { Country }}$} & \multicolumn{4}{|c|}{ Rules by Country in TeleHealth and TeleDentistry } \\
\hline & Type & Year & Rule & Link \\
\hline \multirow[t]{2}{*}{ Honduras } & TeleHealth & - & No & \\
\hline & TeleDentistry & - & No & \\
\hline \multirow[t]{2}{*}{ México } & TeleHealth & - & $\begin{array}{l}\text { No. TeleHealth Law Bill } \\
2015 .\end{array}$ & $\begin{array}{l}\text { http://dof.gob.mx/nota_detalle.php?codi- } \\
\text { go=5420782\&fecha=21/12/2015 }\end{array}$ \\
\hline & TeleDentistry & - & No & \\
\hline \multirow[t]{2}{*}{ Nicaragua } & TeleHealth & - & No & \\
\hline & TeleDentistry & - & No & \\
\hline \multirow[t]{2}{*}{ Panamá } & TeleHealth & - & No. Law Bill April, 2020 & $\begin{array}{l}\text { https://raulfernandezdiputado.com/ante- } \\
\text { proyectos/anteproyecto-de-ley-que-esta- } \\
\text { blecen-los-lineamientos-para-el-desarro- } \\
\text { llo-de-la-telesalud-en-panama/ }\end{array}$ \\
\hline & TeleDentistry & - & No. & \\
\hline \multirow[t]{2}{*}{ Paraguay } & TeleHealth & 2015 & Law 5.482 de 2015 & $\begin{array}{l}\text { http://www.bacn.gov.py/leyes-paragua- } \\
\text { yas/4465/ley-n-5482-crea-el-programa-na- } \\
\text { cional-de-telesalud }\end{array}$ \\
\hline & TeleDentistry & - & $\begin{array}{l}\text { No, but the general rule } \\
\text { is not limiting activities } \\
\text { in Dentistry. }\end{array}$ & \\
\hline \multirow[t]{2}{*}{ Perú } & TeleHealth & 2009 & $\begin{array}{l}\text { Norma Técnica NTS N} \\
\text { 067-MINSA/DGSP-V.01 } \\
\end{array}$ & $\begin{array}{l}\text { http://bvs.minsa.gob.pe/local/MIN- } \\
\text { SA/1428.pdf }\end{array}$ \\
\hline & TeleDentistry & 2020 & $\begin{array}{l}\text { Sanitary guidance } 100 \\
\text { MINSA/2020/DGIESP }\end{array}$ & $\begin{array}{l}\text { https://cdn.www.gob.pe/uploads/docu- } \\
\text { ment/file/716209/DIRECTIVA_SANITA- } \\
\text { RIA_N_100-MINSA-2020-DGIESP.pdf }\end{array}$ \\
\hline \multirow{2}{*}{$\begin{array}{l}\text { República } \\
\text { Dominicana }\end{array}$} & TeleHealth & - & No & \\
\hline & TeleDentistry & - & No & \\
\hline \multirow[t]{2}{*}{ Uruguay } & TeleHealth & 2020 & Law 19.869 de 2020 & $\begin{array}{l}\text { https://www.impo.com.uy/bases/le- } \\
\text { yes/19869-2020 }\end{array}$ \\
\hline & TeleDentistry & - & $\begin{array}{l}\text { No, but the general rule } \\
\text { is not limiting activities } \\
\text { in Dentistry. }\end{array}$ & \\
\hline \multirow[t]{2}{*}{ Venezuela } & TeleHealth & - & $\begin{array}{l}\text { No. TeleHealth Law Bill, } \\
2015\end{array}$ & $\begin{array}{l}\text { https://pandectasdigital.blogspot. } \\
\text { com/2017/02/ley-de-telesalud.html }\end{array}$ \\
\hline & TeleDentistry & - & No. & \\
\hline
\end{tabular}

